Andrews University

Digital Commons @ Andrews University

\title{
A Descriptive Multiple Case Study of Caucasian Female Suicide Attempters: Risk and Protective Factors
}

Janice Johnson Browne

Andrews University

Follow this and additional works at: https://digitalcommons.andrews.edu/dissertations

Part of the Mental and Social Health Commons, Psychiatry and Psychology Commons, and the Women's Studies Commons

\section{Recommended Citation}

Browne, Janice Johnson, "A Descriptive Multiple Case Study of Caucasian Female Suicide Attempters: Risk and Protective Factors" (2002). Dissertations. 248.

https://digitalcommons.andrews.edu/dissertations/248

https://dx.doi.org/10.32597/dissertations/248

This Dissertation is brought to you for free and open access by the Graduate Research at Digital Commons @ Andrews University. It has been accepted for inclusion in Dissertations by an authorized administrator of Digital Commons@ Andrews University. For more information, please contact repository@andrews.edu. 


\section{Andrews \$university}

Seek Knowledge. Affirm Faith. Change the World.

Thank you for your interest in the

\section{Andrews University Digital Library of Dissertations and Theses.}

Please honor the copyright of this document by not duplicating or distributing additional copies in any form without the author's express written permission. Thanks for your cooperation. 


\section{INFORMATION TO USERS}

This manuscript has been reproduced from the microfilm master. UMI films the text directly from the original or copy submitted. Thus, some thesis and dissertation copies are in typewriter face, while others may be from any type of computer printer.

The quality of this reproduction is dependent upon the quality of the copy submitted. Broken or indistinct print, colored or poor quality illustrations and photographs, print bleedthrough, substandard margins, and improper alignment can adversely affect reproduction.

In the unlikely event that the author did not send UMI a complete manuscript and there are missing pages, these will be noted. Also, if unauthorized copyright material had to be removed, a note will indicate the deletion.

Oversize materials (e.g., maps, drawings, charts) are reproduced by sectioning the original, beginning at the upper left-hand corner and continuing from left to right in equal sections with small overlaps.

ProQuest Information and Learning 300 North Zeeb Road, Ann Arbor, MI 48106-1346 USA 800-521-0600

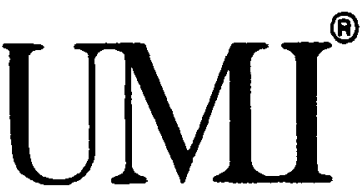




\section{Reproduced with permission of the copyright owner. Further reproduction prohibited without permission.}


Andrews University

School of Education

\title{
A DESCRIPTIVE MULTIPLE CASE STUDY OF CAUCASLAN FEMALE SUICDE ATTEMPTERS: RISK AND \\ PROTECTIVE FACTORS
}

\author{
A Dissertation \\ Presented in Partial Fulfillment \\ of the Requirements for the Degree \\ Doctor of Philosophy
}

by

Janice Ann Johnson Browne

December 2002 
UMI Number: 3081065

Copyright 2002 by

Browne, Janice Ann Johnson

All rights reserved.

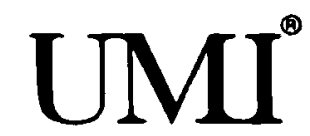

UMI Microform 3081065

Copyright 2003 by ProQuest Information and Learning Company.

All rights reserved. This microform edition is protected against unauthorized copying under Title 17, United States Code.

ProQuest Information and Learning Company

300 North Zeeb Road

P.O. Box 1346

Ann Arbor, MI 48106-1346 
(9) Copyright by Janice Ann Johnson Browne 2002

All Rights Reserved

Reproduced with permission of the copyright owner. Further reproduction prohibited without permission. 


\title{
A MULTIPLE DESCRIPTIVE CASE STUDY OF CAUCASIAN FEMALE SUTCDE ATTEMPTERS: RISK AND \\ PROTECTIVE FACTORS
}

\author{
A dissertation \\ presented in partial fulfillment \\ of requirements for the degree \\ Doctor of Philosophy
}

by

Janice Ann Johnson Browne

APPROVAL BY THE COMMITTTEE:
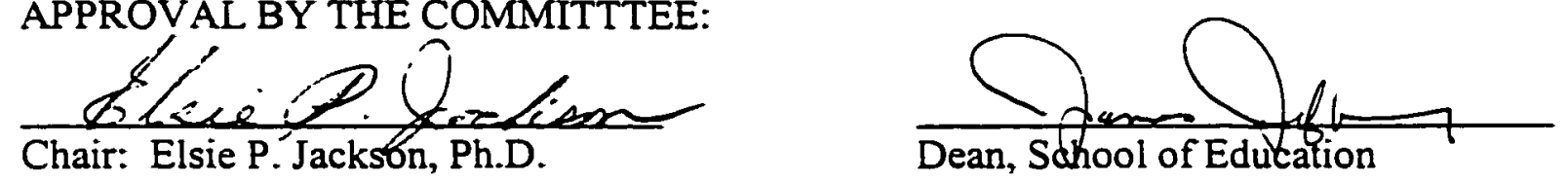

Dean, School of Education

James R. Jeffery, Ph.D.
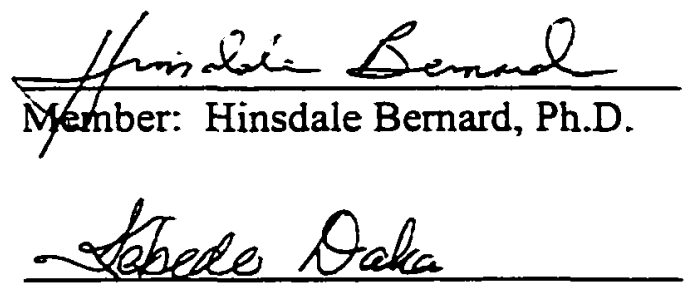

Member: Kebede Daka, Ph.D
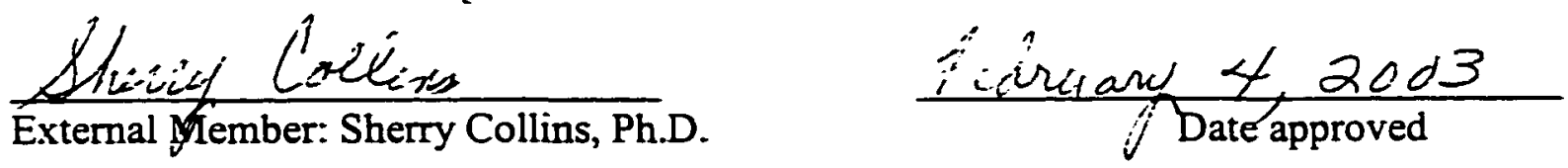


\section{ABSTRACT}

\section{A DESCRIPTIVE MULTIPLE CASE STUDY OF CAUCASLAN FEMALE SUICIDE ATTEMPTERS: RISK AND \\ PROTECTIVE FACTORS}

by

Janice Ann Johnson Browne

Chair: Elsie P. Jackson

Reproduced with permission of the copyright owner. Further reproduction prohibited without permission. 


\section{ABSTRACT OF GRADUATE STUDENT RESEARCH}

Dissertation

Andrews University

School of Education

Title: A DESCRIPTIVE MULTIPLE CASE STUDY OF CAUCASLAN FEMALE SUICDE ATTEMPTERS: RISK AND PROTECTIVE FACTORS

Name of researcher: Janice Ann Johnson Browne

Name and degree of faculty chair: Elsie P. Jackson, Ph.D.

Date completed: December 2002

\section{Problem}

Suicide is a problem globally and in the United States. Suicide rates for youth have remained particularly high. Caucasian men complete more suicidal acts than women, but women are more frequent suicide attempters. To gain information about the phenomenon of female suicide attempting, it is important to study the attempter. Awareness of risk and protective factors is necessary to intervene and prevent future incidences of suicide and suicide attempting.

\section{Methodology}

For this research a descriptive case study design was utilized. Three suicide attempters who had attempted suicide one or more times in the past was the sample 
population for this study. Structured and unstructured interviews were administered to the participants. Interviews were audio taped, transcribed, and analyzed for common . themes.

\section{Findings}

Twelve themes were found in this study. Six themes emerged as answers to question $\# 1$ - What are the risk factors for attempting suicide?

1. Previous suicide attempts

2. Mental Disorders

3. Alcohol and drug abuse

4. Family and childhood dynamics

5. Lack of communication about the suicide attempt

6. Tragic losses

Four themes emerged as answers to questions $\# 2$ - What are the protective factors for the prevention of attempting suicide?

7. Being responsible for self-care

8. Positive relationships

9. Keeping busy helping others

10. Recreation

Two themes emerged as answers to question $\# 3$ - What impact does the failed attempt have on the life of a suicide attempter?

11. Looking beyond themselves: A Higher Power

12. An inner perspective: A bonus life 


\section{Conclusions}

From this study, it can be concluded that women who have previous suicide attempts, have experienced alcohol and drug abuse and some tragic losses, have less than positive family and other relationships, and who do not take responsibility for self-care are at risk for attempting suicide. However, when one attempts suicide and does not complete it, she experiences an inner perspective referred to as the bonus life. 
This dissertation is dedicated to God the Author and Finisher of this study and to my dad whom I loved with all my heart. In loving memory of a gift from God, my dad. Washington Johnson Senior. 


\section{TABLE OF CONTENTS}

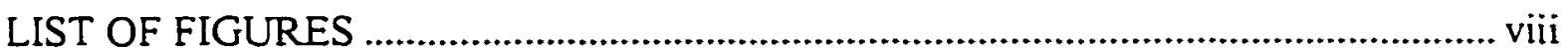

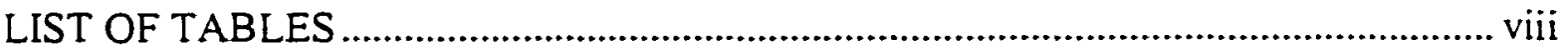

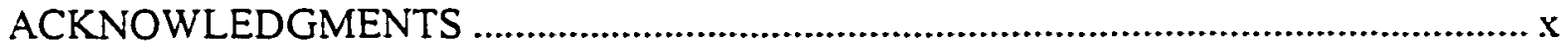

\section{Chapter}

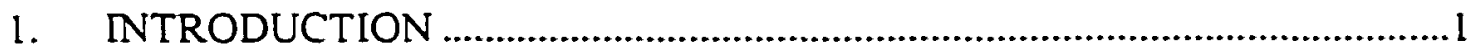

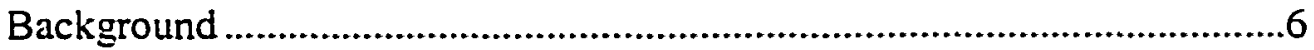

Statement of the Problem.............................................................................

Purpose of the Study ................................................................................... 8

Research Questions ....................................................................................

Significance of the Study ................................................................................

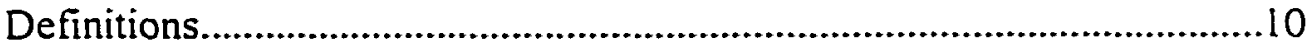

Delimitations and Limitations of the Study .............................................. I

Organization of the Study .....................................................................12

2. REVIEW OF THE LITERATURE

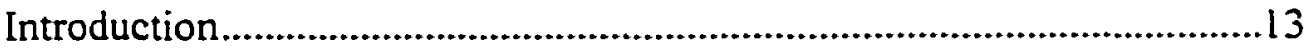

Conceptual Definitions of Suicide .............................................................14

Variations on Suicide Rates .................................................................16

The Surgeon General's Call to Action to Prevent Suicide ...........................18

Risk and Protective Factors for Suicide Prevention ..................................20

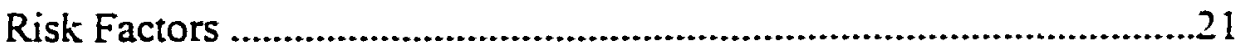

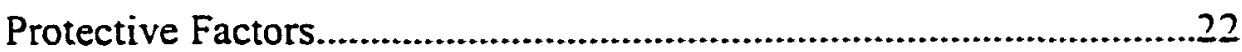

Perspectives on Suicide.........................................................................23

Psychiatric and Psychological Perspectives on Suicide........................23

Sociological Perspectives on Suicide......................................................25

Suicidology Perspectives ...................................................................2.

Religious and Cultural Perspectives on Suicide ......................................30

Ethical and Legal Perspectives on Suicide ...........................................34

Perspectives on Mental tllness and Suicide ...........................................37

Literature and Art Themes on Suicide ........................................................41 
Attempters of Suicide and Methods of Attempting Suicide .44

Summary of Literature Review ........................................................51

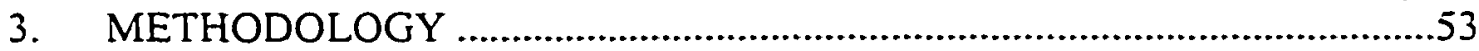

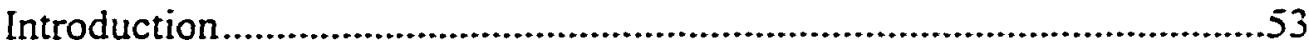

Characteristics of Qualitative Research ..............................................53

Framework of the Method for Suicide Prevention ..................................55

Research Design.....................................................................................56

Discussion of the Validity and Reliability of the Research Process.........61

The Pilot Study ............................................................................62

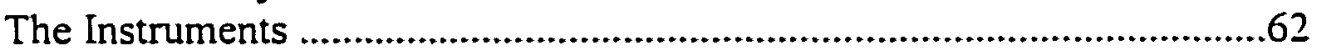

Suicide Attempter Selection .............................................................63

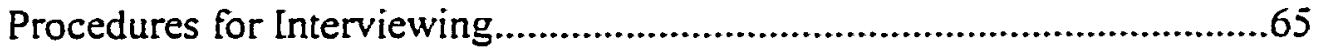

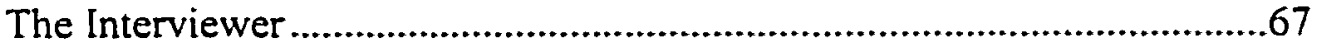

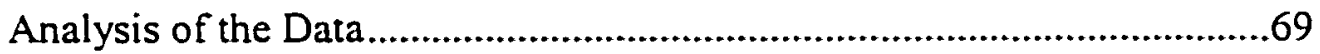

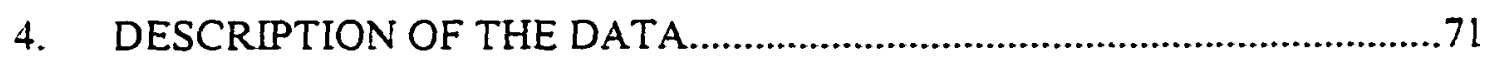

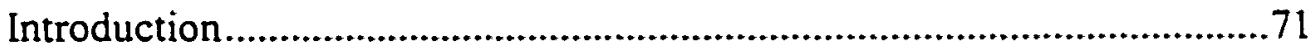

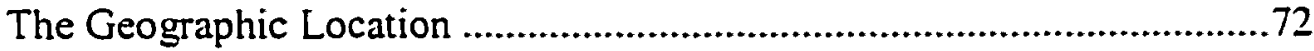

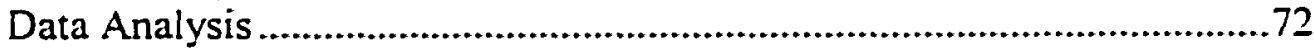

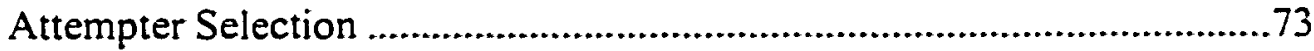

Suicide Attempter Descriptions and Stories ..........................................8 80

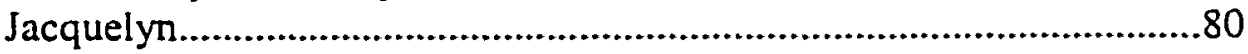

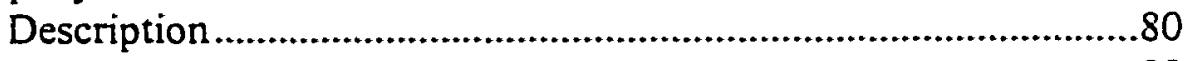

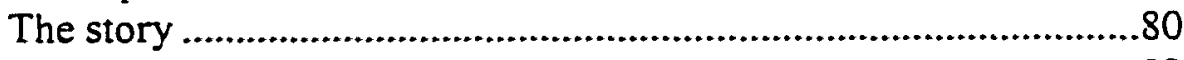

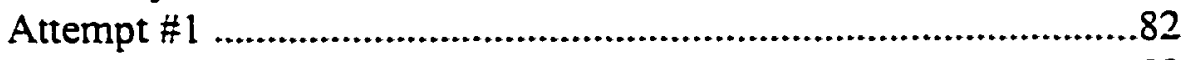

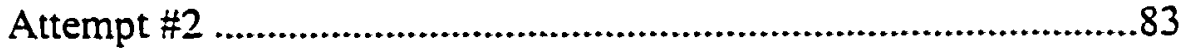

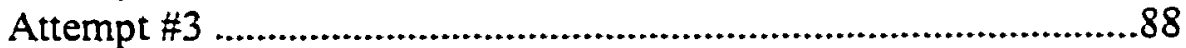

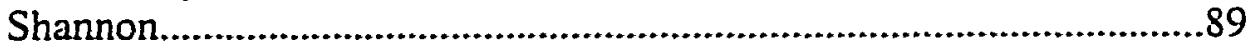

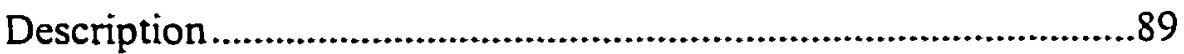

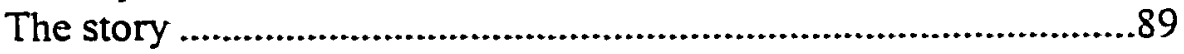

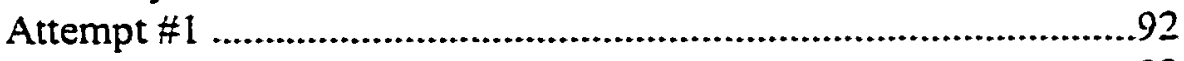

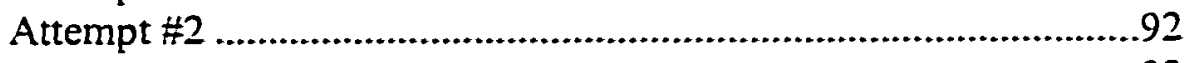

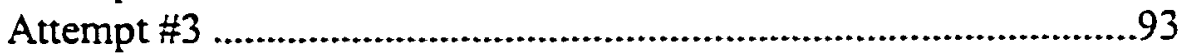

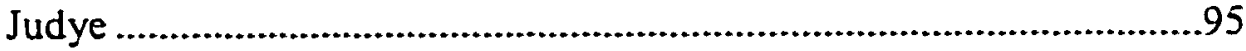

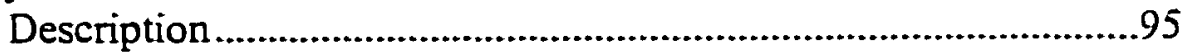

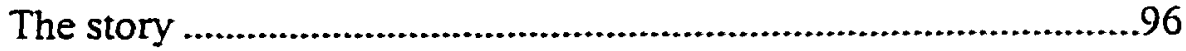

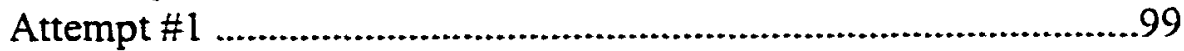

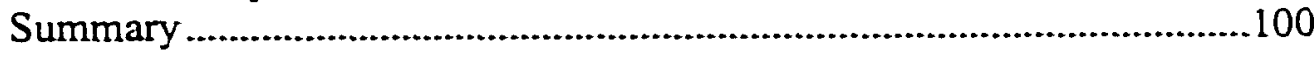

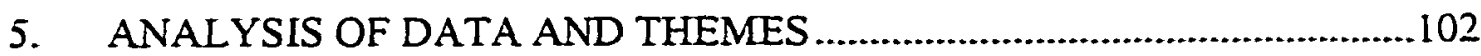

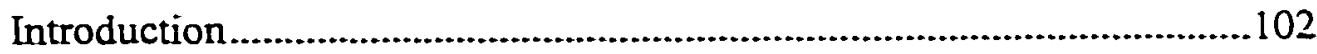

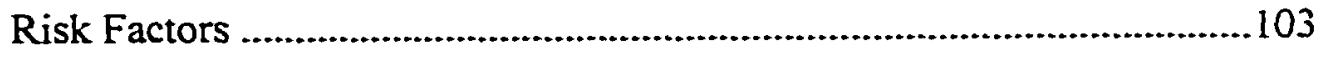

Reproduced with permission of the copyright owner. Further reproduction prohibited without permission. 


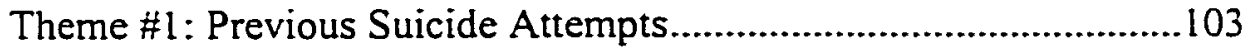

Theme \#2: Mental Disorders .............................................................103

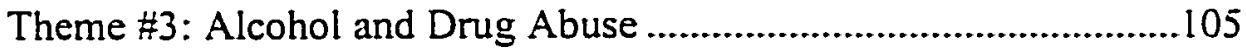

Theme \#4: Family and Childhood Dynamics ........................................107

Theme \#5: Lack of Family Communication About the Suicide

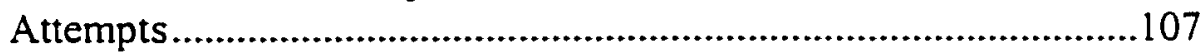

Theme \#6: Tragic Losses .................................................................108

Summary of Risk Factors Themes .........................................................113

Protective Factors........................................................................... 115

Theme \#7: Being Responsible for Self-care .......................................115

Theme \#8: Positive Relationships....................................................118

Theme \#9: Keeping Busy Helping Others ........................................119

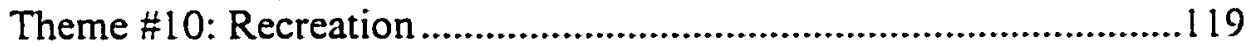

Summary of Protective Factor Themes...................................................122

Impact of Failed Attempts ...........................................................................123

Theme \#1 1: Looking Beyond Themselves: A Higher Power ..............123

Theme \#12: An Inner Perspective: A Bonus Life.............................. 25

Summary of the Impact of the Failed Attempt ..........................................126

6. SUMMARY, FINDINGS, DISCUSSION, CONCLUSIONS AND

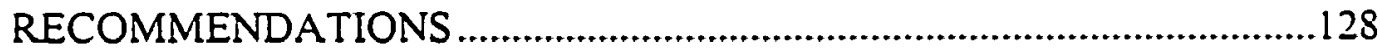

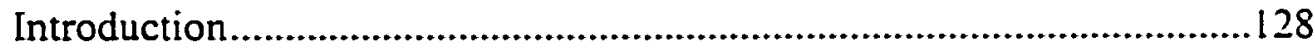

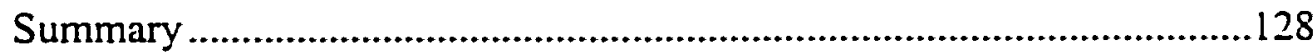

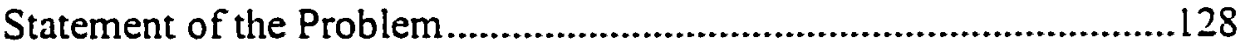

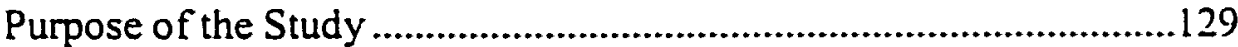

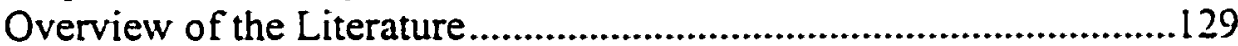

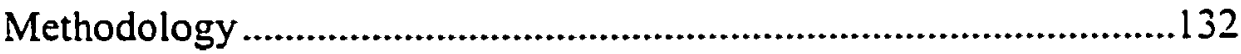

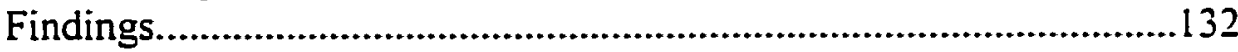

Discussion and Conclusions ............................................................135

Recommendations .................................................................................. 139

Recommendations for Research .......................................................139

Recommendations for Practice ........................................................ 140

Appendix

A. INTEROFFICE E-MAIL AT THE CRISIS CENTER

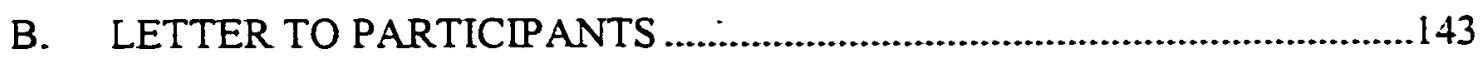

C. CONSENT FORM

D. STRUCTURED INTERVIEW: INTERVIEW GUIDE QUESTIONS ..........148

E. THE UNSTRUCTURED INTERVIEW GUIDE: THE STORY …...............150 
VITA 


\section{LIST OF FIGURES}

1. Individual and Shared Protective Factors ............................................................116

2. Looking Beyond Themselves: A Higher Power ……......................................127

\section{LIST OF TABLES}

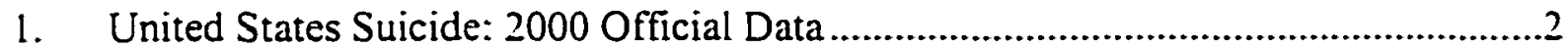

2. General Information About the Attempters ……..................................................

3. Structured Interview Questions and Answers for Jacquelyn ..................................77

4. Structured Interview Questions and Answers for Shannon .......................................78

5. Structured Interview Questions and Answers for Judye ..............................................79

6. Drug Abuse and Mental Health Issues.......................................................................

7. Previous Suicide Attempt .................................................................................104

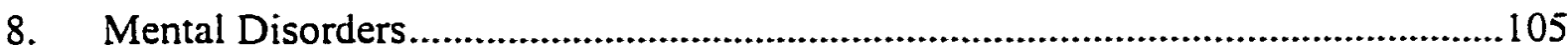

9. Alcohol and Drug Abuse ..............................................................................................106

10. Family and Childhood Dynamics ........................................................................... 109

11. Lack of Family Communication About Suicide Attempts .......................................110

12. Tragic Losses for Jacquelyn.............................................................................110

13. Tragic Losses for Shannon.............................................................................111

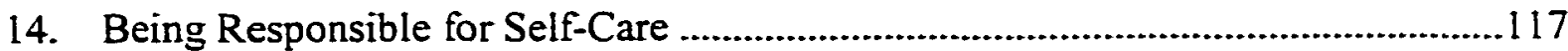

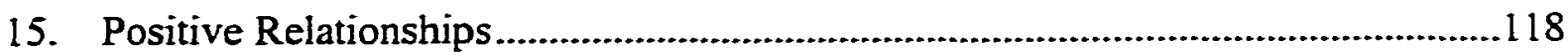

viii 


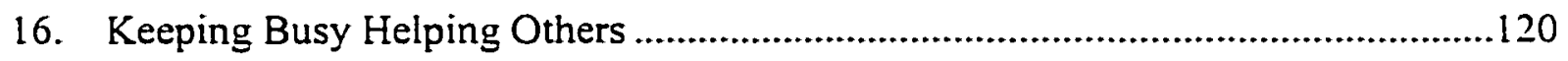

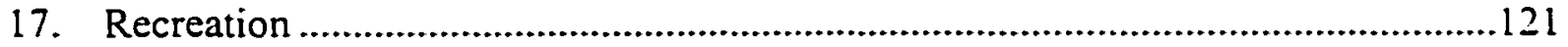




\section{ACKNOWLEDGMENTS}

It is my pleasure to acknowledge those who have helped me along this journey. The completion of this study cannot be attributed solely to my individual resolve. My first thanks goes to God for his wisdom, knowledge, and enabling me to complete this monumental task.

I am indebted to my Chairperson, Dr. Elsie P. Jackson, who led me to the end with scholarly grace and unparalleled dignity. Her knowledge and experience made her a valuable resource. Further I would like to thank my committee members. Dr. Hinsdale Bernard, for his methodological guidance and valuable time, Dr. Kebede Daka, for his willingness to share his expertise in the area of suicide and for his unrelenting support, and Dr. Sherry Collins for acting as my external committee member for her scholarly wisdom, knowledge and valuable time. Sincere appreciation goes to Dr. Tabitha Oteino and Dr. Alberta Yeboah for being second readers of the themes, for their suggestions and critics as experts. I am grateful to Dr. Ingrid Jones for her voluntary spirit, helpfulness, and time spent in jump-starting the process of writing this dissertation.

My heartfelt gratitude goes to my loving husband, Benjamin P. Browne. who has stood by me and encouraged me throughout this complete process in more ways than words can express. Without his constant support this study would not have been possible.

Special thanks to my loving parents, Elder Washington Johnson, Sr., who fell asleep before this joumey was completed but always truly believed in me and believed 
that it would be victoriously completed, and my mother, Dr. Mildred P. Johnson, who was the first to make this journey and showed me that I could do it also. To my siblings, Cynthia, Stephanie, Rosalind, Grayland, and Dr. Washington Johnson, who believed this could be done, I say thank you. A special thanks to my brother Grayland for going above and beyond the call of duty and whose love, encouragement and help were invaluable throughout this process.

Sincere gratitude is extended to my uncle, James Poole, Esquire, who read, critiqued, and encouraged me to complete this process and to my late Aunt Dr. Betty Poole whose memory and determination continues to inspire me immeasurably. I would like to extend appreciation to my sister's-in-law, Joyce, a positive spiritual encourager, and Bernice a gentle sweet spirit. Sincere thanks goes to my brother's-in-law, Muyiwa Adedokun M.D. and Dr. Gil Dingome, Barrister who helped to set a true academic standard. To my niece, Kemi, and nephews, Deji, Washington III, and Andrew, who will one day follow this path in their chosen fields, I express my appreciation for excusing me from some of our usual family activities.

Many thanks goes to Sherry Shaw for her support of this study at the Crisis Intervention Center, Carla Valeris for her outstanding editorial and secretarial skills and Marion Fowler for the hours she spent transcribing interviews. Sincere thanks goes to Carol Castillo, an earthly angel, Elton Allen, Rashad Ahmad and those who encouraged and supported me but whose names are too numerous to mention.

Grateful appreciation goes to the participants in this study who allowed me to enter into their world with the hope of helping others to stay a while longer. Their bonus life could mean life for someone else. 


\section{CHAPTER 1}

\section{INTRODUCTION}

To dispel the silence and shame that too often surround the suicide, it helps to understand the suicidal mind, to better recognize the person at risk.

-K.R. Jamison. An Linquiet Mind

According to Everstine (1998), suicide is the leading psychological cause of death. Suicide is a problem of considerable magnitude in the United States. Unfortunately, more deaths occur from suicide than murder. While globally, mortality due to suicide has distressingly increased by $60 \%$ in the last 45 years, research indicates far more Americans die from suicide than from homicide (McCraig \& Stussman, 1996).

The suicide rate in young people nearly tripled during the period between 1976 and 1996 (U.S. Public Health Service, 1999). Studies show suicide continually ranks as the third leading cause of death for persons between the ages of 15 and 24 . Stimming (2000) says, "Suicide is the leading cause of death among college students (p. 272). To truly understand the magnitude of this problem it is helpful to look at the basic data on demographic characteristics of suicide in the United States, as provided in Table 1.

Suicide is a global pandemic. The World Health Organization's (WHO, 2000) Executive Summary estimated that in the year 2000, one million people would die of suicide. That number was met and continues to climb. Reports also indicate that. depending on the place, suicide attempts can occur about 10 to 40 times more frequently than completed suicides. 
Table 1

United States Suicide: 2000 Official Data

\begin{tabular}{lcccclc}
\hline & Number & Per day & Rate & $\begin{array}{c}\text { \% of } \\
\text { deaths }\end{array}$ & Group number of suicide & Rate \\
\hline Nation & 29.350 & 80.2 & 10.7 & 1.2 & White Males (21.293) & 19.1 \\
Males & 23.618 & 64.5 & 17.5 & 2.0 & White Female (5.182) & +.5 \\
Females & 5.732 & 15.7 & 4.1 & 0.5 & Nonwhite Male (2.325) & 9.9 \\
Whites & 26.475 & 72.3 & 11.7 & 1.3 & Nonwhite Female (550) & 2.1 \\
Nonwhites & 2.875 & 7.9 & 5.9 & 0.9 & Black Male (1.636) & 9.8 \\
Blacks & 1.962 & 5.4 & 5.6 & 0.7 & Black Female (326) & 1.8 \\
Elderly (65+ years) & 5.306 & 14.5 & 15.3 & 0.3 & Native American (297) & 12.2 \\
Young & 3.994 & 10.9 & 10.4 & 12.8 & Asian/Pacific Islander (5.5) & 6.1 \\
\hline
\end{tabular}

Extrapolations about:

Deaths by Suicide (Completions):

- Average of 1 person every 18 minutes killed themselves

- Average of 1 elderly person every 1 hour and 39.3 minutes killed themselves

- Average of 1 young person every 2 hours 12 minutes kill them selves (If the 307 suicides below age 15 are included, 1 young person every 2 hours and 2.5 minutes)

- 4.1 male completions for each female completion

- 11 th ranking cause of death in U.S.A.-Ranks 3 rd for young

Attempts: (Figures are estimates; no official U.S. national attempt data are compiled; based on research findings):

- 734,000 annual attempts in the United States (based on 25:1 death by suicide ratio)

- 25 attempts for every death by suicide for nation

- 100-200:1 for young, and 4:1 for elderly (attempts to deaths ratios)

- 5 million living Americans (estimate) have attempted to kill themselves

- 3 female attempts for every male attempt

Note. "From USA Suicide: 2000 Official Final Data," by J. L. McIntosh, 2000.

Retrieved October 29, 2002, from http://www.iusb.edu/ jmcintos/usa2000summary.htm. 
The WHO (2000) associates mental disorders, particularly depression and substance abuse, with more than $90 \%$ of all suicides. However, suicide results from a combination of many complex sociocultural factors, and tends to occur during periods of socioeconomic, family, and individual crisis (e.g., loss of a loved one, employment. and honor).

Suicide is not a recent occurrence; Van Hooff (1998) notes that in the Greek and Roman world, the conviction that self-hanging prevails in real life loomed large in those societies. The cases reported by literary sources stress the use of weapons. Van Hooff gathered information on more than 1,200 literary cases. In about $40 \%$ of these cases, the suicide weapons used to bring about voluntary death were swords, daggers, knives, and scalpels. According to Van Hooff, there is no "gambling with death" by taking a handful of pills. Society does not view self-killing as a cry for help, but as an act of will.

The prototype of ancient suicide is Ajax. In the Trojan War, he was unanimously recognized as a hero, second only to Achilles. After the death of Achilles, a controversy arose among the Greek heroes about who might inherit Achilles' armor. Ulysses won the argument by cunning speech. The fatal blow to his honor made it impossible for Ajax to face his comrades any longer. He thrust himself on his sword (Van Hooff, 1998).

Many writers have implanted the impression in Western minds that suicide occurred frequently among ancients. Van Hooff (1998) points out that one famous writer in the 16th century inspired painter's by describing the death of Seneca. Peter Paul Reuben, in his painting located in the Alte Pinakothekm museum in Munich, shows the stoic philosopher, Seneca, dictating his last lesson while his veins are being cut. Since this is a voluntary death, Seneca thus completes the act of suicide. 
The Bible contains accounts of suicide. Suicide personalities in the Bible include figures such as Abimelech (Judg 9:54), Samson (Judg 16:28-31), Saul (1 Sam 31:1-6). and Judas (Matt 27:5).

Shniedman (1976) suggests that attempting suicide does not always have a death objective but may have the goal of changing one's life or the life of the significant other and they are a cry for help. Weisman and Kastenbaum (1968) suggest that a suicide attempt entails a calculated risk, because it takes place in a psychosocial context. Survival may depend upon resources for rescue, the individual may know that another person is available at a certain time and will call or visit and interrupt the suicide attempt. The specific form of the attempt may not be one that will take the person's life but get the attention needed to help the attempter.

Weisman and Worden (1974a) point out that all suicide attempts are serious, if they mean that a person has no other options than to harm himself. However, some suicidal attempts portend a higher probability to damage and death than do others. Studies by Lester (1997) have created a continuum of lethality from high to low. Previous suicide attempts put the attempter at a high risk of completing suicide. Lester concludes that previous attempters would rank high on the lethal scale because the attempts could eventually lead to suicide completion. Shniedman (1976) notes that suicide attempts have many meanings and, whatever their level of lethality, ought to be taken seriously.

Stengel (1964) argues that persons who attempt suicide and those who complete suicide represent two different populations, with an overflow from the first to the second. These populations include (a) a group of those who attempt suicide, few of who go on to 
complete it; and (b) a group of those who commit suicide, many of whom have previously attempted it. A person who attempts suicide because he believes that there is no use living may not necessarily mean that he (she) wants to die but that he (she) has exhausted the potential for being someone who matters.

A comparative study of men and women suicide attempters indicated a significant increase among women attempters than men. According to Wrobleski (1995), women attempt suicide three times more often than men, but men kill themselves four times more often than women. Wrobleski (1995) also writes that men and women are socialized differently in that women will ask for help, but it is more difficult for men to ask for help. Suicide attempts are a prelude to suicide completion and should therefore be seriously studied.

Females that attempt suicide as youth tend to consistently attempt as adults. Schuckit and Schuckit (1989) point out that predominance of females as suicide attempters remains consistent from adolescence to adulthood, with the frequency of attempts peaking among female 15 to 24 years of age. Weissman (1994) asserts that the greater frequency of female attempters can be documented in almost all countries, with the possible exceptions of Poland and India.

This qualitative descriptive multiple case study of Caucasian female suicide attempters provides insight into the dynamics of suicide attempts and implications for prevention and intervention. Caucasian females who have failed one or more suicide attempts participated in this study. They shared their stories, cognitive motivations, life experiences, and how the attempt impacted their lives. 
This investigation involved the suicide attempter's background, feelings, and thoughts at the time of the attempt; the reason for the attempts; the number of attempts; their future thoughts on the attempts; and preventive measures they felt were key to preventing suicide.

Murphy (2000) says, "Fewer studies exist on attempts and attempters of suicide than studies on completed suicides" (p. 1). Maris, Berman, and Silverman (2000) state, "It is a well-known fact that nonfatal suicide attempts outnumber completed suicides but the exact ratio is speculative, as no national suicide attempt data are compiled in the United States" (p. 18). Stengel (1964) first estimated that nonfatal suicide attempters outnumbered completers by a ratio of 6-8:1. Mcintosh (1998) argues that the ratio is even larger, 8-25:1.

Life sometimes becomes so painful that persons choose to die rather than to live. Living is to continue in a world of mental, physical, and emotional pain. In the process of painful daily living, the person sees no relief in sight. "Suicide is not chosen; it happens when pain exceeds resources for coping with pain" (Ainsworth, 2002, par. 5).

Suicide is devastating and is painful to the family, friends, and significant others left behind. Even though the individual who completed suicide is dead, the relationship to that person continues in thought, and many questions arise as to why it happened. Death ends a life, not a relationship (Albom, 1997).

\section{Background}

During the fall of 2000 , the researcher accepted a position as Tennessee's Statewide Coordinator for Suicide Prevention. This position resulted from the Surgeon General's Call to Action to Prevent Suicide (U.S. Public Health Service, 1999). As an 
administrator of this program at the Crisis Intervention Center in Nashville, Tennessee, the researcher developed a passion for the prevention of suicide.

This friend took her life by hanging herself in her newly purchased home. One cannot help but ask the question, "Why?" What would have kept her alive? Words inadequately express the devastation that one feels in the wake of such a terrible act. Suicide traumatizes millions of Americans who experience the loss of someone close to them (Ness \& Pfeffer, 1990).

Suicide can make the loss of a loved one especially difficult for survivors. Survivors often have reactions that include feelings of abandonment, rejection, anger. relief, guilt, responsibility, denial, and shame. These reactions are affected by the type and intensity of the relationship, the nature of the suicide, the age, and physical condition of the deceased. Some people feel embarrassed to show that they are grieving for a person who completed the act of suicide. According to Malkinson (1996), grieving is crucial, necessary, and unavoidable for successful adaptation.

Because of the friend's death, the researcher is considered a survivor, along with others who knew and loved her. McIntosh (1996) estimates that each suicide intimately affects at least six other people. Based on the number of suicides from 1972 to 1995 , an estimated 4.06 million survivors of suicide exist in the United States. That figure amounts to about 1 in every 64 Americans.

Three dimensions of knowledge have helped to support this study:

1. The Surgeon General's Call to Action to Prevent Suicide, a blueprint for suicide prevention, is the framework for this study. 
2. Philosophical, psychiatric, psychological, sociological, and medical perspectives on suicide support this study.

3. The classic and timeless works of Durkeim (1951) and Freud (1917/1963) are included in this study.

\section{Statement of the Problem}

According to Hoyert, Smith, Murphy and Kochanek (2001), suicide ranks as the $11^{\text {th }}$ leading cause of death in the United States. Nationwide, 29, 350 people take their lives annually through the act of suicide. Further studies by Hoyert et al. (2001) estimate that 5 million living Americans have attempted to kill themselves. Females account for 5,732 of that number, and Caucasian females account for 5,182 of that number, representing $90 \%$ of all females. The study of Caucasian female suicide attempters has not received due attention from suicidologists.

Therefore, this study aims to bridge an important gap in the knowledge about suicide and suicide attempters by studying the following factors of Caucasian female who have attempted suicide: (a) the risk factors for attempting suicide, (b) the protective factors for the prevention of attempting suicide, and (c) the impact that the failed attempt(s) have on the life of a suicide attempter.

\section{Purpose of the Study}

The purpose of the study is to examine the risk factors of Caucasian female suicide attempters, the protective factors of Caucasian female suicide attempters and the impact of failed attempt(s) on Caucasian females who attempt suicide in order to provide clinicians with implications for prevention and intervention. 


\section{Research Questions}

The following research questions were addressed in this study.

1. What are the risk factors for attempting suicide?

2. What are the protective factors for the prevention of attempting suicide?

3. What impact does the failed attempt have on the life of a suicide attempter?

\section{Significance of the Study}

Because of the high suicide rate in the United States, the Surgeon General has made suicide prevention a priority in his administration. Suicide poses a global problem that is reaching epidemic proportions in the United States.

The rate of attempts for 1999 was 730,000 in the United States. Each completed suicide in the United States represent 25 attempts (Hoyert et al., 2001). Further studies by Hoyert et al. estimate that 5 million living Americans have attempted to kill themselves. Also, three females attempt suicide for each male attempt.

The presence of firearms poses a high risk for suicide (Hoyert et al., 2001). In the United States, 16,599 suicides occurred in which firearms were used, of which 14,479 involved males and 2,120 involved females. Suicide attempters are a high-risk group for future suicide attempts. An early study indicates that, over the long term, about $15 \%$ of previous attempters succeed in taking their own lives (Dahlgren, 1977). More recent studies suggest an average of about 10 to $15 \%$ of individuals making nonfatal suicide attempts eventually go on to kill themselves (Roy \& Linnoila. 1990).

This study is significant for various reasons: (a) It may provide knowledge for practioners and others concerned with the risk and protective factors for suicide attempters, (b) it could be an initial step in providing additional data for program planners 
and healthcare workers in planning policies to reduce suicidal attempts, (c) it will contribute to the body of knowledge about suicide attempters and possibly initiate more research on the subject, and (d) the knowledge acquired in this research may enhance efforts to save the lives of other attempters.

\section{Definitions}

Attempter: A person who tries to intentionally self-inflict death, but is not successful.

An Inner Perspective: A bonus Life: Another chance at life or a new reason to live.

Buerger's disease: Recurrent attacks of inflammation of the arteries and, sometimes, the veins.

Epigram: A short, terse, witty, statement.

Euthanasia: The act of causing death painlessly, so as to end suffering.

Parasuicide: A nonfatal act in which an individual deliberately causes self-injury or ingests a substance in excess of any prescribed or generally recognized dosage.

Polvsurgery: Excessive surgeries.

Protective Factors: Factors contributing to the prevention of suicide attempts.

Risk Factors: Factors contributing to the onset of fatal self-destructive behavior.

Suicide: Intentional self-inflicted death.

Suicide attempt: Unsuccessful self-inflicted death.

Suicide completion: The final and concluded act of intentionally ending one's own life.

Suicidal ideation: Suicidal ideas. 
Suicide ideators: Individuals who think about or form intent to complete suicide.

Suicidal thoughts: Recurring thoughts in the mind of a person to intentionally inflict fatal self-harm.

Suicidology: The scientific study of suicide and suicide prevention.

Survivor: Individuals left behind after the successful completion of suicide by someone they cared for deeply (i.e., family member, significant other, friend, etc.).

World Health Organization: A United Nations Organization responsible for monitoring global health and overpopulation.

\section{Delimitations and Limitations of the Study}

The research is a descriptive multiple case study of attempters of suicide. The data sources included those Caucasian females who have attempted suicide, survived, and were willing to share their suicidal attempt experiences on a voluntary basis.

One limitation of the study is that the research was confined to the state of Tennessee. A second limitation is that only Caucasian female attempters were studied. The third limitation to be considered is the small sample size. Therefore, the researcher advises that clinicians should pay close attention to the description of the attempters and the process used for the interview session when generalizing the results of the study in order to make implications for prevention and intervention for the complete populations of Caucasian female attempters. Due to these limitations, chapter 3 has a thorough discussion on the procedures that were taken to assure for internal and external validity and for reliability. 


\section{Organization of the Study}

Chapter 1 set the stage for this study on suicide and attempters of suicide. It included the introduction and background of suicide and suicide attempters. This chapter defined suicide and attempters, stated the problem of this study, and gave the purpose and significance of the study. In addition, it outlined the research questions, and defined relevant terminology.

Chapter 2 consists of a review of related literature, on suicide, a framework for suicide prevention, and perspectives on suicide. In conclusion, the research includes information on suicide attempters and the methods they use in their attempts.

Chapter 3 provides a description of the methodology utilized in this study. Included is a description of the population, rationale for the use of the population, and the data collection procedure.

Chapter 4 includes a description of the data with profiles of the attempters, a description of the location of the interviews, and the attempters' stories.

Chapter 5 is an interpretation of the data using the process of cross-case analysis for the emerging themes.

Chapter 6 provides the summary, findings, conclusions, and recommendations for further study. 


\title{
CHAPTER 2
}

\section{REVIEW OF THE LITERATIURE}

\begin{abstract}
At this point in the [suicide] trance, the inner pull toward suicide dramatically intensifies. Often it comes in the form of a voice. The voice grows in volume with the stress of the suicide. It demands increasingly to be heard above everything else, and it begins to occupy a greater part of the person's psyche. until it begins to smother more reasonable voices altogether. -Richard Heckler. Waking Up. Alive
\end{abstract}

\section{Introduction}

Chapter 2 is a literature review on the subject of suicide. This chapter begins with a conceptual definition of suicide, and moves into variations on suicide rates and the Surgeon General's Call to Action to Prevent Suicide. Classic works by Freud and Durkeim are mentioned in the chapter and bring a rich timeless view to the subject of suicide. This chapter was built around the research questions that include the risk and protective factors and the impact of suicide attempts on the lives of the attempters.

The following perspectives incorporated in this chapter are psychiatric, psychological, sociological, suicidology, religious, cultural, ethical, legal, mental illness, literature and art themes. This chapter concludes with information about attempters of suicide and the methods utilized by attempters. 


\section{Conceptual Definitions of Suicide}

Sir Thomas Browne (1642) first coined the word "suicide" in his Religio Medici in 1642. Walter Charleton provided a subsequent definition in 1651 (Sharpe 1973). Prior to the introduction of this word, societies used the words "self-killing," "self-destruction," and "self-murder" to convey the same meaning (Venkoba, 1977). Throughout history, the word suicide has had a variety of meanings, from the French Academy's official definition in 1762 as the " murder of oneself" (Soubrier, 1993, p. 35), to Freud (1917/1963), who declared suicide to be "nothing else than a [sort of] exit, an action, an end to the psychic conflicts" (pp. 504-505).

According to Bhatia (1992), suicide is an act of self-inflicted, self-intentioned taking of one's life. Shneidman (1985) wrote, "Suicide is a conscious act of self-inflicted cessation" (p. 206). It is not easy to define suicide. Jamison (1999) says,

Death by one's own hand is far too much a final gathering of unknown motives. complex psychologies, and uncertain circumstances. It [suicide] insinuates itself far too corrosively into the rights, fears, and despairs of the living. For the definition of suicide to stay locked within the crisp categories chipped out by scientists or for it to adhere to the obtuse elaboration spun out by linguists and philosophers. (p. 26)

The Centers for Disease Control and Prevention (as cited by Jemison, 1999) defines suicide as "a death from injury, poisoning, or suffocation where there is evidence that injury was self-inflicted and that the decedent intended to kill themselves" (p. 27). The World Health Organization (1968) defines suicide as a suicidal act with a fatal outcome. The scientific study of suicide and suicide prevention is suicidology (Maris, 1993). Suicide behaviors are complex and multifaceted. Their richness, diversity, and stubborn persistence throughout recorded human history challenge those of us who would understand, predict, and intervene in them. On the most fundamental existential level, we 
pay attention to suicide because it is an ever-present, compelling, unavoidable, and sometimes devastating life issue (Maris et al.. 2000).

About suicidal thoughts and fantasies, the philosopher Nietzsche (1966) said, "The thought of suicide is a powerful comfort, it helps one through many a dreadful night" ( $p$. 91). There are many attitudes about suicide, some more extreme than others. Because of these varying views and thoughts about suicide, objective facts about suicidal behavior have often been obscured by myths and misunderstanding. According to Fremouw, Perczel, and Ellis (1990), some of the most common myths are as follows:

1. People commit suicide without warning. Studies show that suicidal persons generally have had long histories of emotional maladjustment and maladaptive behavior.

2. Sometimes a minor event such as a poor test grade can push an otherwise normal person to commit suicide. Research has shown that in addition to manifesting long-term adjustment problems, suicidal persons also have characteristic cognitive patterns such as rigid thinking, deficient problem-solving skills, and irrational beliefs that predispose them to respond to stressful events with maladaptive behaviors (Ellis, 1986).

3. Only crazy people commit suicide. While persons with schizophrenia or psychotic depression do not infrequently commit suicide, individuals without psychotic processes commit the majority of suicidal acts.

4. If a person committed suicide, his or her situation was probably so bad that death was the best solution. This thought is based upon value judgment. Often in medical settings it is not unusual to hear medical students and residents comment that suicide would be "understandable" or perhaps reasonable for patients with terminal illnesses. However, at least one study by Brown, Henteleff, Barakat, and Rowe (1986) 
showed that patients with terminal illnesses were rarely suicidal and that those patients who did become suicidal were also clinically depressed.

5. People who threaten suicide do not do it. Several studies have shown no less than two thirds of suicide victims have communicated their intentions at some point before committing suicide (Murphy, 1985).

6. People who really want to die will find a way; it will not help to try to stop them. Most suicidal people are highly ambivalent about suicide and at the same time that they desire death they generally also wish desperately to be rescued so that they can have another chance at life.

7. One should not try to discuss suicide with depressed people; it might give them the idea or upset them enough to "push them over the edge." The greater risk is that the topic be passed over. This can result in an even greater sense of isolation.

8. Suicides occur in greatest numbers around Christmas and Thanksgiving. Christmas and Thanksgiving are actually the least risky of the six major U.S. holidays. While the incidence of suicide in the United States is relatively consistent throughout the year, it is lowest during the winter months and highest in the spring (Centers for Disease Control, 1985).

\section{Variations on Suicide Rates}

Historically, public health officials have noted several differences in the dynamics of suicide among Blacks and Whites: Blacks commit suicide less often than Whites, White men have had higher suicide rates than Black men, and both of these groups have had higher suicide rates than Black women.

Elderly White men are more likely to kill themselves than elderly Black men or 
women (Poussaint \& Alexander, 2000). However, Poussaint and Alexander further state that the gap between Black and White suicide rates has begun to shrink, with Black rates climbing to unparalleled and alarming heights. Poussaint and Alexander also noted,

While it is important to note that during the twenty-year period between the 1970's and 1999 the total suicide rate in America declined, from 12.1 deaths per 100,000 in 1976 to 10.8 in 1996 , the suicide rate among teenagers and young adults nearly tripled during that same period. Meanwhile, according to the United States Centers for Disease Control (CDC), the rate of suicides among black males climbed from 7.9 per 100,000 persons in 1970 to 10.9 per 100,000 in 1997 , with the suicide rates for all blacks increasing although less rapidly, during the same period, from 5.1 in 1970 to 6.1 in 1997. (p. 46)

Poussaint and Alexander (2000) believe that depression and isolation are two primary psychological risk factors that are likely to precede suicidal ideations in Blacks.

According to the Centers for Disease Control (U.S. Public Health Service, 1999), the suicide rate among Native Americans, arguably the most isolated ethnic group in America was 1.5 times that of the total United States population between 1979 and 1992. The data also show that completions occur on the average of one person every 18 minutes. One elderly person completes suicide every 1 hour and 35.8 minutes, and one youth completes suicide every 2 hours and 14.7 minutes.

More recent studies by Blumenthal and Kupfer (1990), Gibbs (1997), and Mann (1998) indicate that variations in suicide rates provide opportunities to understand the different roles of risk and protective factors among age, gender, ethnic, and cultural groups. These studies show that risk and protective factors encompass genetic, neurobiological, psychological, social, and cultural characteristics of individuals and groups. These characteristics explain sub-factors such as an individual's accessibility to firearms. This expanding base of empirical information generates promising ideas about how society can change or modify risk factors to prevent suicide. 
Variations on suicide rates include those who survive the suicide of a friend or family member. Satcher (U.S. Public Health Service, 1999) points out that the estimated number of survivors from the over 736,000 suicides from 1975 through 1999 is 4.4 million. This number of survivors grew by 175,000 in 1999 . If a suicide occurs every 18 minutes, the Surgeon General's Call to Action (U.S. Public Health Service, 1999) estimates six new survivors every 18 minutes. Suicide attempts are an ever-increasing problem and are a high cost factor in the medical community.

\section{The Surgeon General's Call to Action to Prevent Suicide}

In 1999, Surgeon General David Satcher announced at a Washington, D.C., press conference that suicide had become the eighth leading cause of death at that time for all Americans, and the third leading cause of death for those between the ages of 15 and 24 . He went on to say that each year we lose more than 5,000 of our youth through selfinflicted violence, and the rates are climbing. An over $200 \%$ rise in youth suicides has occurred since the 1950 s. While the rate of violent crime in the country has dropped, an average of 85 suicides takes place each day. As a cause of death in the Unites States, and a public health problem, the total number of suicides had, by the late 1990 s, topped that of homicides, 31,000 to 21,000 . Completers of suicide prefer the method of death by gunshot $60 \%$ of the time (p. 2).

It was decided by a group of key professionals in the area of human services that a guideline was needed to educate the public on suicide and suicide prevention. The former Surgeon General, David Satcher (U.S. Public Health Service, 1999), published $A$ Call to Action to Prevent Suicide. The surgeon general's call to action introduced a blueprint for reducing suicide and the associated toll that mental and substance abuse 
disorders take in the United States. Based on evidence and prioritization by leading experts, 15 key recommendations serve as a framework for immediate action to prevent suicide. The recommended first steps are awareness, intervention, and methodology (AIM). Awareness: Appropriately broaden the public's awareness of suicide and its risk factors. Intervention: Enhance services and programs, based on population and clinical need. Methodology: Advance the science of suicide prevention.

1. Awareness: Appropriately broaden the public's awareness of suicide and its risk factors in the following ways:

a. Promote public awareness that suicide is a public health problem and is largely preventable.

b. Use appropriate information technology to make facts about suicide, its risk factors, and prevention approaches available to the public and to health care providers.

c. Expand awareness of and enhance resources in communities for suicide prevention programs and mental and substance abuse disorder assessment and treatment.

d. Develop and implement strategies to reduce the stigma associated with mental illness, substance abuse, and suicidal behavior, along with seeking help for such problems.

2. Intervention: Enhance services and programs based on population and clinical care need as follows:

a. Extend collaboration with and among public and private sectors to complete a national prevention strategy.

b. Improve the ability of primary care providers to recognize and treat depression, substance abuse, and other major mental illnesses associated with suicide risk.

c. Increase the referral to specialty care, when appropriate.

d. Eliminate barriers in public and private insurance programs for provision of quality mental and substance abuse disorder treatments.

e. Create incentives to treat patients with coexisting mental and substance abuse disorders.

f. Institute training for all health, mental health, substance abuse, and human service professionals, including clergy, teachers, correctional workers and social workers, concerning suicide risk assessment and recognition, treatment, management, and aftercare interventions.

g. Develop and implement effective training programs for family members of those at risk and for natural community helpers on how to recognize, respond to, and refer people showing signs of suicide risk and associated mental and substance abuse disorders. Natural 
community helpers are people such as educators, coaches, hairdressers, and faith leaders, among others.

h. Develop and implement safe and effective programs in educational settings for youth that address adolescent distress, provide crisis intervention, and incorporate peer support for seeking help.

i. Enhance community care resources by increasing the use of schools and workplaces as access and referral points for mental and physical health services and substance abuse treatment programs.

j. Provide support for persons who survive the suicide of someone close to them.

k. Promote a public/private collaboration with the media to assure that entertainment and news coverage represent balanced and informed portrayals of suicide and its associated risk factors including mental illness and substance abuse disorders and approaches to prevention and treatment.

3. Methodology: Advance the science of suicide prevention as listed below:

a. Enhance research to understand risk and protective factors related to suicide, their interaction, and their effects on suicide and suicidal behaviors. Additionally, increase research on effective suicide prevention programs, clinical treatments for suicidal individuals, and culture specific interventions.

b. Develop additional scientific strategies for evaluating suicide prevention interventions.

c. Ensure that all suicide programs include an evaluation component.

d. Establish mechanisms for federal, regional, and state interagency public health collaboration toward improving monitoring systems for suicide and suicidal behaviors. Develop and promote standard terminology in these systems.

e. Encourage the development and evaluation of new prevention technologies, including firearm safety measures, to reduce easy access to lethal means of suicide. (p. 6-16)

Each year in the United States, approximately 500,000 people require emergencyroom treatment as a result of suicide attempts (McCraig \& Stussman, 1996).

\section{Risk and Protective Factors for Suicide Prevention}

The Surgeon General's Call to Action to Prevent Suicide (U.S. Public Health

Service, 1999) cites several studies that establish suicide risk, protective factors, and interactions of the two as the empirical base for suicide prevention. Risk factors tend to 
increase the potential for suicide and suicidal behavior, while protective factors tend to reduce potential for suicide (Blumenthal \& Kupfer, 1988; Felner \& Silverman, 1995).

\section{Risk Factors}

It is important that risk factors be one of the key areas of study for this research. Being aware of the risk factors increases awareness and possible prevention of suicide. Hennriksson et al. (1993) state that understanding risk factors can help dispel the myths that suicide is a random act or results from stress alone. Mental illness and the combination of dual or multiple diagnoses increase suicide attempts. When some people experience more than one mental disorder simultaneously, they become particularly vulnerable to suicide and suicidal self-injury. Cornelius et al. (1995) point out depression with alcohol abuse as an example of mental disorder combination. Certain risk factors. like previous attempts, will not change; however, the knowledge of previous attempts can alert others to the heightened risk of suicide during recurring periods of a mental or substance abuse disorder or following a significant stressful life event.

The Surgeon General's Call to Action to Prevent Suicide (U.S. Public Health Service, 1999) includes the following risk factors, among others:

Previous suicide attempt(s)

Mental disorders, particularly mood disorders such as depression and bipolar disorder

Co-occurring mental and alcohol and substance abuse disorders

Family history of suicide

Hopelessness

Impulsive and/or aggressive tendencies

Barriers to accessing mental health treatment

Relational, social, work, or financial loss

Physical illness

Easy access to lethal methods, especially guns

Unwillingness to seek help because of the stigma attached to mental and substance abuse disorders and/or suicidal thoughts 
Influence, through direct personal contact or inappropriate media representations, of significant people, family members, celebrities, peers who have died by suicide

Cultural and religious beliefs like the belief that suicide is a noble resolution of a personal dilemma

Local epidemics of suicide

Isolation or a feeling of being cut off from other people. (p. 8)

Awareness of risk factors that can lead to suicide, especially mental and substance abuse disorders, help to form the conceptual framework for the prevention of suicide. Interventions, such as effective treatments for depressive illness, reduce the impact of some factors (U.S. Public Health Service, 1999).

\section{Protective Factors}

Blumenthal and Kupfer (1990) point out that protective factors can include an individual's genetic or neurobiological makeup, attitudinal and behavioral characteristics. and environmental attributes. The Surgeon General's Call to Action to Prevent Suicide (U.S. Public Health Service, 1999) shows that enhancing resilience or protective factors plays an essential role in risk reduction and suicide prevention. Positive resistance to one suicidal period does not have a permanent effect, so programs that support and maintain protection against suicide should remain ongoing.

Listed are the protective factors in the blueprint:

a. Effective and appropriate clinical care for mental, physical, and substance abuse disorders

a. Easy access to a variety of clinical interventions and support for seeking help

b. Restricted access to highly lethal methods of suicide

c. Family and community support

d. Support from ongoing medical and mental health care relationships

e. Learned skills in problem solving, conflict resolution, and nonviolent handling of disputes

f. Cultural and religious beliefs that discourage suicide and support selfpreservation instinct. (U.S. Public Health Service, 1999, p. 9)

Protective factors safeguard against suicide and aid in suicide prevention. 


\section{Perspectives on Suicide}

Suicide can be viewed from numerous perspectives. Agganval, Bhatia, and Aggarwal (1994) found that suicide carries a variety of connotations, depending upon its specified philosophical, psychological, and sociological purposes. For purposes of this research study, the literature review includes the following perspectives on suicide: (a) psychiatric and psychological, (b) sociological, (c) suicidology, (d) religious and cultural, (e) ethical and legal, (f) mental illness, and (g) literature and art.

\section{Psychiatric and Psychological Perspectives on Suicide}

Viennese psychiatrist, Sigmund Freud (1917), and later his American counterpart, Karl Menninger (1966), standardized psychiatric and psychological types of suicides. As Freud saw it, all suicides have three fundamental dimensions: hate, depression (melancholia), and guilt. It follows that all suicides fall into one or more interrelated categories: (a) revenge, a wish to kill; (b) depression and hopelessness, a wish to die; and/or (c) guilt, a wish to be killed. Freud believed that all suicides involve hostility or a death wish originally directed at an external object like one's father, mother, lover, and/or spouse, and others.

Freud (1917/1963) proposed that suicide is aggression against others tumed upon oneself. He theorized that self-hatred, manifested in depression, results from repressed rage toward a loved one or an oppressor, turned back on the self.

Litman (1967) discusses Freud's view on suicide and believes that Freud saw aggression as a product of frustration of sexual impulses and all life energy as sexual energy. However, after witnessing the carnage of World War I, Freud decided that two 
opposing basic instincts exist: life (Eros) and death (Thanatos) drives. Litman further emphasizes Freud's belief that life seeks the peace of death, and the universal goal of all living substances is to return to the pure essence of the inorganic world.

However, Maltsberger (1992), a psychiatrist, posits that a key dynamic in suicidal patients is the projection of their own self-hatred onto the outside world. This projection makes the world seem to the depressed patient unfriendly and hostile, resulting in intolerable mental anguish.

Menninger (1966) viewed suicide as an escape from an intolerable life situation and believed that suicide paralleled other escapes such as the taking of vacations or celebrating of holidays, falling asleep, wandering in delirium, or resorting to drunkenness. Menninger places suicide into three categories: (a) the wish to kill, an instructive instinct that slumbers within the heart of even the tiny child to be apparent as externally directed aggressiveness accompanied by rage almost from the moment of birth; (b) the wish to be killed, the extreme form of submission just as killing is the extreme form of aggression; and (c) the wish to die, a powerful self-destructive tendency with conspicuous aggressive and punitive elements that were thwarted in every case by what appears to be a comparative weakness of the wish to die.

Psychiatrist Mann (1998) tends to think of suicide as reflecting brain neurotransmitter abnormalities or deficiencies of the serotonergic system and sees the etiology of suicide in the brain. In clinical studies by Stanley and Mann (1988) that examine biogenetic amine metabolites in the cerebrospinal fluid, they found a relationship between the serotonin metabolite 5-hydroxyindoleactic acid and suicidal behavior. 
Jamison (1999) points out that serotonin is a chemical found in plants as well as in invertebrate nervous systems and is widespread in the bodies and brains of mammals, including humans. It acts in diverse ways; it controls the diameter of blood vessels, affects pain perception, influences the gut, plays a role in the body's inflammatory responses, and causes platelets to clump. Serotonin has been implicated in connection to suicide. Jamison (1999) suggests that from a psychiatric and psychological perspective, serotonin is significantly implicated in the roots of depression, sleep regulation, aggression, and suicide.

\section{Sociological Perspectives on Suicide}

French Sociologist Emil Durkeim (1951), a founder of the scientific study of suicide, was the first academic to throw aside the curtain on the private acts of suicide. revealing their social patterns. Durkeim associated suicide rates with the levels of social integration among certain populations. He concluded that increased community involvement reduces suicidal risk. Weir (2001) pointed out that 100 years later the observation of Durkeim continues to influence and inform effective suicide prevention and community intervention programs.

Durkeim (1951) argued that there are four basic types of completed suicides, with seven subtypes and six mixed types. The four basic suicides are as follows:

1. Egotistical. Durkeim (1951) hypothesized that egotistical suicide results from excessive individuation or lack of social integration. Suicide by a male on skid row or another social outcast provides an example of the egotistical suicide type. Egotistical suicide results from the individual's failure to fit into his or her society.

2. Altruistic suicide. This suicide results from insufficient individuation and is 
characterized by energy or activity rather than apathy. The altruistic suicide type typically finds the basis for existence beyond earthly life. This type of suicide occurs among religious martyrs.

3. Anomic. Durkeim (1951) defined anomie as literally meaning "without norms." An anomic suicide results from a temporary but abrupt disruption of normative restraint. It occurs during a state of alienation and periods in which the individual lacks purpose. He or she may lack purpose because he or she may be unable to adjust to social changes like severe economic reverses or other events leading to social dislocation. Anomic suicides may occur following stock market crashes.

4. Fatalistic. Although Durkeim (1951) cited few examples of fatalistic suicide, Poussaint and Alexander (2000) believe such examples as slavery in any culture might serve historical interests. In the words of Durkeim (1951), "Do not the suicides of slaves belong to this type, or all suicides attributable to excessive physical or moral despotism? [It is the revolt against] the ineluctable and inflexible nature of a rule against which there is no appeal" (p. 37). Lester (1997) produced meaningful historic evidence indicating that since at least the 17 th century, some Blacks chose to end their own lives rather than endure slavery.

Poussaint and Alexander (2000) expounded upon Durkeim's sociological view of altruistic suicide:

Altruistic suicide results from group domination of the individual, wherein the group's authority becomes so complete that the individual loses his sense of personal identity and sacrifices his life for the collective body. The murdersuicides of 914 members of the People's Temple in Guyana in 1978 and the 1997 suicides of more than 20 members of the Heaven's gate cult in San Diego serve as examples of this kind of suicidal episode. Other examples include a soldier who dies for his country or a Buddhist priest who immolates himself to protest war. (p. 37) 
Henry and Short's (1954) Suicide and Homicide is an extension of Durkeim's anomic type of suicide because it tested the influence of economic changes on the suicide rate. Henry and Short also expanded Durkeim's concept of external restraint to include the Freudian notion of "internal restraint" and expanded the possible aggressive outcomes from suicide to homicide rates.

Durkeim's work (1951) was largely quantitative, with the use of suicide rates as the foundation for his study of suicide. He believed that suicide, seemingly among the most private and individual of human acts, could only be experienced collectively. He was insistent on the use of suicide rates by counting and using numbers to define suicide. The most radical challenge to the Durkeimian sociological approach to the study of suicide has come from Douglas (1970), who questioned Durkeim's procedure of finding suicide information on official statistics such as death records or death certificates.

Douglas (1967) argues that vital or official statistics are unreliable. Douglas's trend toward the study of suicide is qualitative and originated primarily with the ethnomethodology of Douglas. Ethnomethodology concerns uncovering the unstated, implicit, commonsense perceptions held and acted on by the participants in a situation such as suicide attempts.

Douglas (1967) makes three major claims about the sociological study of suicide: (a) suicide has many, not one, different meanings; (b) suicide cannot be explained until we ascertain exactly what it is we are trying to explain (e.g., not simply relying on death certificates, which do not take the meaning of suicide as problematic); and (c) the best way to discover the meanings of suicide is to observe the statements and behavior of individuals actually engaged in suicidal behaviors, such as suicide attempters. Douglas 
argues that it is not possible to predict suicide in abstract collective terms, such as anomie or egoism.

Johnson (1965) set out to show that Durkeim's four types of suicide were reducible to one. The categories of altruism and fatalism were considered by Johnson to be dispensable, because Durkeim could produce very few contemporary and documented examples of their occurrence. Johnson's final point was that the two concepts, egotism and anomie, were identical conceptually. He extracted from Durkeim's thought three essential features of egotism: lack of interaction among the members of society, lack of common conscience (or purpose and goals), and lack of social regulation, which is, of course, anomie.

Johnson (1965) agreed with Gibbs and Martin (1964) that the distinction between anomie and egotism in Durkeim's theory was slight and that there was not much importance to be placed on altruistic suicide. However, Gibbs and Martin criticized Durkeim for other inadequacies, including a failure to give operational definitions of social integration with suicide rates.

\section{Suicidology Perspectives}

Suicidology the scientific study of suicide and suicide prevention is not necessarily a morbid, ghoulish preoccupation, as we might imagine (Maris et al.. 2000). Some suicides may appear rational when, in spite of considerable efforts to live better, our lives are still insufficiently pleasurable or meaningful (Maris, 1981). In a sense, one studies suicide and death in order to live better (Maris et al., 2000). The study of suicide is broad with many components, but the study of suicidology defines, helps to understand suicide better, and sets a course for prevention. 
Shneidman (1993) conceives of suicide as "psychache" or intolerable psychological pain. Shniedman believes that a person can suffer from psychological pain so unbearable as to make him choose to end his life.

Shneidman (1993) claims that people who attempt to commit suicide want to interrupt their tortured self-consciousness to stop the mental pain and anguish. He further believes that intolerable psychological pain is the key commonality in all suicides:

Nearing the end of my career in suicidology, I think I can now say what has been on my mind in as few as five words: suicide is caused by psychache. Psychache refers to the hurt, anguish, soreness, aching psychological pain in the psyche, the mind. It is intrinsically psychological, the pain of excessively felt shame, or guilt, or humiliation, or loneliness, or fear or anger, or dread of growing old, or of dying badly, or whatever. (p. 51 )

Within the scope of research, suicidological subject matter includes information on completed suicides, nonfatal suicide attempts, suicidal ideation, and/or indirect selfdestructive behaviors and parasuicides (Maris et al., 2000).

O'Carroll et al. (1996) found the following: (a) completed suicides are individuals who actually die by their own hand, and (b) a nonfatal suicide attempter is someone who intentionally injures him or herself but does not die. Suicide ideators think about or form intent to commit suicide of varying degrees of seriousness, but do not make an explicit suicide attempt or complete suicide. They may also ideate through indirect, selfdestructive behavior. Self-destructive behavior may occur in the absence of suicidal intention, awareness, or expectation of suicidal outcome. Kreitman (1977) coined the term Parasuicide. Parasuicide is a nonfatal act in which an individual deliberately causes self-injury or ingests a substance in excess of any prescribed or generally recognized dosage. 
Terms like partial, chronic, long-term, and even unconscious also characterize self-destructive behavior. These behaviors may include excessive smoking, eating disorders, polysurgery, alcoholism, risky sports, stress seeking, dangerous occupations, sexual disorder, medical noncompliance, compulsive gambling, psychosomatic illnesses. self-mutilation, drug addition, accident proneness, Buerger's disease, asceticism, and even a chronic habit of overwork (Farberow, 1980).

Shneidman and Farberow (1957) divided suicidal persons into four general classes: (a) those who view suicide as an honorable act, as a transition to a better life, or as a means of avoiding social disgrace; (b) those who are bereaved or in ill health and physical pain and view suicide as an escape from deep anguish; (c) those who are suffering from psychosis and kill themselves in response to hallucinations or delusions; and (d) those who commit suicide out of spite and anger, in the hope that the people whom they are trying to punish will suffer.

Accordingly, Maris et al. (2000) believe that it is misleading to speak of the problem of suicide prevention, because suicide is not one thing or problem but is, in fact, many different overlapping yet somewhat distinct problems. Maris et al. further believe that the success or failure of suicidological science depends in large measure on how carefully they specify and operationally define their dependent variables. Individual suicide cases and socio-demographic data have to be studied differently. Demographic data and observation are both important in suicidological research.

\section{Religious and Cultural Perspectives on Suicide}

According to Rauscher (1981), suicide is often condemned on the grounds that it is "unnatural" in some sense. The sucide does not follow "nature's" way. There are 
various arguments on suicide as being unnatural. Both St. Thomas Aquinas (1990) and Josephus (1927) argued that suicide is unnatural in the sense that it is a violation of the alleged ever-present drive, which all living organisms have to preserve their lives.

According to Aquinas (1990), since everything naturally keeps itself in being and resists corruption as far as it can, it follows that suicide is contrary to the inclination of nature. From this, Aquinas implied that suicide is a mortal sin. Likewise, Josephus (1927) claimed that suicide is repugnant to the nature that all creatures share, because among the animals, there is no one that deliberately seeks death or kills itself. Firmly rooted in all nature's law is the will to live. St. Augustine (1952) believed the Bible is the guideline for the argument against suicide. St. Augustine claimed that the commandment "Thou shall not kill" (Exodus 20:13) could be taken to imply that suicide is a detestable and damnable wickedness.

There are some analogy-based religious arguments that rely on analogies to describe the relationship between human beings and God. Based on these analogies, it is argued that suicide is always wrong. Josephus (1927) believed our existence is a gift from God and suggests that God is indignant when man treats His gift with scom. Aquinas (1990) agrees with Josephus that life is a gift from God to man, and whoever takes his own life sins against God. Smedes (2000) believes that people who take their own lives do not mean to flout the will of God and they do not so much choose death as stumble down into it from a steep slope of despair.

Styron (1990) points out that the historical and religious view of suicide as being shameful has predominated society's thoughts about suicide. Poussaint and Alexander (2000) point out that, while early Christians often embraced martyrdom as evidence of 
their faith, Christianity and Judaism have regarded suicide as a crime against nature and God. They regard life as sacred and believe that what God gives, only God can take away. Poussaint and Alexander further note that some branches of these religions deny burial in consecrated ground to people who kill themselves, unless the survivors deem the suicide unintentional or believe the individual self-inflicted death for a religious cause.

Maris (1981) sampled Chicago suicides and asked questions about the individual's religious attitudes and behaviors. He found that religious affiliation and activity tend to protect one against suicide, if the group norms away from suicide. However, if one belongs to a death cult, such as Jonestown or Heaven's Gate, then religion presents a risk factor, not a protective factor. Based on the Judeo-Christian scriptures (Exodus, 20:15), suicide may constitute a violation of the sixth commandment, "Thou shall not kill." Many religions believe that God, not humans, properly controls life and death (Maris, 1981).

Some cultures have tolerated instances of self-destruction. Their customs or religious philosophy may have allowed self-destruction as an alternative to shame or death at the hands of others. In ancient Greece, Socrates accepted a cup of hemlock (Poussaint \& Alexander, 2000). In feudal England, suicide constituted a criminal act. A person who killed him or herself had broken his or her bond of fealty to the Crown. In some American states, lawmakers have long considered attempted suicide an indictable offense (Poussaint \& Alexander, 2000).

Poussaint and Alexander (2000) further point out that some cultural and historic contexts do not characterize all instances of self as sickness. In ancient Japan, an aristocrat or a warrior might commit a culturally sanctioned ritual suicide, like the hara- 
kiri, rather than face dishonor or capture by enemies. Poussaint and Alexander found that in India following the ancient Hindu custom of suttee, some women sacrificed themselves on their husbands' funeral pyres as proof of their love and devotion. The British prohibited suttee in the 19th century, but the practice persisted for a time in isolated orthodox communities.

Certainly cultures vary in their ideas of self-murder. Bromberg and Cassel (1983) point out that the Eskimo, Norse, Samoan, and Crow Indian accepted, and even encouraged, "altruistic" self-sacrifice among the elderly and sick. Leighton and Hughes (1955) describe the self-inflicted death of the Yuit Eskimo of St. Lawrence Island in this way:

If an individual requests suicide three times, relatives were obliged to assist in the killing. The person seeking suicide dressed in ritual death garb and then was killed in a "destroying place" set-aside specifically for that purpose. To save commonly held resources of food or to allow a nomadic society to move on unhindered by the physically ill or elderly, some societies gave tacit if not explicit approval of suicide. (pp. 327-338)

Cohn (1976) pointed out that Jewish custom forbade funeral orations for anyone who committed suicide; mourners' clothes were not encouraged, and burial was generally limited to an isolated section of the cemetery, so as not to bury what is considered as the wicked next to the righteous. Posner (1987) writes that the Semachot, the rabbinic text on death and mourning, states that "He who destroys himself consciously ('la-daat'), we do not engage ourselves with his funeral in any way" (as cited by Jamison, 1999, p. 160). Over a period of time, less conservative thinking and more compassion were extended to suicide committed while of an unsound mind.

Cohn (1976) noted that as a general rule, Jewish tradition is that on the death by suicide you do everything in honour of the surviving, such as visit and comfort and 
console them, but you do nothing to honour the dead apart from burying them. Even though we see numerous suicide bombings today, in Islamic Law, suicide is a crime as grave as, or even graver than, homicide (Al-Najjar, 1978). Religion and cultures vary on the perspective of suicide and will probably continue as long as there are various cultures and many religions.

\section{Ethical and Legal Perspectives on Suicide}

Two opposite well-known positions on the ethics of suicide are based on the philosophies of Schopenhauer (1969) and Camus (1983). Schopenhauer explicitly denies that suicide is wrong. The only objection to suicide that remains is his claim that the morally ideal person will refrain from suicide. Camus claims that suicide is not legitimate. He further suggests that suicide lacks the majesty of the person who refrains from suicide in the face of the absurdity of human existence; to face the absurdity of human existence, rather than to commit suicide, involves the exceptional. These remarks by Camus suggest that the truly ideal person will not commit suicide.

There are forms of suicide that require the assistance and commitment of others, as is the case with the process of euthanasia. Many herald Derek Humphry (1996) as a spokesperson for euthanasia in the form of assisted suicide. In his book, Final Exit, Humphry instructs readers on how to complete the act of suicide. The following excerpt serves as an example of his detailed instructions:

Decide which day and at what time you intend to die, and let those know who have agreed to be with you. Have your farewell note and other documents (will, insurance policies) ... beside you. An hour beforehand have an extremely light meal--perhaps tea and a piece of toast--so that the stomach is nearly vacant, but not so empty as to feel nauseous or weak. . . Take three travel-sickness pills, such as Dramamine, to ward off nausea caused by the excess drugs taken later. 
Simultaneously, take four or five beta-blocker tablets (such as Inderide, Lopressor, Corzide, or Tenoretic) to slow down the heart. ... When about an hour has elapsed, take about ten of your chosen tablets [e.g., Seconal or Nembutal] with as large a drink of spirits or wine as you are comfortable with.... Have the remaining drugs [perhaps a total of $60 \times 100 \mathrm{mg}$; so about 50 or more] already mixed into a pudding, yogurt, or jam/preserves (whatever pleases you) and swallow all this down as fast as possible. Throughout, keep plenty of alcoholic drink or soda close by to wash all this down and also to help dilute the bitter taste. (p. 142)

Derek Humphry (1996) waged a legal battle in Oregon, first as president of the Hemlock Society and later as president of the Euthanasia Research and Guidance Organization (ERGO) and the Oregon Right to Die Organization. On November 4, 1994, Oregon became the first state in the United States to permit a doctor to prescribe lethal drugs expressly and explicitly to assist in a suicide death (Maris, 1992).

Physicians have assisted suicides for some time in the Netherlands. On February 10, 1993, the Dutch Parliament voted 91 to 45 to allow euthanasia (Maris, 1992).

Dr. Jack Kevorkian remains one of the most radical and controversial advocates of physician-assisted suicide ever. Kevorkian (1991) advocates physician-assisted suicide, which he refers to as "medicide." He also describes the suicide machine used to assist the patient as the "mercitron."

Roleff (1998) discusses the fact that many health care professionals agree to the rationality of suicide under certain conditions and uses a 1995 study by Werth and Cobia on the subject to develop this point. Werth and Cobia (1995) surveyed 200 psychologists and found that $88 \%$ of the survey sample conditionally support the concept of rational suicide. The person considering suicide must be terminally ill, in severe physical or psychological pain, or experiencing an unacceptable quality of life. He or she must choose freely to die. In addition, Werth and Cobia (1995) developed the following 
criteria for a rational suicide: the individual must have met a mental health professional; weighed all the alternatives; considered how the act would affect others; and consulted with friends, family members, and clergy.

Kass (1996), an ethicist, physician, and outspoken critic of the right-to-die movement, argues that legalizing physician-assisted suicide will have extremely dangerous consequences for individuals and society.

Cosculluela (1995) characterizes suicide as rational and permissible when it serves as an expression of one's deepest values or an escape from an unbearable existence. He continues by describing suicide that protects others from death or suffering as obligatory. A soldier's falling on a grenade and a pilot's crashing a disabled plane into a hill to avoid a field full of children serve as examples of rational and permissible suicides.

According to Sullivan (1984), many studies and years of experience presume people attempting suicide are deranged and in need of psychological help. Sullivan further suggests that the law would leave ideators alone and without genuine help to do something irreparable, based on a distorted assessment of their circumstances if laws allowing assisted suicide are passed. Drinan (1994, as cited in Roleff, 1998) writes,

Only God Can Decide. In the end, law cannot really resolve the complexities of a situation that involves religion, ethics, medicine, and what people think of the ultimate mystery of human existence. Amid the clamor and confusion, Catholics and other persons of faith should proclaim quietly and without arrogance or dogmatism that God is the author of all human life. Only God has the right to determine the time of its determination. (p. 29) 


\section{Perspectives on Mental Illness and Suicide}

The phenomenon of suicide has attracted the attention of a wide variety of medical and social disciplines (Venkoba, 1992). Suicide usually involves mental illness. Every demographic group seems to grapple with suicide and suicide attempts as a serious medical issue (Brent, Perper, \& Moriz, 1993; Shaffer, Gould, \& Hicks, 1994).

An important and significant relationship exists between suicidal acts, completed and nonfatal, and mental disorders. Evidence from a variety of population-based investigations has confirmed the findings of extensive, earlier clinically-based literature. The risk of suicide increases by 7 to 10 times higher among individuals with active mental disorders (Maris et al., 2000).

According to Aggarwal et al. (1994), family histories of attempted suicide or completed suicide are present among patients suffering from depression. Vietra. Nieto, Gasto, and Cirera (1992) and the Canterbury Suicide Project (Beautrais et al., 1996) both interviewed persons who had committed acts of self-harm, and reported a high percentage with diagnosable mental disorders.

Suicidal behavior typically occurs in the presence of mental or substance abuse disorders and illnesses that impose their own direct suffering (Conwell \& Brent, 1995; Harris \& Barraclough, 1998; Murray \& Lopez, 1996).

In 1974, psychiatrist Aaron Beck devised the "Hopelessness Scale," designed to gauge hope's role as a modulating variable that links depression and suicidal intent in individuals. Beck's work revealed that, among the patients interviewed, pessimistic thinking, combined with previous suicide attempts, serves in some cases as a reliable indicator of suicide (Beck, Weissman, Lester, \& Trexler, 1974). 
Studies show a large number of people who complete suicide have mental disorders. Balch and O'Bannon (2001) state that few people, if any, simply sit down and make a cool, rational decision to commit suicide. They further note that 93 to $94 \%$ of suicides suffer from some identifiable mental disorder. In one related study, Robins (1981) concluded that mental health professionals had previously diagnosed $47 \%$ of those committing suicide in St. Louis, Missouri, with a psychiatric disorder. Of those diagnosed, $4 \%$ had organic brain syndrome, $2 \%$ were schizophrenic, and $1 \%$ were drug addicts. The total percentage of those with diagnosable mental disorders was $94 \%$. In some instances, unemployment can be connected. Platt (1992) believes that an extinct psychiatric morbidity may cause both unemployment and suicide.

Shepherd and Barraclough (1980) determined that psychiatric problems affect the ability of people to function at work. This often results in job loss. loss of the protective value of belonging to a workforce, and suicide.

Depression and other mental illnesses play a role in the completion and attempting of suicide. Novelist William Styron (1990) wrote that depression directly afflicts millions and indirectly affects millions more who are relatives or friends of victims. An estimated 1 in 10 Americans will suffer from the illness. Styron wrote, as assertively democratic as a Norman Rockwell poster, it strikes indiscriminately at all ages, races, creeds, and classes, though women are at considerably higher risk than men. The occupational list (dressmakers, barge captains, sushi chefs, and cabinet members) of its patients is too long and tedious to give here; it is enough to say that very few people escape being a potential victim of the disease, at least in its milder form. 
The suicidal person suffering from depression typically undergoes severe emotional and physical strain (Dubovsky \& Weissberg, 1983). This physical and emotional exhaustion impairs basic cognition, creates unwarranted self-blame, and generally lowers overall self-esteem. All of these easily lead to distorted judgments (Beck, 1963). The effects also contribute to a sense of hopelessness, which is the primary trigger of most suicidal behavior (Minkoff, Bergman, Beck, \& Beck, 1973).

According to Shneidman (1996), the common emotion in suicide is hopelessness/helplessness. He suggests that at the beginning of life, as infants, we experience rage and this then becomes differentiated. In the adolescent or adult suicidal state, the pervasive feeling is hopelessness/helplessness. The person feels trapped and believes there is nothing else to do except complete suicide, life seems hopeless, and the overwhelming feeling of helplessness becomes all-consuming.

According to many experts, an individual's feelings of hopelessness and failure to recognize solutions to his or her problem indicate suicidal risk with more accuracy than diagnoses of depression per se (Roleff, 1998). Studies have shown that during the period of their obsession with the idea of killing themselves, suicidal individuals tend to think in a rigid, dichotomous way, seeing everything in "all or nothing" terms. They cannot see any range of genuine alternatives (Neuringer, 1961). Studies by Shukla, Varma, and Mishra (1990); Unni, Rotti, and Chandrasekaran (1995); and Unni and Mani (1996) have established severity of depression and degree of hopelessness as indicators of long-term suicidal risk.

Psychopathology, particularly psychotic disorders, may appear disproportionately among those who commit suicide by railroad trains or subway trains. Studies of 
individuals who have jumped into a subway pit ahead of a speeding train, placed their bodies across the tracks, or attempted to stop a moving engine with their outstretched arm indicate high rates of mental disorder among the suicides. The disorders include schizophrenia, bipolar, and other psychotic disorders. These individuals also had histories of inpatient psychiatric hospitalization (Emerson \& Cantor, 1993; Guggenheim \& Weisman, 1972; Lindekilde \& Wang, 1985).

Researchers believe there is a connection between suicide attempts and manipulative behavior. Historical figures give insight to the connection between suicide attempts and manipulative behavior. One of the most infamous and controversial figures in history struggled with a bout of depression and suicidal ideation. Redlich (1993) shares this account:

He spoke of suicide on four occasions, the first time after the failed putch in November 1923. In great excitement, he wanted to shoot himself. On 16 September 1931, he threatened to kill himself after the death of his half-niece, Angela Raubal, Jr. (Geli), with whom he was in love... The third time he expressed suicidal intentions was when the Nationalist Socialist Party split up in 1932. After an attempt to assassinate him on July 1944, he suffered short bouts of depression. On April 30, 1945, in a dual suicide, Hitler and his long-time mistress, now wife (they married on the 29th), Eva Braun, died in his chambers. She poisoned herself with potassium cyanide. (pp. 282-283)

It is assumed Hitler died by simultaneous ingestion of cyanide and a gunshot wound to the head (p. 268). Communications given earlier in the suicidal career of the eventual suicide have more of a signaling function, often directly pleading for a reaction, response, or help. These are called "threats" (Hankoff, 1979).

The word threat often connotes manipulation, a pejorative label in clinical applications. It does not appropriately describe the majority of verbalized intentions regarding self-harm (Berman \& Jobes, 1991). 
Suicidal behavior is both a communication itself and a consequence of failures in more adaptive attempts to communicate. Not surprisingly, in an estimated four of five suicides, the attempter had tried to warn others of his or her intent through a range of behaviors such as direct verbal statements about suicide (Brent et al., 1993; Rudestam, 1971).

Finally it may be argued that some suicidal communications do not appear to have a dyadic component. Rather, they are intended merely as communicated ideations in a context of depression, stimulated by loss or failure, with no apparent intent to influence a specific other's behavior (Leenaars, 1992).

\section{Literature and Art Themes on Suicide}

Styron (1990) wrote, since the tortured lament of Job and in the choruses of Sophocles and Aeschylus, chroniclers of the human spirit have wrestled with a vocabulary that might give proper expression to the desolation of melancholia. Through the course of literature and art, the theme of depression has run like a durable thread of woe from Hamlet's soliloquy to the verses of Emily Dickinson and Gerard Manley Hopkins; from John Donne to Hawthorne, Dostoevski, and Poe; and from Camus and Conrad to Virginia Woolf. Many of Albrecht Durer's engravings contain harrowing depictions of his own melancholia. The manic wheeling stars of Van Gogh foreshadowed the artist's plunge into dementia and the extinction of self. Suffering tinges the music of Beethoven, Schumann, and Mahler and permeates the darker cantatas of Bach. The vase metaphor, which most faithfully represents this fathomless ordeal, belongs to Dante. His all too familiar lines still arrest the imagination with their augury of the unknowable, the black struggle to come: 
Nel mezzo del cammin di nosra vita Mi ritrovai per una selva oscura. Che la diritta via era smarrita.

In the middle of the journey of our life I found myself in a dark wood. For I had lost the right path.

Dante, Inferno, Canto I, 1-4

Styron (1990) says that many have employed these words more than once to conjure the rages of melancholia. However, their somber foreboding has often overshadowed the last lines of the best-known part of that poem, which evokes hope.

Styron (1990) likens the return from the abyss of depression's dark wood to the ascent of poets. They trudge upward and upward out of hell's black depths at last emerging into what Dante saw as "the shinning world."

E quindi uscimmo a riveder le stele. And so we came forth, and once again beheld the stars

Dante, Inferno, Canto XXXIV, 138-139

Despite depression's eclectic reach, studies have convincingly demonstrated that artistic types, especially poets, are vulnerable to the disorder. Depression, in its graver. clinical manifestation, takes approximately $20 \%$ of its victims by way of suicide (Styron, 1990). A long list of artists has fallen to suicide such as Chatterton, Hemmingway, and Plath, among others. These aforementioned artists were gifted individuals who suffered dark untreatable depression, which beckoned them to cold icy yet still waters of death by suicide.

Alvarez (1970) cites the suicide of 17 th-century poet Thomas Chatterton as an example of an individual who possibly overrated his talent and possessed unrealistically high expectations of immediate success. 
Ernest Hemingway, the famous novelist, completed suicide. Hemingway's physician father, as well as a brother, a sister, and a granddaughter completed suicide. In fact, Hemingway's mother later sent him the pistol with which his father had shot himself as a Christmas present:

My father died in 1928--shot himself--and left me fifty thousand dollars. ... When I asked my mother for my inheritance, she said she had already spent it on me ... on my travel and education. ... My mother was a music nut, a frustrated singer and she gave musicales every week in my fifty thousand dollar music room... Several years later, at Christmas time, I received a package from my mother. It contained the revolver with which my father had killed himself. There was a card that said she thought I'd like to have it. (Hotchner, 1966, pp. 115-116)

Finally, in 1961, in Ketchum, Idaho, Hemingway killed himself with a shotgun in the early morning (Maris, 1981). He had just returned from the Mayo Clinic. He was 61 years old.

Heckler (1994) stated that the experience of overwhelming loss forms the centerpiece in virtually all of the personal histories of people who have attempted suicide. According to Heckler, they make statements or form thoughts like "The pain was simply beyond my capacity to contain; life lost all reason and purpose; or there seemed to be no reason to go on" (p. 74). Heckler believes at least one of the three kinds of loss appears in every story. Traumatic loss, extreme family dysfunction, and alienation are the most common precursors to suicide, and the most ruinous.

Heckler (1994) expounded further by saying, that for some, the losses are concrete such as the sudden loss of a parent, the unexpected or unwanted dissolution of a family or a relationship, or the loss of one's physical health. He added to this list extreme family dysfunction, such as spousal abuse and child abuse. The loss of cherished dreams, an abstract loss, can lead to alienation from the world. 
Suicide has been the centerpiece and theme of some of the best-known works by writers such as Shakespeare. In Shakespeare's great tragedy Hamlet, the protagonist utters the famous words, "To be or not to be," effectively capturing the ambiguity of suicide. Considering his secular and spiritual dilemma, the Dane asks himself if it would be "nobler" to suffer "life's slings and arrows," or "to take arms against a sea of troubles," and "by opposing end them" (Hamlet, Act III, Scene I).

\section{Attempters of Suicide and Methods of Attempting Suicide}

Lester (1989) points out that some suicidologists are interested primarily, if not exclusively, in the problem of completed suicide. Others are concerned with the problem of attempted suicide.

Lester (1989) further believes that persons who have completed suicide are deceased and are therefore not available for psychiatric or psychological study. Attempted suicides are alive and able to respond to interviews and complete questionnaires. The study of attempted suicides is important. Lester suggests that attempted suicide deserves study in its own right. Oftentimes the studies of attempters are not included in the study of suicide. Wilkins (1967) noted that current sociological theories of suicide are misleading, because they exclude attempted suicide and suicidal ideation from the realm of behaviors to be explained. Few epidemiological studies on suicide attempts exist. Lester further notes that American sociologists are hindered in any efforts that they might make to study attempted suicide by the fact that not very many epidemiological studies of suicidal attempts and ideation may have been conducted.

Heckler (1994) points out that as tragic and commonplace as suicide is, we know little about what it feels like. We cannot bring the dead back to life and ask them about 
their pain and their sorrow. Also, no records of recovery from suicides exist. He goes on to further say that we have to talk to attempters and find out why they wanted to end their lives. The person contemplating suicide may experience a strong pull to complete the act. Heckler describes the pull or trance in this manner:

At the brink of the attempt, the suicidal trance intensifies to a frightening pitch. People feel extended beyond their capacity for survival. Some describe a deafening cacophony of voices, while others relate an otherworldly stillness and certitude. Emotions of anger or grief may color the suicidal act itself. The act may seem purposeful, peaceful, and/or virtually without feeling. The individual may truncate his or her ability to consider other options, so he or she sees his future through a narrow tunnel, at the end of which lies only one possible outcome. Time exists only as the succession of moments between the present and the one final act. (p. 81)

A nonfatal suicide attempter is someone who intentionally injures him or herself but does not die. He or she becomes available for treatment ( $O^{\prime}$ Carroll et al., 1996). A typical nonfatal suicide attempter is a younger White female, who uses less "lethal" methods (i.e., the method has a lower medical certainty of resulting in death) to attempt suicide. Because she may approach dying with ambivalence, she is likely to attempt an overdose or poisoning. Interpersonal dymamics, including revenge or change in an important relationship, often motivate her. Like Mark Twain's Huckleberry Finn, she may want to be around to see the results or even "be present at [her] own funeral." She may behave impulsively, and her problems may relate to anxiety, panic disorders, and other Axis II personality disorders. However, nonfatal suicide attempters, like completed suicides, also tend to be depressed and abuse alcohol and other substances (Adam, 1990; Black \& Winokur, 1990).

Maris et al. (2000) suggest,

Nonfatal suicide attempts outnumber completed suicides but the exact ratio is speculative, as no national suicide attempt data are complied in the United States. 
Stengel (1964) first estimated that nonfatal suicide attempters outnumbered completers by a ratio of 6-8:1. McIntosh (1998) argues that the ratio is even larger, 8-25:1. Among the young the ratio of nonfatal attempts to completions may be as high as 100-200. Assuming about 31,000 suicides each year in the United States and using the conservative ratio of $8: 1$, there are roughly at least 240,000 nonfatal suicide attempts in the United States annually. (p. 18)

As human beings, we long for care. According to Stengel (1964), in a suicide attempt, some psychologists say the attempter is issuing a challenge to see if anyone out there really cares. Beck (1963) says that suicide attempters also tend to maximize their problems, minimize their achievements, and generally ignore the larger context of their situation.

Outside intervention often prevents suicide. Studies and descriptions of curtailed attempters demonstrate that most suicidal individuals possess neither an unequivocal nor an irreversible determination to die. For example, two psychiatrists in Seattle, Washington, found $75 \%$ of the 96 suicide attempters they studied were actually quite ambivalent about their intentions to die (Dorpat \& Ripley, 1960).

Often suicide attempters are seeking to establish some means of communication with significant people in their lives (Rubinstein, Meses, \& Lidz, 1958) or to test others' care and affection (Stengel, 1964).

Psychologists have concluded that other motives for attempting suicide include retaliatory abandonment, revengeful "abandonment" of them through death (Jensen, 1958); aggression turned inwardly (Henden, 1982); punishment (Menninger, 1966); or an attempt to influence someone else (Stengel, 1964). Communication of these feelings, rather than death, is the suicide attempter's true aim. This explains why paradoxically, but truthfully, many say after an obvious suicide attempt that they really did not want to kill themselves (Stengel, 1964). 
Psychiatrists have long advanced the opinion that underlying a suicidal person's ostensible wish to die actually lays a wish for rescue (Jensen, 1958). Experts believe that attempters do not wish to "leave it all behind," but wish for help (Rubinstein et al., 1958).

Rosen (1970) cited the fact that most individuals attempting suicide are ambivalent, temporarily depressed, and suffering from treatable disorders. These are the reasons that so few ever actually go on to commit suicide, once treated and rescued. In one American study, less than $4 \%$ of 886 suicide attempters actually went on to kill themselves in the 5 years following their initial attempt. A 1977 Swedish study of suicide attempters revealed that, at some time between 1933 and 1942 , only $10.9 \%$ of attempters eventually killed themselves in the subsequent 35 years (Dahlgren, 1977).

Maris (1992) states that usually 35 to 40 years after the first suicide attempt, $10 \%$ of nonfatal suicide attempters will eventually complete suicide at a rate of about $1 \%$ per year initially and somewhat less thereafter. What is not widely known is that multiple suicide attempts, before eventual complete suicides, are fairly rare. A Chicago survey (Maris, 1981) revealed that $88 \%$ of the older White male completers died the first time they attempted suicide. Among eventual suicide completers, only $3 \%$, usually younger women, made five or more suicide attempts.

One commonly held belief about the psychosocial development of suicides is that some lifelong precursors, such as a family history of suicide, loss of a parent at an early age, isolation, etc., interact with acute stressors to "trigger" initial nonfatal suicide attempts (Clark, Gibbons, Fawcett, \& Scheftner, 1989).

Maris et al. (2000) suggest that the initial suicide attempt holds benefits and costs to the attempter. On the positive side, nonfatal suicide attempts almost always get 
attention from family members, friends, and professionals. Others allow the attempter to assume a "sick role." They often temporarily suspend the attempter's ordinary responsibilities. Suicide attempts may even offer the attempter a catharsis or purging, with a short-term elevation of effect.

Maris et al. (2000) further suggest that, on the negative side, the attention resulting from a suicide attempt sometimes stigmatizes the attempter. It may also make it more difficult for the individual to maintain a healthy identity. People may feel sympathetic toward the suicide attempters, but they are also likely to feel angry. Suicide attempts inconvenience and manipulate others. Many people regard suicide attempts as intentional and, to a degree, unnecessary, unlike a physical illness. After a period of recuperation, others expect the attempter to give up the "sick role" and to resume more normal, pre-attempt behavior and responsibilities.

Richman (1991) claims that suicide can serve two functions. First, it most simply provides a means to an end that matters. From this perspective, every household and nearby surroundings provide a treasure trove of self-destructive possibilities for the intended suicide. Second, Richman believes the means may have a special meaning or symbolism of its own, as when an adolescent female ingests her parent's prescription medication at home after an argument with this parent. Durkeim (1897/1951) recognizes that both psychological and cultural factors play a role in the "choice" of suicide method.

The presumed lack of potential lethality of a particular suicide method may make it an attractive choice to those who do not really intend to die. Both children and adult attempters commonly use acetaminophen (Tylenol) in intentional overdose, accounting for more cases than either aspirin or ibuprofen (Velirt \& Rollins, 1988). Myers, Otto, 
Harris, Diaco, and Moreno (1992) found 4 in 10 high-school students underestimated the potential lethality of acetaminophen.

Ingestion of a substance is the leading method of nonfatal suicide attempt. Even if the attempter ingests a lethal quantity, in general it takes time to result in death. This allows for rescue or intervention (Weisman \& Worden, 1974b). Berman, Leenaars, McIntosh, and Richman (1992) present the following case:

A 66-year-old highly ambivalent woman who attempted to slit her wrists (she "couldn't follow through"), then to turn the gas on in her apartment. Not being able to tolerate the wait, she tried to drown herself in her bathtub (but, again, "couldn't do it"). Next, she left her apartment to get her mail. In her mail she found a filled prescription of flurazepam (Dalmane, a sleep aid). She went to a neighborhood convenience store, brought a soft drink, then sat on a park bench and ingested some 50 pills. Expecting to die, she returned to her apartment to lie down on her bed. There the police, who had been called by a neighbor who had smelled escaping gas, met her. She was taken to the hospital after she informed them of what she had done. (p. 298)

Peck (1986) in a further study assessed the state of mind of the person who completes suicide. During his investigation of young, predominantly White Midwestern suicides, Peck found that those who completed suicide by more passive and low-lethality means (e.g., alcohol and barbiturates [44\%] and carbon monoxide poisoning [37\%]) left suicide notes more often than those who chose more active and highly lethal means (firearms [26\%], hanging [18\%]). Differences in time before unconsciousness, not a differential need to communicate, likely account for the different approaches. Lowerlethality methods provide an opportunity for the suicide to share some last moments of thinking.

Big city newspapers have documented a number of unusual suicides and suicide attempts. Professional literature also documents unusual cases. One individual burrowed inside a mattress and asphyxiated (Nelson, McKinney, Ludwig, \& Davis, 1983). Another 
injected poisonous snake venom (Yadlowsky, 1980). Another deactivated a hydraulic chassis supporting his car as he lay underneath, allowing his skull to be crushed (Boyer, 1975). Finally, one man attempted to manually tear a permanent pacemaker from his chest (Rosenthal, Crisafi, \& Coomaraswamy, 1980). Farberow's (1969) bibliography on suicide references a variety of reports of bizarre methods, including self-inflicted guillotining, self-crucifixion, the igniting of sticks of dynamite in one's mouth, swallowing Chinese firecrackers, and even "strangulation by tree root"!

According to the Centers for Disease Control and Prevention's 1996 data. increasing rates of suicide appear to link to the increased availability of firearms in the United States. Markush and Bartolucci (1984) demonstrated that total suicide rates showed significant statistical association to gun prevalence for all demographic groups, except non-White females. Lester and Murrell (1980) also found a significant negative correlation between the strictness of state gun control laws and state suicide rates; the more strict the state law, the lower the state suicide rate. However, Rich, Young, Fowler, Wagner, and Black (1990) reported that increase in other methods may offset any decrease in suicide by firearms.

An important methodological conclusion is that suicidology cannot provide insight only on nonfatal attempters because of convenience. Although they are alive, are readily available in clinics and hospitals, and can undergo standard psychological or mental disorder diagnostic tests and scales in person, interested parties need to keep suicidology in perspective (Maris et al., 2000). Wrobleski (1995) agrees and states,

Learn the medical model of suicide: that suicide results from mental illnesses and treatment is with medicine, psychotherapy, or a combination of both. Support community mental health and federal politicians urging higher priorities and 
appropriations for mental illness research. Talk about suicide; learn about suicide. (p. 86)

\section{Summary of Literature Review}

The word suicide was first coined by Sir Thomas Browne in 1642. Prior to introduction of the word suicide, societies used the words self-killing and self-destruction (Venkoba, 1977). Bhatia (1992) believes suicide is an act of self-inflicted harm and selfintentioned taking of one's life.

The Surgeon General's Call to Action to Prevent Suicide (U.S. Public Health Service, 1999) is the framework for suicide prevention. This call to action introduced a blueprint for reducing suicide and the associated toll that mental and substance abuse disorders take in the United States. Data on variation of suicide rates show that completions occur on the average of one person every 18 minutes. Suicide attempts are an ever-increasing problem in the United States. Each year in the United States, approximately 500,000 people require medical treatment as a result of suicide attempts (McCraig \& Stussman, 1996).

Risk and protective factors are important in the study of suicide and suicide attempts. Risk factors increase the potential for suicide and suicide attempts, whereas protective factors safeguard against suicide and attempts (U.S. Public Health Service, 1999).

Suicide can be viewed from many perspectives. Included in the literature review are perspectives from the disciplines of psychiatry, psychology, sociology, religion, culture, ethics, law, and literature. Perspectives from suicidology and mental illness are 
part of the backbone of this study and serve to highlight the focus of this study on suicide attempters.

The great, enduring suicidologists have all had theoretical biases. Sigmund Freud and Karl Menninger considered suicide a murderous death wish that was turned back upon one's own self. Emile Durkeim saw suicide as an extemal and constraining social fact independent of individual psychopathology. Edwin Shneidman conceives of suicide as a psychache or incontrollable psychological pain (Maris et al., 2000).

Attempters of suicide and methods of attempting are the main focus of this study and are therefore included in the literature review. Heckler (1994) points out that as tragic and commonplace as suicide is, we know little about what it feels like. We cannot bring the dead back to life and ask them about their pain and sorrow, but he goes on to say that listening to those who have decided to end their lives answers the following questions:

How did that pain translate into the wish to die? Could they have acted differently? Could someone have changed the downward course of his life? What was the ultimate cause here? The questions may strike even closer to home; might I have acted differently? Could I have helped if I were there? Could that be me one day? (p.4) 


\title{
CHAPTER 3
}

\author{
METHODOLOGY \\ Research is difficult to pursue in this area. The individual who commits \\ suicide is not around to participate in any investigation. \\ -John Hipple \& C. Peter. \\ The Counselor and Suicidal Crisis
}

\section{Introduction}

"Research which focuses on discovery, insight, and understanding from the perspectives of the research subjects offers the greatest promise of making significant contributions to the knowledge base and practice of education" (Merriam, 1998. p. 3). Merriam's beliefs are a part of this study.

\section{Characteristics of Qualitative Research}

Five characteristics of all qualitative research, according to Merriam (1998), are (a) researchers involved in such research are interested in understanding the meaning that people have constructed, (b) the researcher is the primary instrument for data collection and analysis, (c) the research involves fieldwork, (d) the research involves primarily inductive research strategies, and (e) the product of qualitative research is extremely descriptive. There should be meaning for all of the data collected.

Eisner (1991) holds some of the same beliefs as Merriam (1998) and is also a part of this study. Eisner espouses six features that make a study: 
1. Qualitative studies field focused. Those conducting research go out into the field.

2. Self as an instrument. Researchers must see what is to be seen.

3. Interpretative character. The ability to explain why something is happening.

4. Expressive language. The presence of voice and the use of expressive language are important in furthering human understanding.

5. Attention to particulars. Conventional social science uses particulars to arrive at general statements through statistics. Qualitative studies provide the flavor, it is the ability to render distinctive features through text.

6. Coherence, insight, and instrumental utility. Qualitative inquiry, like conventional quantitative approaches to research, is ultimately a matter of persuasion, seeing things in a way that satisfies.

Alexander Massey (2001) sees qualitative research as systematic empirical inquiry into meaning. Sherman and Webb (1988) agree with Massey and further suggest that qualitative researchers are interested in understanding the meaning people have constructed, that is, how they make sense of their world and the experiences they have in the world. Qualitative research implies a direct concern with experience as it is lived, felt, or undergone.

No amount of experimental research about suicide attempters can take the place of talking to the attempters themselves. If psychologists, counselors, suicide prevention and intervention specialists, and others with an interest in this subject want to find insight into the dynamics of attempters of suicide and prevention, they must listen to the attempters. To learn about suicide attempts firsthand, the researcher interviewed three 
Caucasian female suicide attempters in Tennessee about their experiences with attempting suicide.

\section{Framework of the Model for Suicide Prevention}

In focusing on their suicidal experiences, I have linked my study to the Surgeon General's1999 Call to Action to Prevent Suicide (U.S. Public Health Service, 1999), a model for reducing suicide and the associated toll that mental and substance abuse disorders take in the United States. This model further asserts that suicide and suicide attempts are preventable through education. The framework of the model for suicide prevention is awareness, intervention, and methodology (AIM).

The model allows for the risk and protective factors that influence the attempters. Awareness of risk factors that can lead to suicide, especially mental and substance abuse disorders, help to form the conceptual framework for the prevention of suicide.

Hennriksson et al. (1997, as cited in U.S. Public Health Service, 1999) believed that understanding risk factors could help dispel the myths that suicide is a random act or results from stress alone. Cornelius et al. (1995, as cited in U.S. Public Health Service, 1999) agree by pointing out that depression with alcohol abuse is an example of a mental disorder combination. Interventions, such as effective treatment for depressive illness, reduce the impact of some risk factors.

Though risk factors are of import to this study, protective factors play an essential role in suicide prevention. Satcher's (U.S. Public Health Service, 1999) model shows that enhancing resilience or protective factors can help to prevent suicide. Like Satcher, the researcher firmly believes that awareness, intervention, and methodology are essential to preventing suicide attempts. 
For this research study three females were interviewed to discover (a) risk factors for attempting suicide, their motivations, and environmental influences. It is important to understand the lives of each woman and the factors that caused them to attempt suicide. I also wanted to discover (b) protective factors they have put in place to avoid future attempts. There is never a guarantee that attempters will not repeat the act but it is necessary to do as much as possible to prevent future attempts, and (c) the impact of the suicide attempts on the lives of the attempters. Knowledge of the aftereffects of failed suicide attempts is significant to this study.

\section{Research Design}

This study used non-probability sampling. Creswell (1998) recommended studying 3 to 10 subjects. The important point was to describe the meaning of a small number of individuals who have experienced a phenomenon. It was important to understand relationships, causes, and effects of the attempts and on the attempters. Wiersma (1991) stated that researchers conduct qualitative research to understand relationships, effects, and causes. In this study three criteria were used for selecting participants for the study: (a) females who attempted suicide, (b) failed at the attempts, and (c) were willing to share information about the experience. Their suicide attempt experiences qualified them as purposeful subjects for this study on suicide attempters.

A descriptive case study design was utilized for this research. Lijphart (1971) calls descriptive case studies "atheoretical." He further points out that descriptive case studies are entirely descriptive, move in a theoretical vacuum, and are useful in presenting basic information about areas of education where little research has been conducted. Limited research has been conducted exclusively on Caucasian female 
suicide attempters. This research study on Caucasian female suicide attempters is entirely descriptive and is useful in presenting basic information about their risk and protective factors and the impact of failed attempts on their lives.

According to Higgerson and Rehwaldt (1993), case studies "are valuable learning resources because they present the texture and particularity of the concrete. They are far closer than theories to the untidiness of the immediate situation, but distant enough to be free of actual consequences" (p. ix). These case studies allowed me to present the feelings and the reality about suicide attempting. The researcher was close enough to permissively enter the lives of the attempters and yet distant enough to be able to write what the attempters were conveying with acceptance and open regard.

A qualitative case study provides an intensive, holistic description and analysis of a single instance, phenomenon, or social unit (Merriam, 1998, p. 21). The stories are intense and holistic; direct quotes have been included so that the voice of the attempters can be heard. Analysis of the phenomenon of attempting is also provided with detailed descriptions by the attempters.

The researcher agrees with Wolcott (1992) who sees case studies as "an end product of field-oriented research" (p. 36), rather than a strategy or method. The data in these case studies are a result of going into the environment of the attempter.

Merriam (1998, p. 6) expostulates five characteristics of qualitative research. Merriam bases these characteristics on the view that individuals interacting in their social worlds construct their own individual reality. Additionally, Merriam points out that qualitative researchers are as follows: 
1. Interested in understanding the meaning that people have constructed, how they make sense of their world and the experiences they have in the world. A structured interview (see Appendix D) was used to understand the meaning that the attempters have constructed to make sense of their world and experience with suicide attempts. One instruction was given and that was for them to tell their stories.

2. The researcher is the primary instrument for data collection and analysis. I analyzed the data using the guidelines of Creswell's (1998) recommendation in his text. Creswell (1998) recommended that the researcher examine statements in the transcriptions. In order to find similarities, differences, and themes each statement was examined meticulously and read repeatedly.

3. The research involves fieldwork. The researcher went into the field for three weeks. Participants were interviewed at the location of their choice (see Appendix E). At their request, two interviews were conducted in homes and one at the participants' office. All of the women preferred to do both interviews consecutively on the same day.

4. The research involves primarily inductive research strategy. The inductive strategy involved the structured interview (see Appendix D). Direct questions were utilized to induce thought and to allow the participants to indulge in specific events about the suicide through the direct use of questioning. How the attempters experience their world is important for the researchers understanding in this study. Connelly and Clandinin (1990) agree and state that the heart of narrative analysis "is the way humans experience the world" (p. 2).

5. Since Merriam (1988) says that qualitative research focuses on process, meaning, and understanding, the product of a qualitative study is richly descriptive. I 
included a personal profile of the participant, a detailed description of the interview location, their stories, and voluntary personal artifacts that the informant wanted to share (see epigram at the beginning of chapter 5).

Eisner (1991) espouses six features that make a study qualitative that I have also followed and found helpful as a methodological guide in this study:

1. Qualitative studies tend to be field focused. Those conducting research go out into the field. The researcher went into the environment of each of the attempters.

2. Self as an instrument. Researchers must see what is to be seen. The self is the instrument that engages the situation and makes sense of it. The researcher viewed and listened objectively, yet was able to come away with a sense of having entered their lives.

3. Interpretive character, the ability to explain why something is happening. The researcher explained why these attempts occurred through the use of themes.

4. Expressive language, the presence of voice and the use of expressive language that are important in further human understanding. Eisner (1991) further states, "Qualitative considerations are used in telling stories" (p. 5). The attempters for this research tell their stories. Stories connect and give the basis for the occurrences in the lives of these women. The researcher is the narrator, but the women in this study tell their stories. As the reader follows the stories, the voice of the attempter is heard by the choice of passages and descriptions of their hurt, pain, tragedies, and eventual death act.

5. Attention to particulars. Conventional social science uses particulars to arrive at general statements through statistics. Qualitative studies provide the flavor; it is the ability to render distinctive features through text. The researcher has written the text distinctively with the features of each attempter as they move from childhood to 
adulthood. Eisner (1991) further suggests that those most skilled in the qualitative treatment of language are writers. When their skill is great, they give us material that helps us to understand, paradoxically, what words cannot express. The stories have been written using the feelings, perceptions, and movements of the attempters. Direct quotes are woven into the passages so as to give an understanding that the researchers own words cannot express.

6. Coherence, insight, and instrumental utility. Qualitative inquiry, like conventional quantitative approaches to research, is ultimately a matter of persuasion, seeing things in a way that satisfies. These attempters satisfied the questions in this study through their open, honest, and persuasive stories.

Eisner's (1991) use of description, interpretation, and thematics was also incorporated in this research design. According to Eisner, a description enables readers to visualize what a place or process is like. In chapter 4 , the suicide attempters describe what it is like to want to die and then return to a new life or rebirth. Eisner says interpretation can be regarded as accounting for, putting what has been described into a context. It also means illuminating the potential consequences of practices observed and providing reasons that account for that action. The childhood dynamics, lack of family communication about the attempts, and other themes in this study illuminate reasons for the action of attempting suicide.

Themes are recurring messages that pervade a situation (Eisner, 1991). Pervading messages occur throughout the stories. As Heckler (1994) states,

Each story appears different, and yet they all possess significant commonalties. The story of suicide begins with loss or trauma, an unbridgeable sense of alienation, and a deep need to hide one's pain. Withdrawal begins and then deepens gradually, almost imperceptibly. Eventually, the person who was once 
here is no longer present. He or she may still live in our home and eat at our table, but he or she only goes through the motions of living. Hiding behind a façade, the person becomes isolated, and vulnerable to the urgings of the suicidal trance. Unchecked, the trance draws him or her to one fatal choice. (p. 24)

Chapter 5 consists of 12 themes that emerge from the data, which are occurrences in the lives of the Caucasian female suicide attempters in this research.

\section{Discussion of the Validity and Reliability of the Research Process}

The researcher was concerned with both the internal validity (investigating the content designed to be investigated) and external validity (the generalizability of the results to a wider population in order to make recommendations) the content that should be measured. Measures for internal validity was considered when a pool of questions for both the structured and unstructured interview were generated from the literature and then refined by experts in the field of suicide (Borg \& Gall, 1989).

Internal validity also was taken into account by using the same suicide expert to interview each of the attempters face to face with identical questions. Each attempter was treated in the same manner with the interviewer taking time to build rapport with each attempter and following the same format in asking the questions. For each attempter both the structured and unstructured questions were asked at the same time. Also the attempters were interviewed within the same time period. This time period is important to consider in reducing the extraneous variable of maturation, the change in the subjects during the study (Borg and Gall, 1989).

External validity (the degree to which the findings can be generalized to the population from which the participants were drawn) was addresses through the "randomness" of the volunteers. Due to the small number of attempters the 
recommendations from this study must be considered in the realm of the description of the attempters.

Reliability measures (the capacity to yield similar scores on the same individual when tested under different conditions or at different times) were addressed by drawing from a population where suicide attempters would be found. With this population the researcher was assured that she was asking people questions that they were sure to know the answers. Babbie (1990) says that reliability can be maximized by "asking people only questions that they are likely to know the answers to, ask about things relevant to them, and be clear in what you are asking (p. 133). The use of the pilot study also added a measure of reliability in assuring that the process was clear.

\section{The Pilot Study}

Internal validity was taken into account by the use of a panel of experts who helped to develop the pilot study. These experts were individuals that work with suicide attempters. The pilot study was conducted on one individual who was not a part of the sample. The pilot study helped to gauge the amount of time needed for the interviews and gave the researcher comfort with asking the questions. A tape recorder was utilized to gather the data from both interviews. Based on the pilot study the researcher was confident that 2 hours would be sufficient time for the interviews.

\section{The Instruments}

Measures for internal validity was considered when a pool of questions for both the structured and the unstructured interview were generated from the literature and then refined by experts in the field of suicide (Borg \& Gall, 1989). The first interview was the 
structured interview, which consisted of 23 questions (see Appendix D), and the second interview was the unstructured interview where each attempter told her story and experiences with attempting suicide (see Appendix E).

Babbie (1990) in his book entitled Suvey Research Methods wrote that a researcher can create a reliable instrument by asking "people only questions they are likely to know the answers to, ask about things relevant to them, and be clear in what your are asking" (p. 133). The expert panel helped the researcher to develop the questions because they were experts in the area of suicide intervention and prevention, which built in credibility and internal validity. Questions were developed from the literature searches that were both general and specific to suicide attempters. An expert panel proofread the questions for clarity to help eliminate ambiguity and confusion.

\section{Suicide Attempter Selection}

The purpose of this research guided the selection of participants. The purpose of the study is to examine the risk factors of Caucasian female suicide attempters, the protective factors of Caucasian female suicide attempters, and the impact of failed attempt(s) on Caucasian females who attempt suicide in order to provide clinicians with implications for prevention and intervention. There are two basic types of sampling: probability and non-probability. Random sampling, the most familiar example of probability, allows the investigator to generalize the results from the sample population. According to Merriam (1998), most researchers choose non-probability sampling for qualitative studies because generalization is not a statistical goal of the researcher. Chein (1981) called this method purposive, and Patton (1990) calls it purposeful. If the investigator wants to discover and understand a phenomenon, then he or she must select 
the sample from which the most can be learned.

A criterion was set for the volunteers in the study. The criteria were anyone who had attempted suicide one or more times, was not suicidal by their own admission, and was willing to talk. These participants are distinct in that they attempted suicide and lived to talk about it. They were willing and excited about sharing their stories. None of them had experienced being able to talk about it with their families. Each one was grateful for the opportunity to share their story, which the researcher was interested to hear in-depth as they shared individually. They readily started with their childhood and chronicled their lives to the present. Time and space limited the minute details, but the essence is incorporated in this study.

Suicide attempters have unique needs; they need to talk, to be heard, and to look back with hindsight to see the "why" of the attempt. These women have become crusaders in their own way for the awareness of ways to prevent suicide and suicide attempts. They expressed a need to share their experiences with suicide attempts in public and private settings when they sense that someone else is showing signs of suicidal intent. Each participant has found a place to attend to others as volunteers. As expected, each story was unique; however, there were similarities that were evident. The researcher was surprised at the level of spirituality in relation to suicide attempts held by each attempter.

The director gave verbal permission to the researcher to send an interoffice e-mail memo that would include everyone at the center. This included staff, volunteers, and members of the support groups and the Tennessee-Care Advocacy Center (see Appendix A). The Advocacy Center was once housed in the Crisis Intervention Center programs 
but developed so rapidly in services and size that it had to be relocated. All staff and organizational business continues to be handled jointly.

The process started January 2001. After 6 months of posting the e-mail memo, only one person volunteered to participate in the study. The researcher was also given various names from colleagues at the center and in the state mental health office. Somehow some event or problem would occur and none of these persons could participate in the study. The difficulty came in trying to find more attempters and the reality that no males volunteered for the study.

One day, while preparing for a presentation at the office, the researcher mentioned the proposed research study to a part-time volunteer assistant. The researcher also mentioned the dilemma of having only one person to volunteer for the study. The volunteer assistant had not seen the e-mail and to the researcher's surprise shared that she was a suicide attempter and would be willing to participate in the study. The volunteer assistant gave the researcher the name of another attempter who consented to be in the study. Now I had 3 participants with enough variability in a wide array of attributes to address external validity for generalizing the results when making recommendations for preventive methods. At the end of 2001 , the researcher had three voluntary Caucasian female suicide attempters. The researcher started the interviews March 2002.

\section{Procedures for Interviewing}

Each participant was involved in two 1 -hour interviews, a structured interview that consisted of 23 questions, and an unstructured interview (see Appendixes D and E). The structured interview allowed for specific questions. These questions permitted for comparison of similarities and differences in locating themes. Bogdan and Biklen (1992, 
p. 97) stated that structured interviews allow the researcher to collect comparable data across subjects.

The second interview was an unstructured interview. The only instruction to participants was that they tell their stories in their own words. The unstructured interview gave the participants the opportunity to express their thoughts, feelings, and personal experiences in an uninhibited format. Again, according to Bogdan and Biklen (1992), more loosely structured conversations provide the "opportunity to find out how the informant structures the topic himself' (p. 97). Because it was the researcher's purpose to discover each attempter's own story, the researcher wanted each attempter to be free to share any details, experiences, or memories of her attempts.

Second, the researcher asked the attempters if they wanted both interviews to be completed on the same day or on different days. They unanimously requested that the interviews be in succession on the same day. Internal validity was taken into account by using the same questions within the same period of time. The time period is important to consider in reducing the extraneous variable of maturation, the change in the subjects during the study (Borg \& Gall, 1989).

The researcher's third request was for each attempter to participate in "member checks" as the researcher analyzed the interview transcriptions. The process of verifying the data for this study was designed to evaluate whether the interpretations of the researcher were well grounded and well supported (Creswell, 1998). In this way appropriate measures were taken to follow up on points, clarify the interpretations following naturalistic inquiry and qualitative approach model of Lincoln \& Guba and Merriam, 1985 and 1988 respectively. Member checks by the participants evaluated the 
accuracy of the interpretations and analysis of the researcher. Strategies to protect the trustworthiness and authenticity of the data were implemented throughout the study and assured internal validity.

According to Lincoln and Guba (1985), credibility is a trustworthiness criterion that is satisfied when source respondents (e.g., people who provide the information) agree to honor the reconstructions (p. 329). The member checks are designed to establish credibility by subjecting the themes, interpretations, and meanings for review by the research participants. The rationale for the exercise is to elicit responses from the original constructors of the research. The attempters examined and checked reconstructions of the researcher in the light of their original statements to verify the accuracy of the interpretations and analysis. Checking procedures provided the attempters with an opportunity to return to their interview in order to clarify or affirm the transcript data, as well as to supply me with extra information that might enhance the meaning of a particular statement that was ambiguous or unclear (Lincoln \& Guba, 1985). Getting reliable answers from the participants helped with internal reliability.

\section{The Interviewer}

In addition to clarifying my basis as a researcher, it is useful to say something about myself personally and professionally. The researcher cannot be set aside from the interviewing process. Instead, who I am and what I do led directly to my interest in this research project and had some impact on the interviewing process. The researchers present role in the area of suicide prevention has been discussed in the background of the introduction of chapter 1 . 
Since 1973, the researcher had been involved in clinical services, first as a student counselor while simultaneously pursuing the Master's degree in Clinical Psychology and later as a Psychologist II in a psychiatric hospital for 4 years. It was during this time that the researcher was responsible for two female units employing the skill of working with and interviewing psychiatric patients with a range of mental illnesses who, at some point in their lives, may have been suicide attempters.

After several years of direct clinical experience, it was the researcher's desire to combine knowledge and experience. It was also necessary to enhance the researcher's clinical skills in a more "normal" setting. This was done by accepting a teaching post at Miles College and, later, the challenge of advising, counseling and instructing students at Oakwood College. Many times the interview process entered the counseling process and allowed me to acquire the necessary knowledge to accurately counsel the students.

More clinical experiences took place as an Ombudsman for children and families for the State of Tennessee. This position involved daily counseling, interviewing, and problem solving. After 4 rigorous years of problem solving, the researcher was offered a position as Coordinator of the Surgeon General's 1999 Call to Action to Prevent Suicide for the State of Tennessee.

It is the researcher's firm belief that everyone needs someone to understand, to care for him or her, and to listen without judgment. The researcher has experienced hundreds of hours of interviews through work experiences. The researcher studied how attempters adapted to life after or in between suicide attempts. The researcher noted the types of questions that encourage an attempter to talk freely and that elicited information about her experiences and coping mechanisms. 
The researcher also became aware of some of the practical matters of taping, transcribing, keeping careful field notes, and the strategies for analyzing data in a methodological, purposeful way that leads to accurate description, and to analysis and identification of themes that interpret a person's experience.

In addition to collecting and analyzing the data, the researcher met with two colleagues to share the results. We looked for common threads, common patterns, and themes that flowed throughout the data. It reinforced the value and importance of thoroughly understanding the nature of one's methodology and for using established strategies for description, interpretation, and analysis of data.

The researcher incorrectly thought there might be interference with the attempters being willing to talk openly with a person of color. However, the fact that they were Caucasian did not in any way inhibit their openness and willingness to be a part of this study. Ethnicity was not a consideration in this study. What was a consideration was drawing from a population where suicide attempters were found. The researcher was concerned with the measure of reliability by asking people questions they knew the answers to, and asking them about things relevant to them (Babbie, 1990).

\section{Analysis of the Data}

In analyzing the interviews of each of the suicide attempters it was important to make sense of the data. Merriam (1988) states, "Making sense out of the data involves consolidating, reducing, and interpreting what people have said and what the researcher has seen and read" (p. 178). The data were consolidated after transcription, but because of the massive amount of data it was imperative to reduce it. Usage of all of the information gathered was not practical. 
Merriam (1988) believes qualitative research is the process of making meaning. The researcher then needed to make meaning of the data. This helped with extermal validity in making recommendations for suicide prevention. After organization of the data by consolidating, reducing, and interpreting, the next most important step was description. A description is included in the personal profile of each participant. Educational background, age, family unit, and a physical description gave a rich description of the attempter. The location of the interview setting was also described to draw the reader into the physical surroundings of the attempter. Most notably, description must allow the reader to hear the attempters speak, providing enough of their own words and phrases that their voices may be plainly and clearly heard. Textual descriptions of the experiences were written, using verbatim examples that converge in each attempter's interviews.

Merriam (1988) states, "Between description and interpretation these meanings, understandings, or insights constitute the finding of a study deemed most related to the themes" (p. 178). Thematics is that part of analysis that looks beyond the immediate situation in a search for "the recurring messages that pervade" and connect it to other situations (Eisner, 1991, p. 104). Patterns emerged in the stories and connected the experiences of each of the attempters. Whereas description gives "an account," interpretation accounts "for" (Eisner, 1991, p. 95). Chapter 4 gives a description of the data. 


\section{CHAPTER 4}

\section{DESCRIPTION OF THE DATA}

In this life it is not difficult to die. It is more difficult to live.

- Vladimir Mayakovsky. Russian revolutionary

(Died by suicide, 1931)

\section{Introduction}

This chapter contains a description of the region, data analysis, and attempter descriptions and profiles. Also included are the responses from the structured questions (See Tables 3,4, and 5) and stories, with direct accounts by the attempters. Both the responses to the structured questions and the stories give a full picture and rich description of the attempters' lives, events in their lives, influences, and the suicide attempts.

The complete transcripts for the two interviews have been typed and compiled into two volumes and kept in an archive to protect the confidentiality of the attempters. When referring to the findings in this research volume I will consist of responses from the structured questions and volume 2 consists of responses from the unstructured questions.

The descriptive case study approach to collecting data was chosen because it suits the research questions best and is an inquiry that investigates a phenomenon within its real-life context. Real-life for these attempters is deciding to leave but, in the end, 
finding a reason to stay. There are many defeats that they speak of but have triumphed in spite of the tragedies.

\section{The Geographic Location}

Nashville, Tennessee, is located in the north-central region of the United States. Nashville is the capital city, and the state is comprised of 95 counties. Nashville's population of 569,500 is made up of people from around the world. Industry includes publishing, music, hospital care, and a large number of educational institutions nicknaming it "The Athens of the South." Because it is headquarters for the Baptist National Convention and has more than 700 churches, it is also called "The belt buckle of the South." Nashville spans 502 square miles in land area.

\section{Data Analysis}

The participants designated the locations for the interviews; two were conducted in homes and one in an office. The length of the interviews ranged from 1.5 to 2 hours. The participants are employed, and their occupations are receptionist, advocate counselor, and mental health counselor. Educational background included 1.5 years of college, one college graduate, and one attending college at the time of the interview. The suicide attempters' ages ranged from 31 to 59. They are residents in a north-central location of the United States, Nashville, Tennessee. All names of the participants and other names mentioned in this study are fictitious to preserve confidentiality.

The data collection process began with the structured interview consisting of 23 questions (See Appendix D) backgrounds provided a basis for describing the stories of the attempters in this study. 


\section{Attempter Selection}

In deciding on the criteria for the attempter selection, it was important to have persons who had attempted suicide one or more times and survived to tell their stories. In addition, every effort was made to include attempters who were different in age range, maturity, employment, educational levels, and life situations following what Patton (1990) describes as "maximum variation sampling" (p. 172), a procedure likely to produce two kinds of findings: "(1) high-quality, detailed descriptions of each case, which are useful for documenting uniqueness, and (2) important shared patterns that cut across cases and derive their significance from having emerged out of heterogeneity" ( $p$. 173).

Having selected suicide attempters with these criteria, the researcher analyzed interview transcripts with the goal of describing each attempter's individual experience, identifying aspects of those experiences that were distinctive and those that were shared, and interpreting those experiences--asking the questions "Why?" and "What do these experiences reflect?" The data included two interviews for each participant, a structured interview consisting of 23 questions, and an unstructured narrative allowing the suicide attempter to tell her story. Storytelling is an expressive form of language that is very important to this study.

The first step after receiving the data from the transcriptionist was to read each one for clarity and accuracy. The next step was to verify the transcribed information with each participant. Then organize a list of categories into which most of the data could be sorted after reading each interview. The interviews were read again, selecting and sorting 
information into these categories by using a color-coding technique. As the researcher read the data, each time a category would emerge it was underlined with a different color marker. In this way, as the data of each attempter was compared, the categories could be readily viewed. In some cases categories were added or modified. In other cases, it noted that only some attempters had information that fit into a specific category.

Through this process, the material was reduced in each transcript, omitting information that was not directly relevant to the study and sorting relevant information into categories. At this point, the data were categorized by each individual attempter and combined by themes across attempters. Then the researcher read back through each attempter's condensed material and listed each attempter's responses under the various categories. This step allowed the researcher to (a) describe the group as a whole, (b) identify commonalties among the attempters, and (c) identify features specific to each individual attempter.

Many categories remained the same as the ones already selected; however, during this step the categories were refined, combining some and dividing others. The researcher had a clear summary of the group, which yielded an overview of their experiences with suicide attempts. There were now data sets that allowed the researcher to examine individual attempters, to compare and contrast attempters, and to identify themes running through the stories of all of the attempters. The process followed is an inductive method for determining categories, a process Abrahamson (1983) described as "immersing" oneself in the documents in order to identify those elements or "dimensions" that emerge from the words or speakers. 
For the most part, phrases and sentences formed the units of analysis; however, in some cases, whole paragraphs could be treated as a single unit. This was especially the case when an attempter was describing a specific incident. Berg (1989) noted that research frequently requires the use of such a combination of content elements, the fundamental guideline being to use the speakers' own words as much as possible in the coding process.

Suicide attempters come from all walks of life and share a common theme of pain, anxiety, and negative emotions. The pain is so great that, to the attempter, it seems better to die than to live. Even though they have all experienced tragedies and the tragedy of suicide attempts, they are employed in human service areas. Jacquelyn is a receptionist at a doctor's office, Shannon is a social worker, and Judye is a mental health counselor and part-time college student. The suicide attempters in this study vary in age from 31 to 59 (see Table 2). They also vary in marital status. Jacquelyn is widowed after two marriages. Her second husband died of cancer. Shannon is single and lives with her significant other. Judye is divorced after a very abusive and stormy marriage. Only one of the attempters has a child, which will be further explored in her story. While all of them have attended college, Shannon graduated with a degree in Social Work. Each comes from families with both parents in the home, although two of the attempters report that their families were dysfunctional. Each has siblings. One of the three participants had three siblings who attempted suicide. All three have dual diagnoses and have experienced the death of a friend by suicide (see Table 2). 
Table 2

General Information About the Attempters

\begin{tabular}{lccc}
\hline Demographic Data & Jacquelyn & Shannon & Judye \\
\hline Age & 59 & 31 & 46 \\
Number of siblings & 1 & 8 & 1 \\
$\begin{array}{l}\text { Educational level } \\
\text { 1 l/2 years of } \\
\text { college }\end{array}$ & 4 years of college & Freshman in college \\
$\begin{array}{l}\text { Marital status } \\
\text { Wumber of children }\end{array}$ & 1 & Single & Divorced \\
$\begin{array}{l}\text { Family members who } \\
\text { Have attempted } \\
\text { suicide }\end{array}$ & 0 & 0 & 0 \\
$\begin{array}{l}\text { Friends who } \\
\text { completed suicide }\end{array}$ & 1 & 3 & 0 \\
$\begin{array}{l}\text { Number of attempts } \\
\text { Number }\end{array}$ & 3 & 1 & 3 \\
\hline
\end{tabular}


Table 3

Structured Interview Questions and Answers for Jacquelyn

\begin{tabular}{|c|c|}
\hline Questions & Answers \\
\hline 1. Feeling suicidal presently? & 1. No, I'm not. \\
\hline 2. Comfortable sharing this information? & 2. Yes, I am. \\
\hline 3. How many times have you attempted? & 3. Three times. \\
\hline 4. Do you have a clinical diagnosis? & $\begin{array}{l}\text { 4. Depression and Central Auditory } \\
\text { Processing Disorder. }\end{array}$ \\
\hline 5. Substance abuse connection to suicide? & 5. Yes \\
\hline $\begin{array}{l}\text { 6. Family members attempted or } \\
\text { completed suicide? }\end{array}$ & 6. No \\
\hline $\begin{array}{l}\text { 7. Significant others attempted or } \\
\text { completed? }\end{array}$ & 7. Yes, a friend. \\
\hline 8. Did you enter into a suicide pact? & 8. No \\
\hline 9. Influenced by the media? & 9. Not directly. \\
\hline 10. Discuss attempts with family? & $\begin{array}{l}\text { 10. Not something my family } \\
\text { discussed. }\end{array}$ \\
\hline 11. Did you send any signals? & $\begin{array}{l}\text { 11. I don't think I did, I was } \\
\text { depressed. }\end{array}$ \\
\hline 12. Why the attempt? & 12. I wanted answers, cry for help. \\
\hline 13. Will you attempt again? & $\begin{array}{l}\text { 13. I don't think so. I can never } \\
\text { say never. }\end{array}$ \\
\hline 14. Continue to have suicidal thoughts? & 14. Yes, from time to time. \\
\hline 15. Self perception? & $\begin{array}{l}\text { 15. Had strengths but did not know } \\
\text { it. }\end{array}$ \\
\hline 16. Attempts affected your family? & 16. We never talked about it. \\
\hline 17. How attempt impacted your life? & $\begin{array}{l}\text { 17. Value life, God really cares, } \\
\text { by the universe, receive help } \\
\text { from God and angels. }\end{array}$ \\
\hline 18. What are your risk factors for attempts? & $\begin{array}{l}\text { 18. Lack of family communication } \\
\text { negative family relationship. } \\
\text { depression, and alcohol. }\end{array}$ \\
\hline 19. What are your protective factors? & $\begin{array}{l}\text { 19. Therapy, support groups, } \\
\text { positive people, regular doctors } \\
\text { appointments, hobbies, and } \\
\text { volunteering. }\end{array}$ \\
\hline 20. View life and death differently? & 20. See life as more precious. \\
\hline 21. What kind of hobbies? & 21. Pottery, handwork, animals. \\
\hline 22. Keys to prevention? & 22. Positive family relationships. \\
\hline 23. Any more comments? & 23. No \\
\hline
\end{tabular}


Table 4

Structured Interview Questions and Answers for Shannon

\begin{tabular}{|c|c|}
\hline Questions & Answers \\
\hline 1. Feeling suicidal presently? & 1. Heck no! \\
\hline 2. Comfortable sharing this information? & 2. Yes \\
\hline 3. How many times have you attempted? & 3. Three times. \\
\hline 4. Do you have a clinical diagnosis? & $\begin{array}{l}\text { 4. Bipolar, Substance Disorder } \\
\text { Type I }\end{array}$ \\
\hline 5. Substance abuse connection to suicide? & 5. Yes \\
\hline $\begin{array}{l}\text { 6. Family members attempted or } \\
\text { completed suicide? }\end{array}$ & $\begin{array}{l}\text { 6. Paternal aunt and three siblings } \\
\text { attempted }\end{array}$ \\
\hline $\begin{array}{l}\text { 7. Significant others attempted or } \\
\text { completed? }\end{array}$ & $\begin{array}{l}\text { 7. Best friend and many other } \\
\text { friends in high school. }\end{array}$ \\
\hline 8. Did you enter into a suicide pact? & 8. Never \\
\hline 9. Influenced by the media? & 9. No \\
\hline 10. Discuss attempts with family? & $\begin{array}{l}\text { 10. I tried, just didn't work, family } \\
\text { didn't want to hear about it. }\end{array}$ \\
\hline 11. Did you send any signals? & $\begin{array}{l}\text { 11. Death poetry and explosive } \\
\text { anger. }\end{array}$ \\
\hline 12. Why the attempt? & $\begin{array}{l}\text { 12. Depression, drugs, loss of eye } \\
\text { sight. }\end{array}$ \\
\hline 13. Will you attempt again? & $\begin{array}{l}\text { 13. No plans to, can't guarantee it, } \\
\text { never say never. }\end{array}$ \\
\hline 14. Continue to have suicidal thoughts? & 14. No \\
\hline 15. Self perception? & $\begin{array}{l}\text { 15. Well rounded, talented, } \\
\text { good at my work, and positive. }\end{array}$ \\
\hline 16. Attempts affected your family? & $\begin{array}{l}\text { 16. Mom won't leave the house } \\
\text { any more, more appreciation } \\
\text { of me by my siblings. }\end{array}$ \\
\hline 17. How attempt impacted your life? & $\begin{array}{l}\text { 17. Far more colorful person, scars. } \\
\text { on the wrist, a miracle. }\end{array}$ \\
\hline 18. What are your risk factors for attempts? & $\begin{array}{l}\text { 18. Lack of medication, partner } \\
\text { leaving, }\end{array}$ \\
\hline 19. What are your protective factors? & $\begin{array}{l}\text { 19. My partner, dog, cat rabbit, } \\
\text { sister, networking and the friend } \\
\text { I mother next door. }\end{array}$ \\
\hline 20. View life and death differently? & $\begin{array}{l}\text { 20. Now that I have a network I am } \\
\text { not afraid to live. It is a miracle. }\end{array}$ \\
\hline 21. What kind of hobbies? & 21. I write poetry \\
\hline 22. Keys to prevention? & 22. Recreation, increase network. \\
\hline 23. Any more comments? & 23. No \\
\hline
\end{tabular}


Table 5

Structured Interview Questions and Answers for Judye

\begin{tabular}{|c|c|}
\hline Questions & Answers \\
\hline 1. Feeling suicidal presently? & 1. No, I am not. \\
\hline 6. Comfortable sharing this information? & 2. Yes, definitely. \\
\hline 7. How many times have you attempted? & 3. One time. \\
\hline 8. Do you have a clinical diagnosis? & $\begin{array}{l}\text { 4. Bipolar Affective Disorder and } \\
\text { Alcoholism and Drug Addiction. }\end{array}$ \\
\hline 5. Substance abuse connection to suicide? & $\begin{array}{l}\text { 5. The addiction was discovered } 3 \\
\text { after I was diagnosed. }\end{array}$ \\
\hline $\begin{array}{l}\text { 6. Family members attempted or } \\
\text { completed suicide? }\end{array}$ & 6. No \\
\hline $\begin{array}{l}\text { 7. Significant others attempted or } \\
\text { completed? }\end{array}$ & $\begin{array}{l}\text { 7. Three friends completed suicide. } \\
\text { friends in high school. }\end{array}$ \\
\hline 8. Did you enter into a suicide pact? & 8. No, I didn't. \\
\hline 9. Influenced by the media? & 9. No \\
\hline 10. Discuss attempts with family? & 10.No, I didn't. \\
\hline 11. Did you send any signals? & 11. Wrote a letter to a friend. \\
\hline 12. Why the attempt? & 12. Depression. \\
\hline 13. Will you attempt again? & $\begin{array}{l}\text { 13. I pray I won't, can't really say I } \\
\text { will never try it again. }\end{array}$ \\
\hline $\begin{array}{l}\text { 14. Continue to have suicidal thoughts? } \\
\text { 15. Self perception? }\end{array}$ & $\begin{array}{l}\text { 14. Yes, I have not intention today. } \\
\text { 15. I have a loving heart and care } \\
\text { for people. }\end{array}$ \\
\hline 16. Attempts affected your family? & $\begin{array}{l}\text { 16. Mom never accepted it, she was } \\
\text { angry about the attempt. }\end{array}$ \\
\hline 17. How attempt impacted your life? & $\begin{array}{l}\text { 17. Grace of God, share hope which } \\
\text { is my mission }\end{array}$ \\
\hline 18. What are your risk factors for attempts? & $\begin{array}{l}\text { 18. Alcohol, drugs, depression. } \\
\text { my impulsivity and diagnosis. }\end{array}$ \\
\hline 19. What are your protective factors? & $\begin{array}{l}\text { 19. My faith, belief in God, net- } \\
\text { working, positive friends, } \\
\text { hobbies, volunteering, } \\
\text { recreation, and finding rightful } \\
\text { dog owners. }\end{array}$ \\
\hline 20. View life and death differently? & $\begin{array}{l}\text { 20. Appreciate life more, everyday } \\
\text { more precious, I notice little } \\
\text { things. }\end{array}$ \\
\hline 21. What kind of hobbies? & 21. Mostly volunteer work \\
\hline 22. Keys to prevention? & 22. Education \\
\hline 23. Any more comments? & $\begin{array}{l}\text { 23. I think in this society suicide is } \\
\text { unnecessary. }\end{array}$ \\
\hline
\end{tabular}


Table 6

Drug Abuse and Mental Health Issues

\begin{tabular}{lccl}
\hline Attempters & Drug abuse & Alcohol abuse & Clinical Diagnosis \\
\hline Jacquelyn & $\mathrm{xx}$ & $\mathrm{xx}$ & $\begin{array}{l}\text { Attention Deficit Disorder/Central } \\
\text { Auditory Processing } \\
\text { Disorder/Depression }\end{array}$ \\
Shannon & $\mathrm{xx}$ & $\mathrm{xx}$ & $\begin{array}{l}\text { Bipolar Substance Disorder Type I } \\
\text { Judye }\end{array}$ \\
$\mathrm{xx}$ & $\mathrm{xx}$ & $\begin{array}{l}\text { Bipolar Affective Disorder and } \\
\text { Alcoholism and Drug Addiction }\end{array}$ \\
\hline
\end{tabular}

\section{Suicide Attempter Descriptions and Stories}

Eisner (1991) states that the first step of analysis--description--gives "an account of" (p. 95). In this study, an account of needs to begin with a description of the attempter. Included are the location and setting of the interviews and the attempters' stories.

\section{Jacquelyn}

Description. Jacquelyn is a dark-haired, well-dressed, poised, pleasant 59-yearold Caucasian female who resides in Nashville, Tennessee, and is employed as a receptionist at a doctor's office. The interview took place in her quaint and cozy townhouse. The living room where the interview took place had a large picture window. making the room bright and sunny. Adding to the cheerful ambiance of the setting were green plants of every description, art on the wall, miniature dolls of children from around the world, bookcases filled with books, and two cats.

The story. Jacquelyn began her story by saying that she was a happy little girl 
who grew up in a small town in New England. Her maternal grandparents lived on a farm close by. She said that she loved to go there and explore because they had lots of animals.

At some point something changed in her life. She became really unhappy. She says in her own words.

I'm not saying it was any one event in my life. I am not really sure what it was. At least I became aware fairly young that I wasn't happy at home. And I've thought about that a lot. I don't have answers. I just don't have answers.

Jacquelyn had trouble in school. She would daydream a lot, and some of the subjects held no interest for her. Later in life she learned that she has an Attention Deficit Disorder (ADD) and also a Central Auditory Processing Disorder (CAPD).

Jacquelyn describes the Central Auditory Processing Disorder as a situation where her brain has trouble processing information that she hears. If a person speaks too quickly she cannot keep up with them to understand what they are saying. She describes her brain as "clicking or cutting off" and not being able to understand. In her own words.

I let it rest for a little while then I can pick up some of the words. If someone speaks to me and has a lot of facts in a short amount of time my brain has problems processing all the information. It comes into me too quickly, so my brain just shuts off because I'm overloaded.

Jacquelyn says that she is glad to know about her brain, and that explains a lot of things about her in the past. She believes it explains why she was frequently withdrawn and the trouble she had in school, although she feels that she was an underachiever in school. Jacquelyn said that she was always hearing that she could do better if she would only apply herself. It seemed like she was always in a hole and had to climb out. She said that she got tired of it. 
When she reached high-school age her parents applied for her to go to a school in another state. At that same time her father got a promotion on his job, and her family was going to be moving to the Midwest. Her mother gave her the choice of deciding if she wanted to move with them or to remain in New England. She said, in order to get away from them, she chose New England.

Attempt \#1. The first year she had trouble. She recounts this time by saying, I was just constantly asking myself, who am I?

You know, what am I doing here? Not just at school but in the world. What is my place in the world here? Why am I here? And I had so much trouble, those questions were important to me and I had so much trouble finding answers for me. I couldn't find anything that was satisfying to me. And uh, like I said, I don't recall talking to anyone about it. And so one day I just uh, went over to the gymnasium. And they have a little balcony area and I was going to jump off the balcony. I was standing on the rail ... it happened to be my big sister, you know, we have a big sister, you know, for the new students. And it happened to be her and I heard her saying: What are you doing? You know, I said I'm going to jump off the balcony. And so, you know, she told me wait, wait, wait, you know, uh, let me come up where you are uh say good bye or something you know. Um, so um, she came up the balcony and we just talked. And uh I don't remember all she said. you know. She was telling me not to do it or trying to get me to talk about what's going on, what am I thinking about. And so I said some of the things I was feeling, you know. That I didn't like myself, I didn't know why I was here, I didn't know what I was supposed to do. Uh, I was just feeling miserable uh and just didn't seem like life was worth living. So uh, she talked me out of it or I let her talk me out of it. And uh, so that's when uh, I don't remember the events exactly. I think I went back to her dorm room and uh I just don't remember what took place. But she didn't tell the people around the school.

Jacquelyn was 14 when she made this first suicide attempt. An upper classman who was assigned to be her campus sister did not tell anyone on campus but did report it to the proper school authorities so her parents could be informed. Her mother came, along with a minister from a nearby town. It was decided that she needed to see a psychiatrist in Boston. 
She described therapy as being very Freudian. Neither she nor the psychiatrist talked. She remembers thinking how much she hated her parents and thinking that her parents did not love her. She felt her thoughts were awful and said to herself, "What's the use, I may as well kill myself." Jacquelyn said that in therapy it was difficult to talk and it was also very difficult to talk at home, so she just withdrew.

Two years later, at the age of 16 , she became pregnant but was urged by her parents to give the child up for adoption. She also started drinking around this age. Jacquelyn said that at that time it was a major disgrace to the family for anyone to have a child out of wedlock. She has never seen her daughter, but plans to search for her in the near future and explain the circumstances.

Later she attended a 2-year college and worked at a Midwestern State Hospital. It was at the hospital that she met and dated an $\mathrm{x}$-ray technician. He was handsome, suave, and she liked the attention that he gave her. She did not see the relationship as a negative relationship at first. He became verbally, physically, and sexually abusive. Jacquelyn says she became so wrapped up in his identity that she felt she could not live without him. She knew something was wrong but could not leave him. She tried to get him to go with her to therapy because they both had alcohol and drug problems. He would not comply with her request, however. The relationship was described as "a deadly combination."

Attempt \#2. It was at this time, at the age of 20 , after moving to Seattle, that Jacquelyn made her second attempt by taking a handful of aspirin. She describes the attempt this way: 
And anyway when I was 20, we had moved to Seattle, moved to Seattle. I took a handful of aspirin. I was just; oh what had happened was he was in the kitchen. I was sitting in the living room. He threw a coffee cup at me. And he told me afterwards he was aiming at my face. But the distance and how he threw it, hit my knee, landed, and cut my knee. So I just as for myself had taken aspirin. I took a handful of aspirin. I couldn't go through this any more. I didn't want to live.

She took herself to the hospital. She became cold because the aspirin lowered her body temperature. While sitting in the waiting room, a policeman came and asked her if she was really trying to kill herself or was just trying to get out of a situation. In her confusion all she could think of was that she had a man in her life. He supposedly cared about her, which is what she wanted. Yet on the other hand, a part of him did not care. The police continued the questioning by asking her if she was trying to get back at him. She said, "I told him I wanted to kill myself."

Thinking they were going to commit her, she just waited for about an hour. They stitched up her knee and sent her home to the same situation. With determination, she moved out and got a place of her own, only to return later. The enmeshment was very strong. Jacquelyn says she felt that leaving him was like taking a "chunk" of herself away. Leaving him would be like losing herself. Even during the time of their separation they continued to communicate by telephone and letters.

He liked to write and was a good writer. But, according to Jacquelyn, he had trouble with continuity. One day he decided that they should move to Mexico. On their way from New York City to Mexico, when they got to Ohio. he put her out of the car and left her there. He said, "I don't want you with me anymore. Just get out. Just get out. I am going to go on." He left her there in the midst of gas stations and no police station. After communicating with the attendant at the last gas station, a trucker came in and she 
asked where he was going. He said Florida, and she asked if she could go also. For a moment she said the thought went through her mind that her husband had left her and she had nothing. She felt she needed to go after him. "I thought again and said, why? What am I going to do when I catch up with him? Beat him up or something?" Jacquelyn says it tumed out to be a blessing in disguise.

She arrived in Orlando, Florida, with the trucker and stayed for a week. Because of the humid climate she decided to leave. The trucker was on his way back to Ohio. Jacquelyn asked if she could go back with him, and whether he would just drop her off in a small country town. The small town was in Tennessee. When she got to Tennessee she decided to try to find her husband again. She made up a story but finally told them he left her. She says she can truly understand battered women. They just cannot seem to let go. The people at the police station got her a job there in the town taking care of a lady who had had a stroke. For a while she was in a situation where she did not know where she was going and what she was going to do. She did not know anyone personally and did not make friends very easily. She felt frightened and uncertain and describes herself as introverted.

She worked for the lady 3 months but felt confined. On her off days she would rent a hotel room, walk around downtown, and entertain herself. She met some people, both males and females. They all became friends and socialized together on her off day. Eventually, she got a job in a restaurant as a cook. She describes the restaurant as small, very small, mostly countertop space. During this time she met the man that would be her next husband. He was one of the customers. Jacquelyn describes her husband (Bill) as older and very nice. She says he treated her very well. He was older but she had no 
problems with the age because he was stable with a good job as a carpenter. He was reliable and she needed stability. She had had enough of the instability and taking care of someone else. Later, they were married.

Jacquelyn continued to drink and felt that something inside of her just was not right. She started asking herself questions such as "Who am I? and Where am I going?" She was not taking any medication. She recalls having negative thoughts. She also remembered that while in college a doctor had given her a drug that helped her. She says that the marriage was a better relationship but she felt that he was emotionally unavailable. She wanted to talk about her feelings. Because she could not discuss them with her husband, she started to drink more. When he would come home from work she would be intoxicated. He told her that he used to drink and how one night he decided to quit. With that knowledge and not wanting to bother him with the drinking, she would drink only occasionally.

One winter Bill and Jacquelyn became ill with the flu. Bill, however, never seemed to totally recover. After about a month he cut back on his work hours until he only went a couple of hours during the week. Finally, he would come back home after an hour. He was very concerned, and when they talked about it he said he felt really tired.

Three months later he started to experience terrible pain and lost large amounts of weight. Jacquelyn took him to the hospital. They discovered that he had appendicitis. The doctor also became concemed about the loss of weight and decided to run some medical tests. The test revealed spots on his liver. He deteriorated rapidly and lost more and more weight. A few months later he died. 
Jacquelyn said she was devastated and started drinking as if there were no tomorrow. At age 33, she was a widow. Her depression became so heavy that she stopped working. Nothing seemed to help, even though she was in therapy. Finally, she was given medication but it caused her to develop a manic side. emotions the opposite of depression, to the extreme. She was then given the drug lithium for the manic episodes and an antidepressant, but over a period of several years the medication was not effective. The goal of the psychiatrist was to find something that would work for her. Most of the drugs in 1973 just made her sleep excessively.

Again, she started to drink heavily. Drinking and driving almost took her life. Fortunately, she did not kill anyone else. Jacquelyn said the only thing she can remember is leaving home intoxicated, hitting a tree, and losing consciousness. The next memory she had was being in jail screaming and hollering to be let out. She was arrested for drunk driving. The police kept her until she became sober and sent in a bail bondsman to get her released and to take her home. The incident scared her so much that she joined a religious group, but she had a problem with the doctrine that you could not take medication. She says she did like the structure that the religion gave her but she needed to take her medication and remain in therapy, which prompted her to leave her church.

For 4 years she did not drink. Then she met and started dating a friend who drank. He offered her a drink and, instead of refusing the drink, she took it and started to spiral down again. In her own words she says,

And I met some guy, you know, we were going out and he said how about a drink? Well I thought I haven't had a drink in so long, I probably could have a drink. I didn't understand that I was an alcoholic. You know I couldn't have a drink because I'd get started all over again. I didn't understand that. It got me started all over again. Drinking calmed something down. I liked that, but it also got me into all kinds of negative stuff and um, for me it was almost like a form of 
suicide. It was like you could leave your life for a little while. As long as I was drinking I could leave, be somewhere else.

Jacquelyn said that she was very unhappy and still confused about the thought of who she was and what she was here on this earth for. She felt that her "self" was going in different directions. She increased her already excessive drinking. She felt her introversion kept her from going out and meeting more people, but kept her out of more trouble.

Attempt \#3. At the age of 45,12 years after the death of her husband, she was drinking one night and decided that she would just end it all. This is her account:

But, but I was 45 . And this was still, you know, this was still twelve years after my husband died. So I worked through all that. And I just, I was just drinking one night and thought, just end it, I've had it. And, oh yeah, my house had burned down. I forgot that. A year after my husband's death my house bumed down. It wasn't anything fancy. Just a fire and I lost everything and I had no insurance. A year before my husband died, my mother died. She had lung cancer. Again I just reached the place where I just ... again I just reached the place where I just. My religion wasn't helping me. Not with the same old questions, what was I doing here? Where was I going? What was it all about? So I decided I wanted to hang myself. Yeah, I had a gun but a gun; it was ... it was too messy. Yeah, and I just thought. Naah. So I just thought, I'll hang myself. So I got a cord and I attached it to a light fixture. You know and just jump on a chair. I was just going to jump down, you know, it was just short enough where my feet wouldn't touch the ground. Well, when I went to jump, the light fixture pulled out of the ceiling. I was so angry, I was just so angry. So I called my doctor and I said, "This is what I've done," so he called an ambulance and had me taken to Nashville. Anyway, that was my last attempt. I have gotten depressed in subsequent years and thought of suicide, but never made another attempt. I had I guess come far enough in therapy and part of it was just acceptance.

Jacquelyn said that the answers do not matter now. She says she keeps looking

but not as in a crisis state of mind. These are her words:

I'm really hoping that your work will help a lot of other people and mainly the important thing is you will get there if you never give up. And there's an expression that I hear this a lot, "you don't leave before the miracle happens." You don't know what's around the next comer, maintaining that perspective has 
helped me. You know when I get down, feeling like ending it all I think, tomorrow may be the very day that I've always wanted all, my life. Other pieces of the puzzle happen and I wouldn't have been here to find out about it. So I try to turn around all of my questions from dead serious to interesting. Like detective work.

In closing her story she said, "I've still got a whitie here." She feels that there are still answers and she will find them day-by-day.

\section{Shannon}

Description. Shannon is a fair-haired, pleasant, articulate 31 -year-old Caucasian female who resides in Nashville, Tennessee. The interview took place at her office building in a conference room. The room was private and out of the way of traffic and interruptions. Her demeanor was one of helpfulness, sincerity, and openness. Her appearance was neat and professional. She was the first person who readily agreed to do the interview. When I arrived at her office she had everything in place for the allotted time of the interview.

The story. Shannon started by saying she would be 32 years old in 2 weeks. She was born in Phoenix, Arizona, and her parents were very strict Mormons. They believe that suicide is a big sin and, in her words, "You'll go straight to hell for that."

Shannon said her childhood was boring and that she cannot really remember any of it except that her father was a very angry man. He was a policeman and she expressed that, being a policeman, he encountered horrible things. He worked long hours, and when he got home he would be very angry. He could not take it out on the people at work because of police brutality. She says she remembers him coming home and trying 
to step into the father role but they, as kids, were used to listening to mom. "We didn't want to listen to dad," she says.

Shannon is the second of eight siblings. Shannon says she actually raised her youngest brother for about 2 years. In her words,

My mother got all pissed off. She was 40 when she had him. She had a nervous breakdown, kind of. So, I would take care of all of the kids. Being the second oldest, the oldest girl, I took care of all the kids. I raised Johnny. I actually named him too. When he started calling me mom, she got all pissed off and said no more of that [Giggles]. You know you can't blame her for that.

Shannon started drinking at the age of 13 , near the end of her sixth-grade year. She says she had easy access to the alcohol because her friend would bring her dad's alcohol to school in the canteen she carried in her lunch box. She also started smoking and remarked, "Now this is not good in a Mormon religion." When she got into high school she attended seminary, which is like church before school classes. She remembers getting up at 6:00 in the morning, as she says, "to be preached at all day." Shannon says that she did not want to listen and would go to the park and party. Both she and her brother would skip their classes and not tell on each other. She said his activity was fighting and hers was drinking and smoking.

Shannon says she started doing hard drugs like cocaine at the age of 15 or 16 in her freshman year in high school. On one occasion, she and one of her friends were dropped off at a football game. They left the football game and went to a drinking party in the park across the street. This is what she encountered, in her own words:

They held us down. They actually tried to set me on fire. They burned my wrist, stabbed me several times. I lost my eyesight. My eye got pulled out of my socket. [They] cracked [me] in the head. Lots of stitches but sight came back and it was in the left eye, not in the right, a big frustrating thing. And you know that's a huge, huge event in your life. 
Shannon says no one wanted to talk about it especially her family; they did not want anybody to know. She says they were embarrassed and did not want their friends to know. Shannon remarked that she could not understand that kind of behavior from her family.

She became pregnant from the rape. She continued to use cocaine during her pregnancy. Shannon says she was almost 15 when the baby was born (a stillbirth) and died and no one wanted to talk about that either. In her words she said, "It was a real downer and no one still wants to talk about what was so painful and hurtful."

Shannon says she had sexual identity issues at the age of 17 and the friend who she was with was openly gay. The boys said they targeted them because of their sexuality. There were no hate-crime laws, so the attackers went unpunished. Shannon said she had sexual identity issues before the rape. Afterwards it became, in her words, "bigger." She remembers feeling angry all the time and breaking up with her then boyfriend.

At the age of 17 , her best friend completed suicide. Shannon describes it this way:

And when I was 17, my best friend in high school completed suicide. I had talked to her the night before. We were supposed to go out and play racket ball. I wouldn't play because I couldn't see. But there were three of us. She said I don't need to go play that anymore. And we would go play just to hit things, as an outlet kind of thing. She had called and said she was canceling. She was okay and all that stuff. Well, that night she took an overdose. Apparently, it didn't work very well, so she slit her wrists and shot herself too, like she was impatient or something. That was Mary, and so she died. 
Attempt \#1. Shannon said that everything just seemed to build up on top of the negative events in her life. It was during that time that she made her first attempt. This is how she described it:

I slit my wrist and took an overdose at the same time. Maybe that was what she [Mary] was doing. But that's what I did, and I just went into my room and lay down. My brother came, then my mother, and they all yelled. I went to the hospital and I stayed there for 6 weeks doing drug rehab.

Shannon says she had psychological counseling and family therapy. She says the rehabilitation and psychological counseling helped; she is not on drugs and drinking anymore. The family therapy did not work. Her family would get so angry that they had to be separated into different rooms. She described it as a "mess." According to Shannon, she decided to celebrate her birthday the day that she slit her wrists and went to rehabilitation. This is how she describes her mother's reaction and her new birth:

My mother thinks that's weird. People here just don't get it. But it's like a rebirth. I'm a heck of a lot nicer to people cause I'm not on drugs and stuff. And I did get counseling and I've been in counseling for the past 15 years.

Shannon says that when she returned home she just went back to the routine. She says she was expected to go back to church and go on with life as usual. However, one day at a school play rehearsal she started to cry uncontrollably. One of the girls took her in the restroom, consoled her, and asked what was wrong. She replied that she just wanted to die. She was taken to the hospital. The psychiatrist diagnosed her as manicdepressive and started her on Lithium. But the lithium did not have a chance to get into her blood system and she felt really depressed, according to Shannon.

Attempt \# 2. Another loss coupled with rejection occurred around this time. She had a sister who decided to leave home and had previously made a promise to Shannon. 
This is how she describes it:

[My sister said] I promise I won't leave you in this horrible house with these horrible parents. Then she moved away to Utah to chase some guy named Bobby who looked like Tom Cruise [in] Top Gun. You can't blame her for that, but she went with Denise. She went with one of her friends from church. I could have gone. I was really disappointed. I was really, really mad and disappointed. All kinds of things, and that's what triggered that [the second attempt] I think. A friend from church, you know. The first one was with pills and a razor; the second attempt was just with pills. I took pretty much the whole entire cabinet. Cause when you're going to do something you've got to do it right.

Shannon talked about the process to follow the second attempt

That wasn't even a big hospital stay but that went down with charcoal and that was nasty. You know, when they pump your stomach and then they give you charcoal. Charcoal is supposed to absorb the drugs in your stomach or anything that's left. Okay, but then, what they don't tell you is that you pee charcoal, you crap charcoal. It comes out of your nose. It comes out of your spit, and saliva. You sweat charcoal. You cry charcoal. It's nasty.

At the age of 20,2 months before her birthday, her doctor changed her medication because it had damaged one of her kidneys. She was very depressed. To preserve the one kidney she had left, she was changed to another medication. That medication only caused her to regurgitate, thereby emptying her system of all of the medication. She became more depressed.

Attempt \#3. Shannon describes the events leading up to her third:

My mother left me to baby-sit one night. It was Monday night, 7:00 o'clock. We had been fighting. My little sister and I had been fighting. The one who slit her wrist when she was 8 [years old]. We were all yelling at each other. They [my parents] just left. And I had been planning this anyway because, the Sunday before that, it was a week and a day before this happened. So it was actually two Sundays. They [my family] had gone out to some church something or another. I had found my father's rifle in the back of his closet. Plain as can be and there right above it were the bullets [giggles]. So, I had actually taken it out, loaded it, and cocked it. Then one of my friends, Kelsey, says "Hey whatcha doin?" I said, "Oh, I just got the gun out." She said, "What? Put that back! You walk half over here and meet me and I'll meet you half way," and she left [to meet me]. She was 
doing chores and she was in a lot of trouble but she came out there, she walked out and she met me half way. We went back to her house and hung out there until her parents came back. But I had put it back exactly the same way, except that it was loaded and cocked. I figured I'd go back in [to the room where the gun was located later]. I'd just unload it and nobody would ever know.

Shannon says a week went by, and this is how she describes her third and last attempt:

But then a week went by, and I was being off this medicine. We were fighting. She [my mother] left me with these kids. Two of them were screaming, hollering, and running around. One was sitting off in the comer. She liked to play office. [She was pretending] like she was some sort of an executive with a briefcase and these memos. And she was over there playing like she was some sort of big shot. Jane, she was about 4 then. I planted her in front of the TV. I was going back into my parents' room when Johnny comes in. He's about almost 2. I said, "Here you hold this and pull this," and he did. He shot me right through. He didn't know what he was doing. He doesn't remember. In fact now, I don't even think that he knows that he was involved. I just think they just tell him that he was in front of the TV. But, I said, put the gun down and we went out. And I said, you know crap, he's back here a little kid. I just can't fall down and die right in front of him. It will traumatize him forever. I went out there and that's when I said, "Heather, I've been shot." She said no. I said Uh-uh. She said show me; prove it, I had my hand over my chest. There was a hole in my shirt, my favorite Mickey Mouse shirt, and an itty-bitty thing of blood. She got up to come over and see. Then she says "Oh." Then she went over as calm as could be and she called 911 and said my sister shot herself. And then I said okay, we're good. So I said, "Johnny go watch TV." Johnny and Jane were all watching TV. I lay down on the kitchen floor. The person on the other end of the phone was telling Heather to get some towels or go get this or something, because she kept running back and forth. She brought me a towel. This didn't help because I wasn't bleeding outside, I was bleeding inside but she did that [bring the towels].

Shannon described the events that took place between the attempt and the hospital admission. She tells how her father and all of the municipal organizations came to her rescue. She said people she knew and had grown up with were there. Included were her boyfriend and his father, the fire chief. Her family was told that she would probably die. At the hospital her brother was in the next room getting a cast put on his arm because when he heard the news he crashed his hand into the wall. 
Five days later she was discharged from the hospital. When she arrived home, her little brother Johnny came running and flung himself upon her. That made her bleed into her lung. She had to be taken to the hospital again. She was in the hospital for a couple of weeks with a coagulated lung and an infection where the bullet entered. No one had detected the infection previously. This was the reaction of her parents to this attempt and the occurrences that followed:

Then I went home and they pretended like nothing happened. The only time that they ever did talk about it, and I did try, the only time that they ever talked about it was when Annie started cutting on herself. And then they said, "Well Annie why are you doing this?" Because I went through all this huge thing and nobody will talk to me about it. I don't have any help. And the only time we talked about it was when my mother said, "Annie is cutting on herself because you did this." So it was more like this is your fault. So, that was that. They still don't talk about it. Even now it makes mom cry. [My father] he's just like stony faced and stuff. He's more like talk to your Mom about that and then, you know, changes the subject. But then when I was there I decided, oh my gosh, if I stay here any longer I'm just going to die. They are going to suck the life out of me if I don't do it myself. This happens in my family. People get really sick. They get really depressed. My Mom just doesn't know what it could be. But, when you move, you get better.

At the age of 24 she was invited by a friend to move to Tennessee where she was residing at the time of this study.

\section{Judye}

Description. Judye is a dark-haired, well-dressed, friendly, articulate, Caucasian female who resides in a small town outside of Nashville. The interview took place in her lovely home. The house is very neat and beautifully furnished. There are plants, pictures of family, and artwork nicely placed throughout the house. She has a dog that belonged to her deceased mother and three cats all having their individual "cuddle" spots, as she calls it. The room where the interview took place was bright, sunny, and light blue. The 
color of the room and the plants gave it a feeling of spring. Judye is a part-time college student and works part-time at a mental health facility with psychiatric patients.

The story. Judye says she was born on a farm into a very loving family and is the fourth of five children. Judye felt that it was important to start with her birth because there are a lot of people out there who are like her and feel depressed or inferior. These are her words:

When I was born, I think this is important to tell. There are a lot of people out there like me. I didn't know this until a few years ago [and] here I am 46. My mother took the drug thalomide. I found that out and I don't blame her in any way at all. But, as you know, I have [only] two fingers on my right hand. I had plastic surgery done when I was nine months old. Thank goodness I don't remember it. I thought that I was left-handed. Then I learned later that I was really born right-handed. I just find all of these things very interesting.

Judye says sometimes when she plays sports she hesitates as to which hand to use, but her psychiatrist has told her not to make a big deal about it. Her body is just trying to decide which hand to use. She says sometimes adults will say inappropriate and hurtful things, but children will say, "Look mommy at Miss Judye's hand" and see it as no big deal. She says she prefers for people to just ask. Judye says she thinks this had a lot to do with her feeling different and she did not know how to express it.

It was when she entered school that she found out that she was different because her parents treated her, as she says it, "normally." Judye says that since she has been in therapy she has learned about passiveness and aggressiveness. She also realizes that the women in her family are very passive and do not know how to "take up for themselves."

She describes a situation that occurred in school:

So in school there was a bully who would come down and get me out of the room in first grade. When the teacher would go and get ice cream he would charge people a nickel to see my hand. It's just like, um, I didn't tell things. It's like I 
kept everything to myself. Back then every time school started they would come and get me for speech class. And I really wish today that I had that. But every year it would upset me so much because I was the only little girl in there. The rest were boys, I was like first, and second grade and they were seventh and eighth. It was a male teacher and they allowed things like that to go on.

Judye goes on to say:

My parents always got me out of it [speech class] but they said in the second grade I came home and I remember climbing up on to their big bed and just crying and crying for 2 days. I would not tell people what was going on. I don't know why. Finally, when my Mom said if that's a problem, I'll just call the teacher. It's no big deal. I said, well yeah but next year they will come and get me too. I had an imaginary friend, so I'd tell my imaginary friend everything, and maybe that's why I didn't talk to the people. So I think that has had an impact [on me] all of my life.

Judye says on the outside she was a happy-go-lucky person always smiling. She really did not know her feelings. She says it is important to mention that she had an older friend that she confided in. She would tell her everything and now she sees her friend who listened to her as "keeping her safe."

She says that in the fourth grade she was painfully shy, but she loved it when the

workers would come and perform work on the farm. This is how she describes it:

I was so shy, but I loved it when we had workers out on the farm. It was something that kind of intrigued me about them. I was always around them, but at a distance. There was a woodchopper who came, I begged him not to cut down the tree, and it's still there today. I would hide. I wouldn't go up and talk to him, but I would wave bye to him. I though it was so much fun when he came and I would look forward to it. There was also a man there who was painting the house. Let's see. I'm [in] the second grade and my little brother was just born. and Mom got a new washer. The big washer box was out in the yard. I used to like to play in the box. This man is painting the house and I' $m$ in the box, inside the box. He can't see me, and he doesn't know that I'm in there [in the box]. This man had a reputation for drinking. So I was playing around in the box. It was my little safe area. It was a way that I could still be around him but I could kind of be invisible too. He told my parents years later that it would scare him so much because he had been drinking and he saw this box move a little bit. [Giggles]. Then he'd go back to painting and he would see the box move a little bit more. He was so relieved to find out that it was me moving in the box. 
According to Judye, when she was in the fourth grade something about her personality changed. These are her words:

Then in the fourth grade I had a teacher [who] was really good at helping to build my self-esteem and so forth. We did a play and he told us we could come and do as many different things as we wanted to do. Usually at my piano recitals you could hardly get me out there. It took my Mom and the piano teacher to push me out. But in this skit, I mean our play, I did ten separate things. I did some skits. I did some dances. I did some poetry, I played the piano, and everything that I could think of. My Mom and Dad were sitting back there in the back and they were just astonished. They were looking at each other saying, "This is not our Judye."

Judye says she must have had the bi-polar swings as far back as fourth grade. She also says that many children are possibly bi-polar but it is hard to share their feelings. She expresses that it is important to watch their periods of isolation when they do not want to be with their friends. She recalls periods of time where she did not want to be around any of her friends, and at other times she was very outgoing.

She says her family was warm and loving but later she realized after the attempt that they talked about the facts and events of life but never talked about feelings. Judye says she never really knew her feelings and she thought anger was bad. She goes on to say she does not think her parents knew their feelings either. Two or 3 months before the attempt Judye said she felt depressed, but did not know it by the label of depression. She says they come from a small country town and no one would talk about depression because they did not know much about it. You never heard about anyone going to a psychiatrist, or you may have heard about it on television as a joke. For about 3 months her severe mood changes occurred with the depression. Because she did not know what was taking place within her, she thought she was a horrible person who God had put here on earth. 
She visited her doctor and he gave her antidepressants, but she did not know that he was treating her for depression. She says, "Again, the women in my family are very passive." We were taught not to ask the doctor's questions because my mother thought it would insult them. You did not ask about your condition or the medicine.

Judye lost 17 pounds and felt terrible. New Year's came and went. After the holiday she called the doctor for more drugs. She went to the doctor again on Wednesday for more medicine. Her doctor told her that he saw a change in her and noticed that she avoided eye contact. She wishes that he had told her and her parents that he was treating her for depression. On the way home from the doctor's office, and after 3 weeks of depression, she started to think about suicide. This is how she described her feelings:

[After] 2 or 3 weeks of depression I thought about suicide a lot and I thought about how I wanted to attempt it. I would drive up on the mountain [where] we lived very close [to the edge]. I would stop the car. I would just look off into the valley, and I would think, you know, this is how I want to do it. Then I would think with my luck that I would just end up really maimed, be a cripple and that my parents would have to take care of me. So I did know in my mind that when I attempted this suicide that I did want to complete it, that I did want to be dead. So for 2 or 3 weeks I kept thinking about altemative ways. I did have a lot of medication in my house because this doctor unfortunately prescribed a lot of medications and narcotics. I am not blaming my addiction on him because we all have to be responsible, but I think just the fact that he had his license taken away a couple of times for over prescribing narcotics can give you an idea about how much I had and I was in the doctor's office about every week.

Attempt \#1. Judye started experiencing constant and painful headaches and stomachaches. She would go and get what she calls "some wonderful narcotics." This would help her to escape her feelings for a while. Judye ultimately decided to attempt suicide, and this is how she describes it: 
So then that Wednesday like I said, on the 3rd of January, I went home. I decided to attempt and thought that I would complete suicide. I had gone by a friend's house that had been so sweet to me and I left her a rose and a short note. I can't remember much about the note. It wasn't long but it was thanking her for everything that she had done. I went home and I started swallowing the pills. This person had enough insight to call my parents and have my parents to call the doctor. My doctor asked my parents if they had a key to my home. They were to take the key, get into my house, and see how I was and to call him and so forth. He said under no circumstances, please, don't let Judye stay alone tonight. My parents did not realize that I was serious. We never had a suicide in the family and they just didn't realize. They thought it was all a hoax, or attention getting, because I was the happy-go-lucky person in the family. I was really the caregiver in the family. I took care of everybody else. So my mother was kind of angry at me because I had bothered the doctor. My father, I don't think he knew what to think. I was smart enough that I talked them into leaving. I had promised the doctor on the phone that I wouldn't do anything.

Judye was hospitalized 2 days later; she retained the bi-polar disorder diagnosis and acquired a second diagnosis of alcohol and substance abuse, a dual diagnosis. She says her parents did not talk about it or realize the seriousness of the attempt. She is presently complying with her psychiatrist and stays on her medication. Judye says it is her mission to help others in this kind of situation so she is a volunteer speaker on the subject of suicide and mental illness.

\section{Summary}

Responses from both the structured (see appendix D) and unstructured (see appendix E) interview questions show that the risk factors for each of the 3 attempters were (a) mental disorders, (b) alcohol and drug abuse, (c) family and childhood dynamics, (d) lack of family communication about the suicide attempts and (e) tragic losses (see Tables 3-5, and 8-13). Two of the attempters had an additional risk factor of (f) previous suicide attempts (see Table 7). 
Responses from the structured and unstructured interview questions show that the protective factors are (a) being responsible for self-care, (b) positive relationships, (c) keeping busy helping others, and (d) recreation. (See Tables 14-17.)

These results support the prevailing literature on suicide and attempted suicide for risk factors (Cornelius et al., 1995; US Public Health Service, 1999; Balch \& O'Bannon, 2001; Platt, 1992) and the protective factors (Blumenthal, 1990; US Public Health Service, 1999).

Finally, the responses from the structured and unstructured interviews show the impact failed suicide attempts have on a suicide. These factors are looking beyond themselves to a Higher Power and an inner perspective of a bonus life or a greater respect for life (see Figure 2).

In chapter 5 these factors will be explored and analyzed in a thematic structure. 


\section{CHAPTER 5}

\section{ANALYSIS OF DATA AND THEMES}

Dying. softly dying, slowly passing time, the anger subsides and reality sets in. things to be lost steps to take. gotta take guts to say goodbye.

\section{Introduction}

This chapter is the analysis of the data through the use of themes in cross-case analysis. Twelve themes emerged from the data. The first set of 6 themes emerged as risk factors: (1) previous suicide attempts, (2) mental disorders. (3) alcohol and drug abuse, (4) family and childhood dynamics, (5) lack of family communication about the suicide attempts, and (6) tragic losses. The second set of 4 themes emerged as protective factors: (7) positive relationships, (8) keeping busy helping others, (9) being responsible for self-care, and (10) recreation. The third set of 2 themes emerged from the impact of the suicide attempts on the lives of the attempters: (11) looking beyond themselves: a Higher Power and (12) an inner perspective: a bonus life. Each of the themes answers the research questions. The first set of 6 themes answers research question $\# 1$ about risk factors. The second set of 4 themes answers research question\#2 about the protective factors. The third set of 2 themes answers research question $\# 3$ about the impact of the suicide attempts on the lives of the attempters. 


\section{Risk Factors}

The following themes are the risk factors that emerged from the structured interview, consisting of 23 questions, and an unstructured interview, which are the stories of the attempters as they told them. There was a commonality of risk factors with few differences for the attempters. The one difference, which is found in the first theme, is that Judye was the only non-previous attempter.

\section{Theme \#1: Previous Suicide Attempts}

Previous suicide attempts are a risk factor (U.S. Public Health Service, 1999). The researcher concludes from the stories that previous suicide attempts were a high risk factor for two of the three attempters. Jacquelyn and Shannon, each attempted suicide three times and are therefore considered previous attempters (see Table 2). It is evident from their stories that as well as a loss or anger, they were not on or were changing medication. The following are the quotes from their stories about their attempts (see Table 7).

\section{Theme \#2: Mental Disorders}

Studies by Vietra et al. (1992) and the Canterbury Suicide Project study (Beautrais et al., 1996) showed that a growing number of suicide victims suffer from mental disorders. All three attempters have similarities with mental health issues and all have a psychiatric diagnosis. Jacquelyn informed the researcher that she was diagnosed Attention Deficit Disorder (ADD), Shannon was diagnosed as Bipolar Substance Disorder Type 1 and Judye was diagnosed as Bipolar Affective Disorder and Alcoholism and Drug Addiction. Table 8 presents the way in which the attempters answered. 
Table 7

Previous Suicide Attempts

\begin{tabular}{|c|c|}
\hline Attempter & Excerpts from Stories \\
\hline \multirow{3}{*}{ Jacquelyn } & $\begin{array}{l}\text { Attempt \# } \\
\text { "One day I just went over to the gymnasium, they have a little balcony } \\
\text { area and I was going to jump off the balcony. Someone came in [as I] } \\
\text { was standing on the rail and it happened to be my big sister, we have a } \\
\text { big sister for the new students, and it happened to be her. I hear her } \\
\text { saying, what are you doing". You know I said I am going to jump off the } \\
\text { balcony. And so, you know she told me to wait, wait. and wait and to let } \\
\text { her come up and say goodbye. She was telling me not to do it, or trying } \\
\text { to get me to talk about what was going on." }\end{array}$ \\
\hline & $\begin{array}{l}\text { Attempt } \# 2 \\
\text { "I was sitting in the living room, he threw a coffee cup at me and told me } \\
\text { afterwards he was aiming at my face. But the distance and how he threw } \\
\text { it landed on my knee. So I just as for myself [took] a hand full of aspirin. } \\
\text { I couldn't go through this anymore. I didn't want to live like this. I just } \\
\text { wanted out altogether." }\end{array}$ \\
\hline & $\begin{array}{l}\text { Attempt\#3 } \\
\text { "I wanted to hang myself. Yeah. I had a gun. but a gun. it was too messy. } \\
\text { Yeah, and I just thought, naah. so I just thought. ['Il hang myself. So I } \\
\text { got a cord and I attached it to a light tixture you know and just jumped on } \\
\text { a chair. I was just going to jump down. you know, it was just short } \\
\text { enough [so that] my feet wouldn't touch the ground. Well, when I went } \\
\text { to jump, the light fixture pulled out of the ceiling. So I called my doctor } \\
\text { and said this is what I've done.... Anyway that was my last attempt." }\end{array}$ \\
\hline \multirow{3}{*}{ Shannon } & $\begin{array}{l}\text { Attempt \#l } \\
\text { "A couple of months later, everything just all built up on top of it [my } \\
\text { best friend's suicide] and I slit my wrist and took an overdose at the same } \\
\text { time." }\end{array}$ \\
\hline & $\begin{array}{l}\text { Attempt } \# 2 \\
\text { "The first one was with pills and a razor, but the second attempt was just } \\
\text { with pills.... I took pretty much the whole entire cabinet, cause when } \\
\text { you're going to do something, you 've got to do it right." }\end{array}$ \\
\hline & $\begin{array}{l}\text { Attempt } \# 3 \\
\text { "Then a week went by and I was off this medicine. We [my siblings] } \\
\text { were fighting. She [my mother] left me with these kids. Two of them } \\
\text { were screaming, hollering, and running around. One was off in the } \\
\text { comer. she liked to play office. I planted her in front of the TV. I was } \\
\text { going back in my parent's room when Johnny comes in [the room]. He's } \\
\text { about aimost two. I said, here, you hold this and pull this and he did. He } \\
\text { shot right through, he didn't know what he was doing." }\end{array}$ \\
\hline
\end{tabular}


Table 8

Mental Disorders

\begin{tabular}{ll}
\hline Attempter & \multicolumn{1}{c}{ Excerpts from Stories } \\
\hline & "Depression, and this is over a period of time not necessarily originally. \\
& $\begin{array}{l}\text { Then I developed a manic side in my late twenties and also just recently } \\
\text { within the last year, I found out that I had ADD [attention deficit } \\
\text { disorder] and Central Auditory Processing disorder. So those factors I'm } \\
\text { sure added to those suicide attempts." } \\
\text { Jacquelyn }\end{array}$ \\
& "My risk factor is my depression."
\end{tabular}

Shannon

"Yes, I have a dual diagnosis that is Bipolar Affective Disorder and Alcoholism and Drug Addiction."

Judye

Theme \#3: Alcohol and Drug Abuse

Alcohol and drug abuse issues affected the suicide attempters in this study.

Attempted suicides have a high incidence of alcohol abuse. In a study by Petronis, Samuels, Moscicki, and Anthony (1990), the authors found that those who had attempted suicide in a community sample more often abused alcohol and, incidentally, cocaine than did those who had not attempted suicide. Mental disorders and drug abuse combinations are double factors that also influence the attempter. Drug abuse is a pain reliever for many persons who are experiencing physical or emotional pain. Satcher (U.S. Public Health Service, 1999) points out that depression with alcohol abuse is an example of a mental disorder combination. Each of the participants in this study had been involved with the use of alcohol and drugs. Two of the three regularly attend Alcoholics 
Anonymous weekly. Excerpts from their stories about alcohol and substance abuse are presented in Table 9.

Table 9

Alcohol and Drug Abuse

\begin{tabular}{|c|c|}
\hline Attempter & Excerpts from Stories \\
\hline Jacquelyn & $\begin{array}{l}\text { "I started drinking once and a while when I was sixteen. Um, it was } \\
\text { infrequent at first.... I started dating a guy that was an x-ray } \\
\text { technician. Um, he was a handsome guy. We began an intimate } \\
\text { relationship... and um, he had alcohol and drug problems too. I tried } \\
\text { marijuana for a while but I didn't like the way it made me feel." }\end{array}$ \\
\hline Shannon & $\begin{array}{l}\text { "I was seventeen, drug and alcohol and all kinds of escape stuff. Those } \\
\text { drugs were alcohol, cocaine, and nicotine, what ever." } \\
\text { "At the end of school we started drinking. I was } 13 \text {, we started } \\
\text { drinking because Sharon's father who had his own distillery, [laughs] } \\
\text { had bottles of stuff and she would put it in her little canteen in her } \\
\text { lunch box. Something like whiskey, vodka, and stuff and bring it to } \\
\text { school. In about the eighth grade I started smoking ... but I started } \\
\text { using actual hard drugs, cocaine when I was } 15 . "\end{array}$ \\
\hline Judye & $\begin{array}{l}\text { "We discovered, the addiction about } 2 \text { or } 3 \text { months after the bipolar } \\
\text { [disorder]. Because what happened is the doctor said okay something } \\
\text { still is not leveling out correctly with the drugs. And he was a very a } \\
\text { smart man and informed me about addictions. And I saw that I had } \\
\text { been using a lot of medications and alcohol all of my life to alter my } \\
\text { moods." } \\
\text { "[After the attempt] they called the psychiatrist. [He] came in the next } \\
\text { day and in a couple of hours he picked up on all the drugs I was on. I } \\
\text { can't remember but there was a sleeping pill, and I remember when he } \\
\text { left the room, he said, 'I am pulling all of these drugs' and I said but I } \\
\text { won't be able to sleep. He turned around and said, 'Judye nobody ever } \\
\text { died from a lack of sleep!' So he was just the perfect person.... I was } \\
\text { having addiction problems." }\end{array}$ \\
\hline
\end{tabular}




\section{Theme \#4: Family and Childhood Dynamics}

Negative family functioning can influence the suicide attempter. According to Fremouw et al. (1990), stressful home environments may be characterized by problems ranging from parental depression, psychosis, or other pathologies, to marital conflict and violence. Jacquelyn characterized her family environment as being lonely and stressful, Shannon spoke of her father's anger and siblings that repeatedly attempted suicide. Judy felt that the females in her family were passive which contributed her eventual suicide attempt. Each of the attempters made the following statements from her stories about her family and childhood dynamics (see Table 10).

\section{Theme \#5: Lack of Family Communication About the Suicide Attempts}

There was a lack of family communication about the suicide attempts, which caused more emotional pain. In response to Question 10 (see Appendix D), concerning discussion of the attempt with family members or significant others, the responses were uniformly "no" and that no one in the family wanted to discuss the attempts.

Communication of their feelings, rather than death, is the suicide attempter's true aim (Stengel, 1964). There was no open communication about the attempts with any of the participant's family members. For each of the attempters it continues to be an issue that was never discussed by their families. Shannon said the only time her suicide attempt was mentioned was when a sibling engaged in self-cutting. It was then that Shannon's attempts were mention as being the blame for her sister's behavior. Each attempter expressed similarities with the lack of communication about the suicide attempts from their families as they commented (see Table 11). 


\section{Theme \#6: Tragic Losses}

Relational, social, work, or financial loss is a risk factor that influences suicide attempts (U.S. Public Health Service, 1999). It can be concluded that tragic events that lead to suicide were found in each of the stories. To loose a loved one or all of one's possessions as well as a best friend is a tragic loss. These attempters experienced all of the previous losses. Two of the three attempters, Jacquelyn and Shannon, had tragic events to occur in their lives that influenced their decisions to attempt suicide. Both women felt devastated and turned to suicide as a way out of their pain.

Two of the three attempters shared tragic losses. Jacquelyn had a number of tragedies such as the death of her mother a year before her husband died and a fire the year after he died that consumed her house. She had no insurance and consequently lost everything. These tragedies, paired with her clinical diagnosis, were almost lethal. Even though we discussed her drug abuse and drunk driving in the context of mental health issues, this was probably an unconscious attempt to end her life, to ease the pain of her losses, and to escape. All of the losses occurred consecutively for 3 years starting with the death of her mother. See Table 12 for the excerpt from Jacquelyn's story.

Shannon agrees with Jacquelyn about escaping and also related some tragic occurrences in her life. Her tragedies were compounded by rape, a pregnancy that followed that violent act, and the death of a baby girl after carrying her for 6 months. In the midst, after and up until this time, no one in her family has acknowledged the pain she felt from any of these traumatic incidences. Later she was again disappointed by what she considered a tragic loss, her sister leaving home, and not taking her as promised. What Shannon says in her story is presented in Table 13. 
Table 10

Family and Childhood Dynamics

\begin{tabular}{|c|c|c|}
\hline Jacquelyn & Shannon & Judye \\
\hline $\begin{array}{l}\text { "I had difficulty } \\
\text { getting along with my } \\
\text { parents. I don't know } \\
\text { what age it started but } \\
\text { it seems to me like it } \\
\text { was always that way. } \\
\text { My values were } \\
\text { different from theirs. } \\
\text { I was interested in } \\
\text { things they weren't } \\
\text { [interested in]. My } \\
\text { parents were prejudice } \\
\text { against people for a } \\
\text { lot of reasons, It could } \\
\text { be race, it could be a } \\
\text { different type of job, } \\
\text { and it could be } \\
\text { income. My family } \\
\text { just seemed to focus } \\
\text { so narrow." }\end{array}$ & $\begin{array}{l}\text { "My childhood was boring, I } \\
\text { can't really remember any } \\
\text { of it. My father was a very } \\
\text { angry man. I do remember } \\
\text { that from my childhood. He } \\
\text { was a policeman ... being a } \\
\text { policeman, I am sure he } \\
\text { encountered horrible things. } \\
\text { He would come home and } \\
\text { get mad at us. My mother.. } \\
\text {. she had a nervous } \\
\text { breakdown. Being the } \\
\text { oldest girl I took care of all } \\
\text { of the kids. I raised Johnny } \\
\text { for two years; my mother } \\
\text { got pissed off when he } \\
\text { started calling me mom. } \\
\text { She was forty when she had } \\
\text { him. Anyway, no more of } \\
\text { that." } \\
\text { "I know my mother was a } \\
\text { big influence on my sister. } \\
\text { She never attempted but she } \\
\text { was a cutter. She would } \\
\text { take a razor or knife and cut } \\
\text { into her skin." } \\
\text { "But then when I was there } \\
\text { [at home] I decided, oh my } \\
\text { gosh. If I stay here I'm just } \\
\text { going to die. They are going } \\
\text { to suck the life out of me, if } \\
\text { I don't do it myself. This } \\
\text { happens in my family. } \\
\text { People get really sick they } \\
\text { get really depressed. My } \\
\text { mom just doesn't know } \\
\text { what it could be, but when } \\
\text { you move you get better." }\end{array}$ & $\begin{array}{l}\text { "I will start when I was a little } \\
\text { girl, when I was born. I think } \\
\text { this is important to tell } \\
\text { [because] there are a lot of } \\
\text { people out there like me and it } \\
\text { may have something to do with } \\
\text { depression or feeling inferior. I } \\
\text { didn't know this until a few } \\
\text { years ago. My mother took } \\
\text { thalomide. .. I don't blame her } \\
\text { in any way but as you know I } \\
\text { have [only] two fingers on my } \\
\text { right hand. I didn't know this } \\
\text { until a few years ago, here I am } \\
46 . \\
\text { "I didn't know that I was } \\
\text { different until I went to school } \\
\text { because my parents would treat } \\
\text { me like I was normal. When } \\
\text { the teacher would go and get ice } \\
\text { cream, there was a bully who } \\
\text { would come and get me out of } \\
\text { the room in first grade and } \\
\text { charge people a nickel to see } \\
\text { my hand. ... After I got my } \\
\text { psychiatric condition... I } \\
\text { learned that I am very passive. } \\
\text { Hopefully, I've changed but all } \\
\text { of the women in my family are } \\
\text { very passive so we really didn't } \\
\text { know how to take up for } \\
\text { ourselves." }\end{array}$ \\
\hline
\end{tabular}


Table 11

Lack of Family Communication About Suicide Attempts

\begin{tabular}{|c|c|c|}
\hline Jacquelyn & Shannon & Judye \\
\hline $\begin{array}{l}\text { "It was not something } \\
\text { that my family talked } \\
\text { about either with me } \\
\text { personally or among } \\
\text { themselves. I don't } \\
\text { know, uh, we never } \\
\text { talked about it." }\end{array}$ & $\begin{array}{l}\text { "I slit my wrist and took an } \\
\text { overdose at the same time. } \\
\text { My brother came and then my } \\
\text { mother and they all yelled. ... } \\
\text { I stayed in drug rehab for six } \\
\text { weeks [and] we did family } \\
\text { therapy too. The family } \\
\text { therapy didn't really work } \\
\text { because nobody wanted to talk } \\
\text { about anything." } \\
\text { "And then I went home and } \\
\text { they pretended like nothing } \\
\text { happened. Because I went } \\
\text { through this huge thing [rape, } \\
\text { loss of sight and baby] and } \\
\text { nobody will talk to me about } \\
\text { it. I don't have any help. } \\
\text { They still don't talk about it, } \\
\text { even now, it makes mom cry." }\end{array}$ & $\begin{array}{l}\text { "I guess sometimes it is } \\
\text { really difficult for the family. } \\
\text { A lot of times they are in } \\
\text { denial and they just can't } \\
\text { accept the fact that a family } \\
\text { member actually wants to } \\
\text { take their life... so it is } \\
\text { difficult for them. I don't } \\
\text { think my family has accepted } \\
\text { it to this day. You know it } \\
\text { was like with my father. Just } \\
\text { pull yourself up by the } \\
\text { bootstraps. My mother was } \\
\text { angry with me. I don't think } \\
\text { she accepted or realized it. I } \\
\text { think she was angry with me } \\
\text { because I had bothered this } \\
\text { doctor who intervened that } \\
\text { night. She thought I was } \\
\text { wasting his time. They never } \\
\text { made the connection." }\end{array}$ \\
\hline
\end{tabular}

Table 12

Tragic Losses for Jacquelyn

\begin{tabular}{|c|c|}
\hline Excerpts from the Story & Specific Losses \\
\hline $\begin{array}{l}\text { "So they did a little exploring and they found a spot on his liver. He } \\
\text { [my husband] died a few months later. That just devastated me. I } \\
\text { started drinking like there was no tomorrow. You know, and so, } \\
\text { um, I uh, went out one night. I had taken the car after I had been } \\
\text { drinking. And I remember very little of it because I was in a black } \\
\text { out [unconscious state]. I remember leaving home and then I } \\
\text { remember traveling. I just remember the accident. Fortunately, I } \\
\text { did not hit anyone. . . . I hit a pole and damaged my car [so] that it } \\
\text { couldn't operate. I looked up, my face had hit the steering wheel } \\
\text { [and] that in turn inflated the airbag. Before I know it, there is a } \\
\text { police car behind me. And so I got arrested for drunk driving." }\end{array}$ & $\begin{array}{l}\text { Mother died of } \\
\text { lung cancer } \\
\text { Husband died of } \\
\text { liver cancer } \\
\text { House with all of } \\
\text { her possessions } \\
\text { burned with no } \\
\text { insurance }\end{array}$ \\
\hline
\end{tabular}


Table 13

Tragic Losses for Shannon

\begin{tabular}{|c|c|}
\hline Excerpt from the Story & Specific Losses \\
\hline $\begin{array}{l}\text { "When I was a freshman in high school. When I } \\
\text { was with one of my friends we skipped out on a } \\
\text { football game that we had been dropped off at and } \\
\text { went to a drinking party down the road. On the } \\
\text { way back, uh, we were beaten up and raped. They } \\
\text { held us down; they actually tried to set me on fire. } \\
\text { They burned my wrist, and stabbed me several } \\
\text { times. I lost my eyesight. My eye got pulled out of } \\
\text { my socket and [they knocked a] crack in my head. } \\
\text {. Lots of stitches, but sight came back and it was } \\
\text { in the left eye, not the right [eye]. And you know } \\
\text { that's a huge event in your life... and nobody } \\
\text { wanted to talk about it especially not the family. } \\
\text { And they didn't want anybody else to know like } \\
\text { their friends and stuff because it was a big shame } \\
\text { thing. I don't know I don't get that. Some people } \\
\text { are like that." }\end{array}$ & $\begin{array}{l}\text { Violation of personhood } \\
\text { through rape } \\
\text { Loss of eye because of the } \\
\text { violent rape } \\
\text { Loss of child from the rape } \\
\text { because of the cocaine use } \\
\text { during the time of the baby's } \\
\text { development } \\
\text { Her sister left with her } \\
\text { boyfriend and with her friend } \\
\text { from church after promising } \\
\text { she would take Shannon with } \\
\text { her. }\end{array}$ \\
\hline $\begin{array}{l}\text { "But then I was fourteen when I started doing } \\
\text { cocaine. I got pregnant from that [the rape]. I } \\
\text { carried that baby for about six months and then she } \\
\text { was spontaneously aborted. That's what they call } \\
\text { it. It's a miscarriage but you are so far along that } \\
\text { it's a live birth. But it was cocaine induced." }\end{array}$ & \\
\hline $\begin{array}{l}\text { "What kind of triggered that [the second attempt] } \\
\text { was this sister who had said, oh, I promise, if I go } \\
\text { you can come with me. I promise I won't leave } \\
\text { you in this horrible house with these horrible } \\
\text { parents. Then she moved away to Arizona to chase } \\
\text { some guy named Jack who looked like Tom Cruise. } \\
\text { I She went with one of her friends from church. } \\
\text { I was really, really mad and disappointed. I took } \\
\text { pretty much the whole cabinet." }\end{array}$ & \\
\hline
\end{tabular}


To conclude this section on themes that are risk factors, the Surgeon General's Call to Action to Prevent Suicide (U.S. Public Health Service, 1999) cites several studies that establish suicide risk. Risk factors tend to increase the potential for suicide and suicidal behavior (Blumenthal \& Kupfer, 1988; Felner \& Silverman, 1995). These risk factors certainly increased the likelihood for these attempters to act against themselves in trying to end their lives.

Being aware of the risk factors increases awareness, and possible prevention of suicide is important in the study of suicide prevention. Hennriksson et al. (1993) state that understanding risk factors can help dispel the myths that suicide is a random act or results from stress alone. In this study, it was found that these attempters did not arbitrarily attempt suicide or act from stress alone, but a combination of factors caused the attempters to feel that death was their only choice. As cited in the literature by Satcher (U.S. Public Health Service, 1999), risk factors include the following, among others:
a. Previous suicide attempts
b. Mental disorders, particularly mood disorders such as depression and bipolar disorders
c. Co-occurring mental and alcohol and substance abuse disorders
d. Family history of suicide
e. Hopelessness
f. Impulsive or aggressive tendencies
g. Barriers to accessing mental health treatment
h. Relational, social, work, or financial loss
i. Physical illness
j. Easy access to lethal methods, especially guns
k. Unwillingness to seek help because of the stigma attached to mental and substance abuse disorders and/or suicidal thoughts
1. Influence, through direct personal contact or inappropriate media representations, of significant people, family members, celebrities, peers who have died by suicide
m. Cultural and religious beliefs like the belief that suicide is a noble resolution of a personal dilemma 
n. Local epidemics of suicide

o. Isolation or a feeling of being cut off from other people. (p. 8)

Four of the themes on risk factors in this section were found in the literature: (a) previous suicide attempts, (b) mental disorders, (c) alcohol and drug abuse, and (d) tragic losses. Two of the themes on risk factors were found in this research study. These themes include (a) family and childhood dynamics and (b) lack of family communication about the suicide attempts.

\section{Summary of Risk Factors Themes}

Previous attempts are the first risk factor found in this research. Two of the attempters had attempted to end their lives on three occasions. Previous attempts put the attempters at a high risk and can be fatal. Mental disorders is the second theme; all three of the attempters have been diagnosed with a mental disorder. Depression and bipolar disorders are common in suicide attempters and, if left untreated, can lead to death. Alcohol and drug abuse is the third theme and is common among suicide attempters. Use of these substances helps the person to dull the pain or escape from unbearable situations. Judye said, "It dulled the pain."

The fourth theme is childhood and family dynamics, which plays a major role in the development of the child and increases the possibility of future attempts as noted in the cases of these attempters. Two of the attempters had families that created an environment of anger and frustration to the point of strongly influencing them to attempt suicide. Shannon is quoted as saying, "People get sick if they stay home, but get well, when they leave home. I don't think my mother knows this." 
Lack of family communication is the fifth theme and was a problem for all of the attempters. All three attempters expressed that they never had any family communication about their attempts. Instead, neither their feelings nor the act of attempting to take their lives were acknowledged. Jacquelyn said, "We didn't discuss anything." Shannon said it was mentioned when she was blamed for her sister's skin-cutting behavior, but not in the context of empathy or sympathy.

A tragic loss is the sixth theme that was seen in the lives of Jacquelyn and Shannon. Jacquelyn lost her first husband through abandonment, when after an abusive relationship of 2 years he left her on the highway. At the time of her second marriage, her mother died of lung cancer and a year later her husband died of cancer. The subsequent year after her husband's death, her uninsured house burned to the ground with all of her earthly possessions. It was shortly after these events that she attempted to take her life.

Shannon was violated through rape and was almost killed during that brutal act. She lost her sight in both eyes but later recovered her sight in the right eye. She suffered a cracked skull, was set on fire, and became pregnant from this rape, but she later lost the baby. Her family never talked about any of the tragic events or asked how she felt. She attempted to take her life after these tragic losses. These risk factors were influential in the attempt of suicide by the participants in this study. Six themes emerged in this section on risk factors. Four of the themes match the literature and two themes were found in this research. 


\section{Protective Factors}

It is of some theoretical and practical interest that research has revealed many risk factors for the expression of aggression but fewer protective factors. In the framework for suicide prevention in the Surgeon General's Call to Action to Prevent Suicide, the protective factors are fewer than the risk factors. As cited in the literature, protective factors have the potential to prevent suicide (U.S. Public Health Service, 1999). Theme 7, being responsible for self-care, and Theme 8 , positive relationships, matched the literature.

Theme 9, keeping busy helping others, and Theme 10, recreation, were found in this study. Some protective factors are shared by all of the women in this study while others are specific to the individual (see Figure 1). These are the protective factors that surfaced as themes in this study.

\section{Theme \#7: Being Responsible for Self-care}

Being responsible for self-care involves staying on medication and ongoing, supportive health care relationships. Taking care of themselves involves regular checkups for good mental and physical health. Positive resistance to one suicidal period does not have a permanent effect, so programs that support and maintain protection against suicide should remain ongoing (U.S. Public Health Service, 1999). Women are caretakers by nature however, it is important that women take care of themselves mentally and physically. In each case the attempters have been involved in continuous self-care. Their comments are shown in Table 14. 


\begin{tabular}{|c|c|c|}
\hline $\begin{array}{l}\text { Jacquelyn's } \\
\text { Protective } \\
\text { Factors }\end{array}$ & $\begin{array}{l}\text { Shannon's } \\
\text { Protective } \\
\text { Factors }\end{array}$ & $\begin{array}{l}\text { Judye's } \\
\text { Protective } \\
\text { Factors }\end{array}$ \\
\hline & & 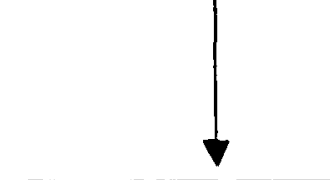 \\
\hline $\begin{array}{l}\text { Attend Alcoholics } \\
\text { Anonymous, and Over- } \\
\text { Eaters Anonymous } \\
\text { meetings } \\
\text { Surround my self with } \\
\text { positive people } \\
\text { Engage in positive self- } \\
\text { taik } \\
\text { Hobbies to occupy self } \\
\text { with a creative outlet } \\
\text { such as knitting, pottery, } \\
\text { painting. } \\
\text { Being the caregiver for } \\
\text { my animals } \\
\text { Having a goal to } \\
\text { complete college } \\
\text { Employment }\end{array}$ & $\begin{array}{l}\text { Being in a relationship } \\
\text { with my partner } \\
\text { Being the caregiver for my } \\
\text { dog } \\
\text { Being the mother figure for } \\
\text { my needy friend } \\
\text { Writing poetry } \\
\text { Sister } \\
\text { Family } \\
\text { Shared Protective Factors } \\
\text { Staying in compliance with } \\
\text { their medication } \\
\text { Regularly scheduled visits } \\
\text { with their psychiatrists } \\
\text { Ongoing therapy } \\
\text { Recreation. hobby, or } \\
\text { outlet } \\
\text { Having positive friendships } \\
\text { Keeping busy helping } \\
\text { others }\end{array}$ & $\begin{array}{l}\text { Religion-faith and } \\
\text { belief in God } \\
\text { Working on } \\
\text { recovery continually } \\
\text { Working on a } \\
\text { journey } \\
\text { Appointing my } \\
\text { family as guardian if } \\
\text { I become unable to } \\
\text { make decisions } \\
\text { about my mental } \\
\text { health } \\
\text { Permission given to } \\
\text { my doctor to } \\
\text { hospitalize me if } \\
\text { necessary }\end{array}$ \\
\hline
\end{tabular}

Figure 1 . Individual and shared protective factors. 
Table 14

Being Responsible for Self-Care

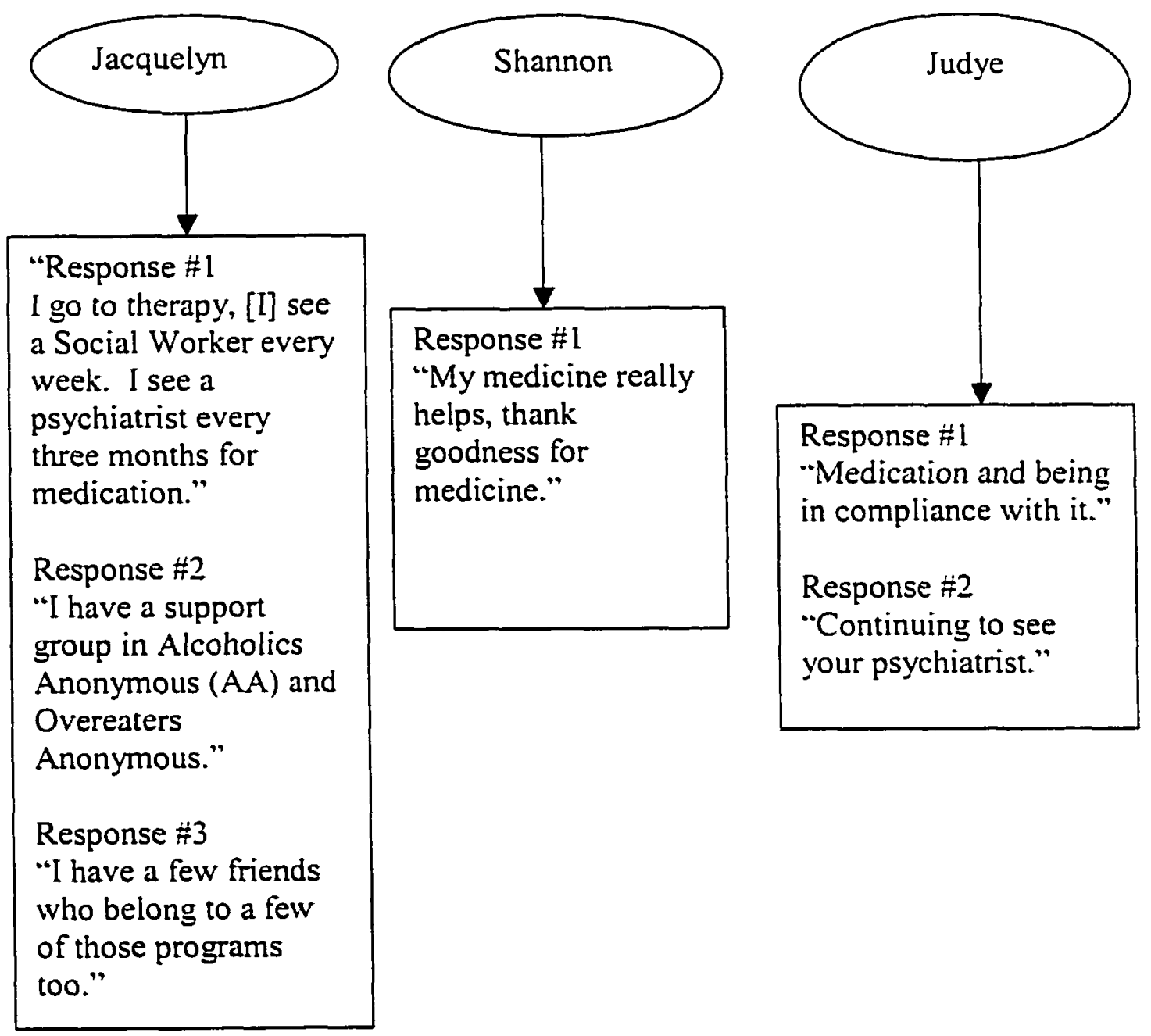




\section{Theme \#8: Positive Relationships}

Research has shown that positive relationships are a protective factor just as a negative relationship can be a risk factor (U.S. Public Health Service, 1999). Negative abusive relationships are a risk factor for suicide attempts just as positive relationships are a protective factor. One of the women in this study was involved in a relationship that was so abusive that it caused her to attempt to take her life with aspirin. It can be concluded that women in abusive relationships are high risk for suicide. All of the women believe that positive relationships are important in keeping a balanced self and deterring suicide attempts. Across the three cases, all three attempters said that positive relationships were a protective factor for them. The following table presents the responses of each woman.

Table 15

Positive Relationships

\begin{tabular}{|c|c|c|}
\hline Jacquelyn & Shannon & Judye \\
\hline 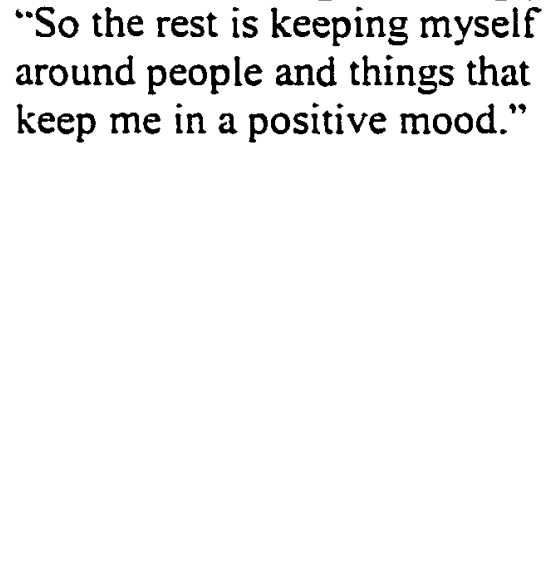 & Gloria [my partner]. & $\begin{array}{l}\text { "Friends are very } \\
\text { important. Having a few } \\
\text { friends that know you well } \\
\text { enough and that you know } \\
\text { that you can call at } 1: 00 \\
\text { o'clock in the morning or } \\
\text { whatever, and they are } \\
\text { going to be there. } \\
\text {.. The network system } \\
\text { and friends and staying in } \\
\text { some type of recovery } \\
\text { program is important." }\end{array}$ \\
\hline
\end{tabular}




\section{Theme \#9: Keeping Busy Helping Others}

Keeping busy helping others is a theme that emerged as the participants for this study were being interviewed. The participants all saw a need to be involved in a network of helping others. In some instances hopelessness and uselessness can be seen in the stories of the attempters. It is important that these women be actively engaged in being helpful and engaging in activities that make them feel useful to others. This "helping others" also includes caring for animals. Table 16 presents what they articulated.

\section{Theme \#10: Recreation}

Recreation is expressed as having a creative outlet or hobby. The attempters articulated that they have a need to be busy but creative at the same time. Jacquelyn has an interest in crafts and fine art, Shannon writes poetry (see epigram at the beginning of chapter 5 before the introduction), and Judye considers school her hobby. Healthy body, healthy mind, and healthy outlets are necessary for these women to stay on a positive course in their lives. Recreation is important to keep their minds occupied with positive, enjoyable creative activities. Table 17 presents how they described their recreation.

The framework for suicide prevention includes the following protective factors: (a) effective and appropriate clinical care for mental, physical, and substance abuse disorders; (b) easy access to a variety of clinical interventions and support for seeking help; (c) restricted access to highly lethal methods of suicide; (d) family and community support; (e) learned skills in problem solving, conflict resolution, and nonviolent handling of disputes; and ( $f$ ) cultural and religious beliefs that discourage suicide and support self-preservation instinct. 
Table 16

Keeping Busy Helping Others

Jacquelyn

"Mostly volunteering [is

my hobby.

"In the past I have

volunteered, in the past when I wasn't working. I like to do volunteer work it keeps me positive."

"Part of my living is helping others."

"I love animals and I spend a lot of time with them. I had these two strays that showed up and I worked and worked until I found out that they belonged to a doctor in Murfreesboro. I am hoping that I might be able to do this more and more. It's real exciting."

\title{
Shannon
}

\author{
There is an individual \\ who works here who \\ has recently been \\ discussing suicide a \\ great deal and has \\ decided that she will \\ go into the garage, \\ turn on the car, and go \\ to sleep forever. She \\ said the only reason \\ she didn't do it is \\ because of her cat and \\ her father who she \\ takes care of. That's \\ the only thing holding \\ her. So people like \\ this person. I did \\ discuss this with my \\ director who has \\ already stepped in.
}


Table 17

Recreation

Jacquelyn

"I like to do a lot of handwork, like needle point. crocheting, and sewing. I've done some painting and pottery, these are some classes I've taken in school."

\begin{tabular}{|l|}
\hline \multicolumn{1}{|c|}{ Shannon } \\
\hline $\begin{array}{l}\text { "I write poetry. } \\
\text { my writing is } \\
\text { my outlet." }\end{array}$ \\
\\
\hline
\end{tabular}

"I'm trying to get into reading, I don't know if you consider school a hobby." 
Two of the themes on protective factors in this section were found in the literature. These themes are (a) being responsible for self-care and (b) positive relationships. Two additional themes were found in this study: (a) keeping busy helping others and (b) recreation.

\section{Summary of Protective Factor Themes}

Protective factors, such as being responsible for self-care and being involved in positive relationships, were found in the literature and help to strengthen the research. Theme 7, being responsible for self-care, is important for the attempter. The attempters all agreed that being in compliance with their medication and keeping regularly scheduled appointments with their psychiatrists or social workers were necessary to protect themselves from becoming suicidal. Shannon is quoted as saying, "My medicine really helps, thank God for medicine."

Theme 8, positive relationships, is another important protective factor. Attempters realize that it is also necessary to remain in positive relationships that facilitate healthy social outlets. Jacquelyn is quoted as saying, "Keeping myself around positive people and things that keep me in a positive mood."

Additional protective factors that were found in this study are Theme 9 , keeping busy helping others and Theme 10 , recreation. The attempters expressed that they have a need to help others, including animals. Helping someone else gives the attempters stability and the feeling of being needed. Judye expressed her excitement about helping to find the owners of lost animals.

Theme 10 dealt with recreation as a creative outlet, whether it is inside or outside, is a positive activity for attempters. Keeping the mind and body active is a protective 
measure for these attempters. Jacquelyn likes to stay busy with crafts, Shannon writes poetry, and Judye says school is her outlet.

\section{Impact of Failed Attempts}

The themes found in this section can be labeled "A bonus life." The attempters are grateful to be alive and never see life the same. This commonality pervades each of the suicide attempters' self-reports. The themes are discussed in the following sections.

\section{Theme \#11: Looking Beyond Themselves:}

\section{A Higher Power}

Alvarez (1970) believed that survivors of suicide attempts have a changed life.

with entirely different standards. Jacquelyn, Shannon, and Judye talked about looking beyond themselves and a Higher Power in the following way.

Jacquelyn, the first attempter to be interviewed, had many thoughts and questions in her mind about who she was and why she was here (on earth). She turned to religion for a while, but when the depression engulfed her she decided that life should end. When she did not complete suicide after three attempts this is what she said:

I believe in God, I believed God was good and helpful. I didn't know why I was not able to figure things out for myself or at least over a period of earlier years. ... I held God responsible to some extent because I figured God had all of the answers. ... When I attempted suicide I felt totally abandoned. Although I didn't have a lot of anger at God, I just didn't understand. But then when the first attempt didn't succeed, the third attempt didn't succeed, I figured that's my help or part of it. That is my help not to succeed [at suicide].... I saw a lot of things in between [that] God was doing for me that I couldn't do for myself. . . .

Because I did not succeed, it really does show me that God really does care about me.... I am loved by the Universe and I can receive help from God and angels. 
Shannon attempted suicide three times and failed each time. Shannon says she has physical scars from all of the attempts. Because of the many scars and failed attempts she perceives her reasons for the attempts in this way:

Marks on the wrists. I was involved in a shooting. Well I shot myself. I'm not so proud of that but essentially I did shoot myself. So I've got scars, a bullet hole here (points to chest), a bullet hole in [my] back, a huge scar right here (again, pointing to her chest) where they took out my lung. It's amazing I took off part of my heart.... They said it was like the hand of God reaching down and saying, "Child, you're not going to do that." It was somebody; I did this in my family's bedroom with my father's gun. It's a miracle I'm even alive, let alone to be up and walking around with full use of my left arm, which had been paralyzed at the time. So God had some kind of action there. Either that or I really am a medical miracle and I don't think that's the case.... When you don't die it's, "Oh thank you God," and maybe I won't do that again.

Judy suffered a period of depression for about 2 or 3 weeks. During that time she

thought of suicide often. She reports that she drove up to the top of the mountain and thought about ending her life, but said with her luck she would probably end up as a cripple with her family taking care of her. She finally decided one night to end her life by using all of the narcotics she had received from her doctor. Judye was rescued, and this is what she says about that failed attempt:

I understand it was the grace of God. I feel, well, everyone has a purpose here on earth. Sometimes we learn what it is and sometimes we don't. But I feel that He [God] has shown me His reason for sparing me and for me being here today. I think He actually answered my prayer. I know He did when I said help me God. ... I am just grateful.

Jacquelyn, Shannon, and Judye have looked beyond themselves and feel that there was a Higher Power responsible for the failed attempts. They express gratefulness for being alive today. 
Theme \#12: An Inner Perspective: A Bonus Life

The attempters articulated what Shneidman (1976) refers to as a "bonus life. Shniedman suggests that sometimes death is intended and only fortuitously avoided. One's life after that, what has been called "a bonus life," is forever different. Life is never the same. Failed suicide attempts can lead to what is seen by some attempters as a new reason to live, or as one attempter stated it, "a mission." The following is what they articulated:

Jacquelyn describes her attempt as a near-death experience and says,

My suicide attempts were like a near death experience because I see it that way. I wasn't dead at all but I came that close [to dying]. I was willing to be dead and it made me see life as more precious. ... It just gives me more of an appreciation of what I have, more of an appreciation of what others have, and what others go through. ... I've always been sensitive to how other people feel or how I perceive they feel. My own attempts have made me even more aware of the seriousness. I pay more attention to what people say and take it more seriously. They've [my attempts] helped me to see and attest to the value of my life. I care about the value of everyone else's life and then I forget about me. I am alive today for reasons, I can't tell you. I feel I'm very fortunate.

Shannon says,

It made me a far more colorful person. How many people do you know who have been shot? Some people see these scars on my wrists; they automatically say "Oh, yeah, you've done" that [and] they want to share ... concern for other people, like my friend here at work. I said, "Gee, Joann, I'm really worried about you. You keep talking about this so much." Depending on what they say, I have no problem telling them that ['ve done that [attempted suicide]. I'm sorry I did that. It hurts [and] I would not recommend it to you.

Shannon also says that the day she slit her wrist and went into rehabilitation was a new beginning of life for her. This is how she expressed it:

I'm not on drugs and I am not drinking anymore. I'm not doing all that stuff. Hey, I feel better. So I decided that I was going to celebrate my birthday, the day that I had slit my wrists and gone into rehabilitation. So I don't celebrate it in March. I celebrate it in April. My mother thinks it's weird, but it's like a rebirth. 
Judye expresses herself in this way:

Every illness is the same, it affects everybody spiritually, mentally, emotionally, and psychologically. I think people share their hope, strength. and experiences, which I got out of Alcoholics Anonymous (AA). And this is what I am trying to do [share my experiences], which is my mission. There is a passage that says showing others that suffer how we were given help is the very thing which makes life worthwhile to us now and is the key to life and happiness for others. With it [the key] you can avert death and misery for them. So I feel like with sharing my story and talking to people, hopefully I can avert some death and a lot of misery. I view life differently. Little things can bring joy. When I pull the shade there is a little Holly tree that is just precious to me. I have a peace lily plant and it just blooms and blooms. The other night when I came in, God drew me to it and it had another bloom. I notice things now that I wouldn't have noticed earlier.

\section{Summary of the Impact of the Failed Attempt}

These Caucasian females who attempted suicide and survived now have a new inner perspective (see Figure 2). They attribute their being alive to a Higher Power. They see a divine intervention in their suicide attempts. The defeats were real. the losses were painful, and the death wish was aborted. They feel that it was not meant to be, it was not their time, and they now look beyond and within themselves.

A bonus life, a rebirth, a new beginning, these are all expressed by the suicide attempters in this research study. Eisner (1991) says qualitative research should bring out empathy. As the researcher I empathize with the participants in the study, but I also rejoice with them because they lived to tell their stories. These women notice more, see more, feel more, and know more. Shannon referred to her failed attempt as a rebirth, Judy refers to hers as a mission, and Jacquelyn has found some of the answers to her questions and lives to find new ones each day. With this awakening they now realize they have "a bonus life" (see Figure 2). 


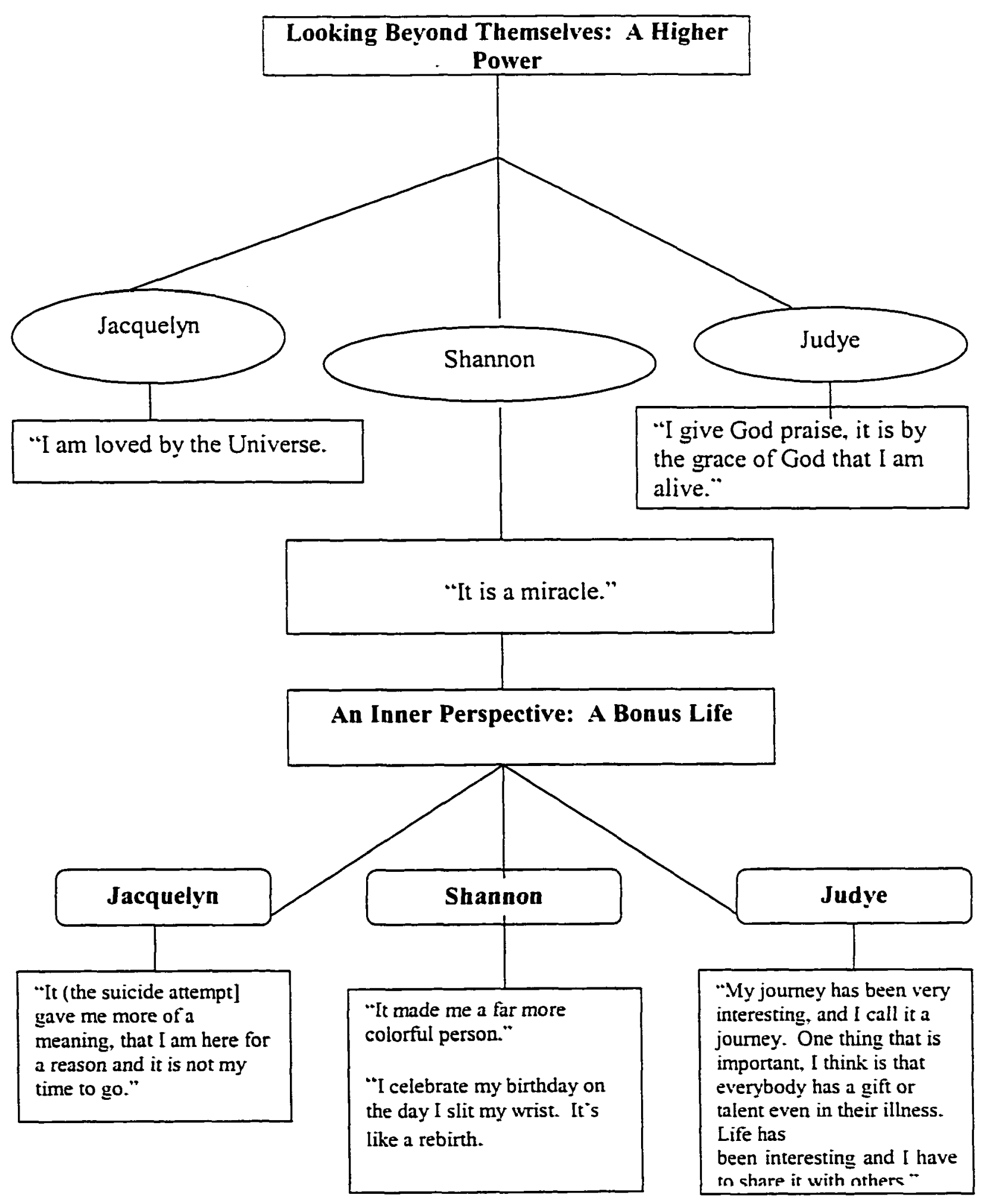

Figure 2. Looking beyond themselves: A higher power. 


\section{CHAPTER 6}

\section{SUMMARY, FINDINGS, DISCUSSION, CONCLUSIONS, AND RECOMENDATIONS}

The last enemy that shall be destroyed is death.

-1 Cor 15:26

\section{Introduction}

This final chapter presents a summary of the study, discussion of the findings, conclusions, and recommendations proposed as a result of the findings. The summary includes an overview of the problem, the literature review, the methodology utilized in the study, and a review of the data findings.

\section{Summary}

\section{Statement of the Problem}

According to Hoyert, Smith, Murphy, and Kochanek (2001), suicide ranks as the 11 th leading cause of death in the United States. Nationwide, 29.350 people take their lives annually through the act of suicide. Further studies by Hoyert et al. (2001) estimate that 5 million living Americans have attempted to kill themselves. Females account for 5,732 of that number, and Caucasian females account for 5,182 of that number, representing $90 \%$ of all females. The study of Caucasian female suicide attempters has not received due attention from suicidologists. 
Therefore, this study aims to bridge an important gap in knowledge about suicide and suicide attempters. By studying the following factors of Caucasian female who have attempted suicide: (a) the risk factors for attempting suicide, (b) the impact that the failed attempt(s) have on the life of a suicide attempter.

\section{Purpose of the Study}

The purpose of the study is to examine the risk factors of Caucasian female suicide attempters, the protective factors of Caucasian female suicide attempters, and the impact of failed attempt(s) on Caucasian females who attempt suicide in order to provide clinicians with the implications for prevention and intervention.

\section{Overview of the Literature}

The literature reviewed covered several areas related to the study of suicide and suicide attempts. The literature review began with the origin of the word "suicide," first coined in 1642 by Sir Thomas Browne. Suicide carries a variety of connotations, depending upon its specified philosophical, psychological, and sociological purposes (Aggarwal et al., 1994).

Included in the literature is The Surgeon General's Call to Action to Prevent Sticide (U.S. Public Health Service, 1999), a model for suicide prevention. This framework encased the risk and protective factors that prevent suicide. Risk factors tend to increase the potential for suicide and suicidal behavior, while protective factors tend to reduce potential for suicide (Blumenthal \& Kupfer, 1990; Felner \& Silverman, 1995; Silverman \& Maris, 1995).

Variations on suicide rates show that there are racial, gender, and age differences 
in suicide rates. Men commit suicide more than women, but women attempt suicide more than men. Elderly White males have the highest rate of suicides, White females are the next highest, and suicide for youth ages 15 to 25 years is the third leading cause of death.

Perspectives on suicide are paramount to the understanding of suicide. Within the psychiatric and psychological perspectives, Freud (1917/1963) and Menninger (1966) standardized psychiatric and psychological types of suicides. French Sociologist Emil Durkeim influences the sociological perspective on suicide. He concluded that increased community improvement reduces suicidal risk. A hundred years later, that observation continues to influence and inform effective suicide prevention and community intervention programs (Weir, 2001).

Within the perspective of suicidology, suicidological subject matter includes information on completed suicides, nonfatal suicide attempts, suicidal ideation, and/or indirect self-destructive behaviors and parasuicides (Maris et al., 2000). Research and study of voluntary death with the goal of preventing suicide are what suicidology encompasses. Suicidology is defined as the scientific study of suicide and suicide prevention (Shneidman, as cited in Maris, 1993).

The religious perspective on suicide includes the writings of Styron (1990), who espouses that the historical and religious view of suicide as shameful has predominated society. Poussaint and Alexander (2000) cite that cultural perspectives on suicide show that some cultures have tolerated instances of self-destruction. In ancient Greece, Socrates accepted a cup of hemlock.

Ethical and legal perspectives are cited in the literature review. On November 4, 
1994, Oregon became the first state in the United States to permit a doctor to prescribe lethal drugs expressly and explicitly to assist in a suicide death (Maris, 1992). Ethically, it is up to the individual to decide. Legally it has been accepted in some courts of law. As Drinan (1994, cited in Roleff, 1998) says, "Only God can decide" (p. 29). In the end, law cannot really resolve the complexities of a situation that involves religion, ethics. medicine, and what people think of the ultimate mystery of human existence.

Literature and art themes point to the fact that many literary works have included suicide as its centerpiece by writers such as Hamlet and Shakespeare among others.

Perspectives on mental illness are important in understanding suicide. The phenomenon of suicide has attracted the attention of a wide variety of medical and social disciplines (Venkoba, 1992). Suicide usually involves some form of mental illness, and every demographic group seems to grapple with suicide and suicide attempts as a serious medical issue (Brent et al., 1993; Shaffer et al., 1994).

Depression and other mental illnesses play a role in the completion and attempt of suicide. The suicidal person suffering from depression typically undergoes severe emotional and physical strain (Dubovsky \& Weissberg, 1983). When this illness goes untreated, it becomes more difficult for the individual to see life as worth living and can therefore lead to serious consequences such as suicidal thinking, attempts, or eventual death.

A discussion of the main focus of this research, suicide attempting, is included in the literature review. As tragic and commonplace as suicide is, we know little about what it feels like. Heckler (1994) points out that we cannot bring the dead back to life and ask them about their pain and sorrow. However, we can look at the suicide attempter, the 
risk, and protective factors and try to prevent the loss of life. Often suicide attempters are seeking to establish some means of communication with significant people in their lives (Rubinstein et al., 1958).

Lastly, the literature review ends with the connection between suicide attempts and manipulative behavior. The word "threat" often connotes manipulation. It does not appropriately describe the majority of verbalized intentions regarding self-harm (Berman \& Jobes, 1991). Every statement about suicide should be taken seriously. Suicidal behavior is both a communication itself and a consequence of failures in more adaptive attempts to communicate. Rudestam (1971) and Brent, Bridge, Johnson, and Connolly (1998) state that, in four of five suicide attempts, the attempter has tried to warn others of his or her attempt through a range of behaviors such as direct verbal statements about suicide. The literature ends with Heckler (1994) further pointing out that listening to those who have decided to end their lives provides some answers to the question. "Why?"

\section{Methodology}

For this research a descriptive case study design was utilized. Three suicide attempters who had attempted suicide one or more times in the past was the sample population for this study. Structured and unstructured interviews were administered to the participants. Interviews were audiotaped, transcribed, and analyzed for common themes.

\section{Findings}

The three research questions that were set forth in the beginning of this research are as follows: 
1. What are the risk factors for attempting suicide?

2. What are the protective factors for the prevention of attempting suicide?

3. What is the impact of the failed attempt on the life of the attempter?

These questions were answered in the emerging themes that capture both risk and protective factors and the impact of the failed attempt on the lives of the attempters.

Twelve themes emerged in this research study. The first six themes answer question \#1 on risk factors in the first set: (1) previous suicide attempts, (2) mental disorders, (3) alcohol and substance abuse, (4) family and childhood dynamics, (5) lack of communication about the suicide attempt, and (6) tragic losses. Themes 1,2 , and 3 strengthen the research cited in the literature review on risk factors. Theme 4, Family and Childhood Dynamics, was a finding in this study. Negative family functioning can influence the suicide attempter as seen in the responses from the attempters. Theme 5. Lack of Family Communication about their feelings and the attempts, can heighten feelings of depression that can lead to suicide. These six themes also answer the first research question on risk factors. (See Tables $3,4,5,6,7,8,9,10,11,12$, and 13.)

Four themes answer question \#2 on protective factors in the second set: (7) being responsible for self-care, (8) positive relationships, (9) keeping busy helping others, and (10) recreation. Themes 1 and 2 were found in the literature review and answer the second research question on protective factors. Themes 9 and 10 were found in this study and provide insight on the impact that the failed attempt had on the attempters and answers question \#3. These themes are (11) Looking Beyond Themselves: A Higher Power and (12) An Inner Perspective: A Bonus Life. (See Tables 3, 4, 5; Figure 1; and Tables 14, 15, 16, and 17.) 
At the beginning of chapter 5 , the researcher looked at themes of risk and protective factors already in the literature, as discussed in the summary. The findings . showed that positive relationships are very important (see Table 15). Therefore, women who are in an abusive relationship are not in a positive environment that can lead to suicide attempts, as in the case of Jacquelyn. Feeling trapped in an abusive relationship can influence a person to attempt to take his or her life. The story of Jacquelyn highlights this finding, as seen in this excerpt from her story about her abusive relationship that caused her to attempt suicide (see Table 7):

When I was working at the Chicago State Hospital, I started dating a guy that was an $x$-ray technician. He was a handsome guy, kind of suave. you know. He paid me attention and I liked that, you know? Well it turns out (and a lot of this I didn't recognize at the time) I'd see signs but I'd overlook it. So we began an intimate relationship and he was abusive. He was verbally abusive, sometimes physically or sexually abusive. But at that point my identity was so wrapped up in his identity that I felt I couldn't live without him. But of course I had trouble because it was part of me that knew something was wrong and was really unhappy with the relationship. I would try to get him to go for help because he needed it. He would sometimes go to therapy and then he'd stop. He kind of had a drug and alcohol problem too, and the two of us as a combination were kind of deadly too. [When he stopped therapy] I'd think oh not that again. Anyway we had moved to Seattle and I took a handful or aspirin. I just, oh what had happened was. He was in the kitchen; I was sitting in the living room he threw a coffee cup at me and he told me afterwards he was aiming at my face but the distance and how he threw it landed it and hit my knee and cut my knee. So I just took a hand full of aspirin. I couldn't go through this anymore. I didn't want to live like this anymore. So I went to the hospital and I just, you know, was cold, I had a reaction to the aspirin, it lowered my body temperature too much. I just wanted out altogether because I couldn't leave him or I didn't know how to leave him. So suicide seemed to be the way out of everything because everything looked so dark.... So the police asked me if I took the pills because I was trying to get back at him for what he had done. I said no, I was trying to kill myself. He asked me again and I told him "no" I wanted to kill myself. Then I went home.

Even though the relationship was abusive, she felt enmeshed and could not seem to free herself from the relationship except through death. Thus, she attempted to take her life. This finding was not cited in the literature; however, it has implications for 
women's issues on domestic violence and battered women. At one point, Jacquelyn went on to say (see Table 7):

I left but we would call and write each other. I could not get out of the relationship, I couldn't. I left twice and couldn't, just couldn't stay away. I think once it was close to a year. I'd talk to him on the phone and we'd write. I finally went back to him I just could not leave him. I understand about battered women when they talk about well, why don't you just leave? You know I understand why they cannot leave cause [it was] like he was a part of me and I'd be cutting off a part of myself. As bad as it was, you know, I could not leave. So he finally left me.... We were in New York, he decided we were going to Mexico.... [Just] about [in ] Ohio he decides this is where I get out. He said, I don't want you with me anymore, just get out, just get out. I am going to go on.

In Jacquelyn's thinking the only way this unhealthy bond could be broken was through suicide. Fortunately for her, the abuser left her. This finding may be helpful in the study of women's issues and the relationship of suicide attempts to women in abusive relations.

\section{Discussion and Conclusions}

The discussion and conclusion of this research is based on the particular context and experiences of 3 Caucasian female suicide attempters in Tennessee. Twelve themes emerged from the experiences of Jacquelyn, Shannon, and Judye, themes that connect their stories and experiences with attempting suicide (see Tables 7, 8, 9, 10, 11, 12, 13, $14,15,16$, and 17$)$.

Previous suicide attempts, mental disorders, alcohol and drug abuse and family and childhood dynamics were cited in the literature as risk factors for suicide (U.S. Public Health Service, 1999). It can be concluded that individuals who have attempted suicide more than once have a greater chance of completing the act of suicide than one who attempts only once. Therapeutic groups for attempters and survivors at Crisis Centers are 
important for individuals who have experienced suicidal behavior.

In this study the women were diagnosed as having a mental disorder. It can also be also be concluded that the mental disorder influenced the attempt. Each of the persons was either not on medication or in-between medication trials when the attempts occurred (see Tables $3,4,5,6$, and 8 ). Regularly scheduled appointments are necessary to maintain good mental health. Alcohol and drug abuse are a major factor in suicide attempts. It can be concluded that alcohol and drugs are generally utilized to dull the pain but when they no longer give the desired effects the person may see suicide as a final alternative to end the pain (see Tables 6 and 8). It is important that these women attend self-help groups to encourage them to abstain from use of drugs and alcohol.

The family and childhood dynamics were negative in each case. Family members suffered from anger, depression, and other maladaptive behaviors that in some ways affected the attempters and eventually led to their self-destructive behavior. It could be concluded that when families are dysfunctional they create dysfunctional children in some cases and may affect their desire to attempt suicide (see Table 10). In some of these cases family therapy or individuals in the family could have benefited from individual therapy (see Table 11 ).

Two risk factors, lack of family communication about the suicide attempts, and tragic losses were found in this study (see Tables 11, 12, and 13). The participants in this study did not have open, honest, healthy communication with her family about their suicide attempts. It can be concluded that the lack of communication and acknowledgement of engaging in such an act leaves attempters feeling more isolated, demeaned, hopeless, and misunderstood. The cry for help continues to be overlooked. 
Family therapy classes could be of benefit to families that do not have skills in healthy family communication.

Tragic losses are overwhelmingly painful to anyone, however the losses in connection to the risk factors mentioned in this study create an existence so painful that suicide is seen as the only remaining choice (see Tables 12 and 13 ). It could be concluded that major or numerous tragic losses can be unbearable for the person therefore influencing them to believe that suicide is the answer to the pain of the loss.

Being responsible for self-care was cited in the literature as a protective factor for the prevention of suicide (U.S. Public Health Service, 1999). Women tend to be caretakers of others rather than themselves and often become overloaded but continue to take care of others and neglect themselves. Not only is it important for women to have regular visits with their mental health caregivers, it is important that they have regular physical check-up and total physical care (see Table 14).

Positive relationships, keeping busy helping others, and recreation were found in this study (see Tables 15, 16, and 17). Each of the women in this study felt that it was important to be involved in positive relationships. Sometimes women tend to be in negative relationships and remain in them for periods of time, or until their death by murder. Negative relationships tend to damage the woman's self-esteem or self-image. Many times the women will remain in the negative relationship because of their own insecurities, dependence, or fear of failure. Unfortunately, although the woman tries to please the negative person or abuser in this relationship it is never acceptable and the woman may feel that there is no use in continuing with life and attempt suicide. 
Counseling and relationship classes are helpful to individuals experiencing self-esteem problems (see Tables $3,4,5$, and 14).

Keeping busy helping others is important as a safe guard against suicide attempts (see Table 16). Because these women in some cases felt unimportant to others it was necessary that they found an issue, person or idea to connect themselves to. These entities have given them a sense of being useful to themselves and others. Idleness can cause depression whereas a positive action such as keeping busy helping others is a positive coping mechanism. Recreation is a protective factor that is often disregarded (see Table 17).

Women tend to focus on care of others, work and in some cases involvement in organizations. Women sometimes see themselves as too busy to engage in recreation. The women in this study see recreation as a way of relaxing, keeping themselves from idle depression and as a form of creativity. In conclusion recreation is important because it gives the person a special time to relieve stress and in some cases anxiety due to all work and no relaxation (see Table 17).

The last two protective factors were found in this study, looking beyond themselves: a Higher Power and an inner perspective: a bonus life. These women have learned to look beyond themselves to a Higher Power. Each realizes that it was something greater than themselves that helped them through their darkest times and brought them to a more positive time in their lives (see Figure 2). As they looked back over the events in their past lives they remarked, "it was the grace of God, the hand of God reached down and kept me and I did not succeed, it really does show me that God really does care" (Volume 2, unstructured responses). These remarks explain that they 
now look beyond themselves and instead to a greater power. Looking beyond themselves to a greater power is a positive coping mechanism that enables them to guard their lives more cautiously and to know that there is hope for a good life to be used in a positive manner (see Figure 2).

An inner perspective: a bonus life is the culmination of all that is good and has been learned by these women (see Figure 2). These women have looked within themselves and have determined that they are worthy, capable and valuable. Each new day brings with it the answers one was seeking, love, that one was looking for and peace that one of these women desperately sought. Each of these women now have a bonus life. They have been given another chance at life. They lived through the pain, losses. sickness, and hopelessness to arrive at a place of acceptance and courage. They accept their defeats and have the fortitude to continue to move on knowing that tomorrow may be the day that the answer comes.

\section{Recommendations}

This was not a comprehensive study of suicide attempters, because it reflected only 3 cases. This study on Caucasian female suicide attempters can be seen from numerous viewpoints. The study is merely a starting point in looking at this phenomenon in society. The following recommendations will be divided into research and practice and are provided as a basis for further study:

\section{Recommendations for Research}

1. A cross-cultural study should be conducted to compare suicide attempters across cultural boundaries and in different geographical locations. 
2. Further study should be conducted on attitudinal differences in people who attempt once as opposed to multiple attempts.

3. A study should be conducted on abused women and attempted suicide.

4. A further study should be conducted on male suicide attempts.

\section{Recommendations for Practice}

1. Therapeutic groups for attempters and survivors at Crisis Centers are important for individuals who have experienced suicidal behavior (see Tables $3,4, \& 5$ ).

2. Regularly scheduled appointments for individuals who are prescribed medication for diagnosed mental disorders (see Tables $6 \& 8$ ).

3. Self-help groups such as alcoholics anonymous are important for encouragement to abstain from alcohol (see Tables $6 \& 9$ ).

4. Family therapy and family dynamics classes for dysfunctional families who nced to learn healthy ways to communicate within the family (see Tables $10 \& 15$ ).

5. Relationship classes for women who have difficulty choosing positive relationships and also posses low self-esteem (see Table 15).

6. Membership in organizations that reach-out to others in need such a homeless or other groups that allow a person to feel useful (see Tables $15 \& 16$ ).

7. Involvement in exercise, correct diet, medical check-ups and activities that relax the mind and body (see Table 17).

8. Membership in an organization that renews the mind and inner being (see Figure 1). 


\section{APPENDIX A}

\section{INTEROFFICE E-MAIL AT THE CRISIS CENTER}

\footnotetext{
Reproduced with permission of the copyright owner. Further reproduction prohibited without permission.
} 
TO: $\quad$ All Crisis Staff

From: Janice Browne, Coordinator Tennessee Suicide Prevention

Re: Need of participants for graduate research

I am a graduate student at Andrews University in Berrien Springs, Michigan. I will be conducting research for my dissertation on suicide attempters. If you are interested, have any persons in your groups that are interested or know of anyone who is interested in participating in this study please ask them to contact me at my office number, (615) 741 2633, home number (615) 299-8720, or e-mail me at, brownej777@aol.com Thank you everybody. 


\section{APPENDLX B}

\section{LETTER TO PARTICIPANTS}

Reproduced with permission of the copyright owner. Further reproduction prohibited without permission. 


\section{Janice A. Browne 5124 Lickton Pike \\ Goodlettsville, TN 37072 \\ Phone (615) 2998720}

Dear Madam,

I am requesting your participation in a descriptive case study of suicide attempters. Your cooperation in this study will provide invaluable insight into ways of preventing suicide.

I will conduct the research project using a sixty to ninety minute one-time interview. I am also requesting your permission to include your personal profile in the dedicated section of the study, along with the interview.

If you are willing to be a participant in this study, please sign and date the attached consent form that I have mailed (faxed or delivered) to you. I will gather and handle information I receive from you in a confidential fashion. Also. I promise to protect your anonymity unless otherwise instructed by you.

I realize that you have an extremely busy schedule. However. I am hopeful that you will take some time from your busy schedule and complete the consent form. If you choose to fax this information. you may fax the form to me anytime day or night at (615) 299-8720, Sunday through Friday 12:00, Central Standard Time (The fax number is the same as my telephone number as listed above.).

I will travel to your location unless you choose to designate another location. Please let me know when I can begin the process. I look forward to hearing from you and thank you in advance for your wholehearted consideration in this very important study.

Sincerely.

Janice A. Browne

Attachment(s) 
APPENDIX C

CONSENT FORM

Reproduced with permission of the copyright owner. Further reproduction prohibited without permission. 
Researcher Janice A. Browne

Andrews University

School of Education

Department: Leadership

Berrien Springs, Michigan 49103

Topic of qualitative research study: A Descriptive Multiple Case Study of Caucasian Female Suicide Attempters: Risk and Protective Factors.

Purpose: This study will describe the thoughts, feelings, intent, and viewpoints of suicide attempters and the impact the attempt (s) has had on their lives. I propose to discover what attempters suggest for intervention and prevention, based on their personal battle with suicide.

Potential Benefits: Suicide is a cruel and devastating act for those who attempt, complete, or survive it. Suicide traumatizes millions of American who experience the loss of someone close to them. Therefore, this study will be beneficial to a variety of stakeholders including the researcher, subject(s), survivors, health care professionals, crisis intervention center personnel/volunteers, suicide prevention organizations, and society.

I will keep the information and data I collect during this investigation confidential. I will not disclose the identity of the participants the write-up of the study unless otherwise indicated by the participant.

Each participant will choose the location, home, office, or other location, of her involvement in the study. The interview process will consist of one face-to-face, tape recorded interview, lastingl -2 hours.

It is recognized that participation in this study is of a voluntary nature. The researcher or participant is free to withdraw at any time without penalty of prejudice. Because or the voluntary nature of participation there will be no form of payment, reimbursement of costs or other type of inducement for participation in the research.

Participants have the opportunity to ask questions and receive satisfactory answers before consenting to participate in this study. 
I hereby give consent to participate in this study:

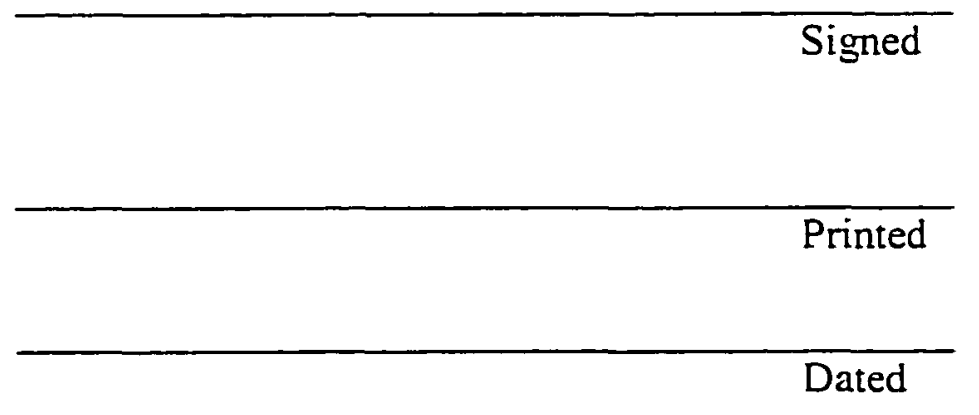

Please send me a report on the results of this research project. (Please circle one.) YES NO

Note: Criteria for this study: (1) Attempters of suicide; (2) Caucasian female; (3) Willingness to participate in study on suicide/suicide attempts. 


\section{APPENDIX D}

STRUCTURED INTERVIEIV: INTERVIEW GUIDE QUESTIONS

Reproduced with permission of the copyright owner. Further reproduction prohibited without permission. 
I am in the process of collecting data for a study that I am conducting through the Leadership Program at Andrews University. My topic is: A Descriptive Multiple Case Study of Caucasian Female Suicide Attempters: Risk and Protective Factors.

I want to talk with you bout your personal experience with suicide and your suicide attempt(s). I am asking your permission to record this interview for accuracy in data transcription. The personal information you share with me will be kept in the strictest of confidence and your identity will not be mentioned anywhere in the manuscript. I will keep your identity anonymous.

Because of the sensitivity of this subject, if you feel uncomfortable at any point and do not want to continue or need to take a break, please inform me and I will follow your instructions.

1. Are you feeling suicidal at this present moment?

2. Are you comfortable sharing this information?

3. How many times have you attempted suicide?

4. Do you have a clinical diagnosis that may have influenced you to attempt suicide?

5. Was substance abuse connected in any way to your suicidal attempt(s)?

6. Have any members of your family attempted or completed suicide?

7. Have any of your friends or significant others completed or attempted suicide?

8. Did your enter into a suicide pact with anyone at the time of your suicide attempt(s)?

9. Where you influenced by anyone in the media to make the suicide attempt(s)?

10. Did you discuss the attempt(s) with any family members or significant others?

11. Did you send any signals of your attempt? If so, what were the signals?

12. Why did you attempt to take your life and what were the circumstances surrounding your attempt(s)?

13. Will you attempt again?

14. Do you continue to have suicidal thoughts?

15. How do you perceive yourself as a person?

16. How has the attempt impacted the life of your family and others with whom you are associated?

17. How has the suicide attempt impacted your life?

18. What are your risk factors (triggers) for attempting suicide?

19. What are your protective factors that would keep you from attempting suicide?

20. Do you view life and death differently since your attempt(s)?

21. What kind of hobbies, creative activities, or other outlets do you engage in to safe guard against another attempt?

22. What do you think are the overall keys to sticide prevention that you can share with me in this study in order to help others?

23. Do you have any comments that you would like to add to this portion of the interview? 


\section{APPENDLX E}

THE UNSTRUCTURED INTERVIEW GUIDE: THE STORY

Reproduced with permission of the copyright owner. Further reproduction prohibited without permission. 
This is the story portion of my study. I want to hear your story.

Please tell me about your suicide attempt(s). If at any point you want to stop or make adjustments, I will grant your request.

Reproduced with permission of the copyright owner. Further reproduction prohibited without permission. 


\section{REFERENCE LIST}

\footnotetext{
Reproduced with permission of the copyright owner. Further reproduction prohibited without permission.
} 


\section{REFERENCE LIST}

Abrahamson, M. (1983). Social research methods. Englewood Cliffs, NJ: Prentice-Hall.

Adam, K. S. (1990). Environmental psychosocial and psychoanalytic aspects of suicidal behavior. In S. J. Blumenthal \& D. J. Kuper (Eds.), Suicide over the life cycle. Washington, DC: American Psychiatric Press.

Aggarwal, N. K., Bhatia, M. S., \& Aggarwal, B. B. L. (1994). Pattern of suicides in Northeast Delhi. Indian Journal of Social Psychiatry: 10, 20-22.

Ainsworth, M. (2002). If you are thinking about suicide read this first. Retrieved October 15, 2001, from http://www.mentanoia.org/suicide/

Albom, M. (1997). Tuesday's with Morrie. New York: Doubleday.

Al-Najjar, Y. (1978). Suicide in Islamic law. In H. Winnick \& L. Miller (Eds.), Aspects of suicide in modern civilization (pp. 18-23). Jerusalem: Academic Press.

Alvarez, A. (1970). The savage God: A study of sticide. New York: Random House.

Augustinus, St. (1952). The city of God: Books I-7 (Fathers of the Church Series, Vol. 8). Washington, DC: Catholic University Press.

Babbie, E. (1990). Survey research methods. Belmont, CA: Wadsworth Publishing Co.

Balch, B. J., \& O'Bannon, R. K. (2001). Why we shouldn't legalize assisted suicide. Retrieved from http://www.nrlc.org/euthanasia/asisuid.html

Barraclough, B., Bunch, J., Nelson, B., \& Sainsbury, P. (1974). Cases of suicide. British Journal of Psychiatry, 125, 355-373.

Beautrais, A. L., Joyce, P. R., Mulder, R. T., Fergusson, D. M., Deavoll, B. J., \& Nightingale, S. K. (1996). Prevalence and comorbidity of mental disorders in persons making serious suicide attempts: A case-control study. American Journal of Psychiatry, 153, 1009-1014.

Beck, A. (1963). Thinking and depression. Archives of General Psychiatrin; 324-326. 
Beck, A., Weissman, A., Lester, D., \& Trexler, L. (1974). The measurement of pessimism: The hopelessness scale. Journal of Consulting and Clinical Psychology. 42, 861-865.

Berg, L. B. (1989). Qualitative methods for the social sciences. Boston: Allyn \& Bacon.

Berman, A. L., \& Jobes, D. A. (1991). Adolescent suicide: Assessment and intervention. Washington, DC: American Psychological Association.

Berman, A. L., Leenaars, A. A., McIntosh, J., \& Richman, J. (1992). Case consultation: Mary Catherine. Suicide and Life-Threatening Behavior, 22, 142-149.

Bhatia, M. S. (1992). A dictionary of psychiatry, psychology; and neurolog: Delhi: CBS Publishers and Distributors.

Black, D. W., \& Winokur, G. (1990). Suicide and psychiatric diagnosis. In S. J Blumenthal \& D. J. Kupfer (Eds.), Suicicle over the life cycle. Washington. DC: American Psychiatric Press.

Blumenthal, S. J., \& Kupfer, D. J. (1988). Overview of early detection and treatment strategies for suicidal behavior in young people. Journal of Youth and Adolescence, 17, 1-23.

Blumenthal, S. J., \& Kupfer, D. J. (1990). An overview and synopsis of risk factors, assessment, and treatment of suicidal patients over the life cycle. In S. J. Blumenthal \& D. J. Kupfer (Eds.), Suicide over the life cycle: Risk factors. assessment, and treatment of suicidal patients. Washington, DC: American Psychiatric Press.

Bogdan, R. C., \& Biklen, S. K. (1992). Qualitative research for education: An introduction to theory and methods. Boston: Allyn and Bacon.

Borg, W.R., \& Gall, M.D. (1989). Educational research--An introduction (5th ed.). New York: Longman.

Boyer, B. (1975). Meanings of a bizarre suicidal attempt by an adolescent. Adolescent Psychiatry. 4. 371-381.

Brent, D. A., Bridge, J., Johnson, B. A., \& Connolly, J. (1998). Suicidal behavior runs in families: A controlled family study of adolescent suicide victims. In R. J. Kosky, H. S. Eskkevari, \& S. Hadi (Eds.), Suicide prevention: The global context. New York: Plenum.

Brent, D. S., Perper, J. A., \& Moriz, G. (1993). Psychiatric risk factors for adolescent suicide: A case-control study. Journal of American Academy of Child and Adolescent Psychiatry, 32, 521-529. 
Bromberg, S., \& Cassel, C. K. (1983). Suicide and the elderly: The limits of paternalism. Journal of the American Geriatrics Society. 31, 698-703.

Brown, J., Henteleff, P., Barakat, S., \& Rowe, C. J. (1986). Is it normal for terminally ill patients to desire death? American Journal of Psychiatry, 143, 208-211.

Browne, T. (1642). The religio medici. Retrieved October 31, 2001, from http://www.uoregon.edu/Wrbear/browne/medici.html

Camus, A. (1983). The myth of Sisyphus and other essays [Trans. Justin O'Brien]. New York: Vintage Books.

Centers for Disease Control. (1985). Suicide surveillance report: United States, 1970 1980. Atlanta: U.S. Department of Health and Human Services.

Chein. I. (1981). Appendix: An introduction to sampling. Austin. TX: Holt Rinehart \& Winston.

Clark, D. C., Gibbons, R. D., Fawcett. J., \& Scheftner, W. A. (1989). What is the mechanism by which suicide attempts predispose to later suicide attempts? A mathematical model. Journal of Abnormal Psychology. 90(1), 42-49.

Cohn, H. (1976). Suicide in Jewish legal and religious tradition. Mental Health and Society. 3, 136.

Connelly, F. M., \& Clandinin, D. J. (1990). Stories of experience and narrative inquiry. Education Researcher, 9(5), 2-14.

Cosculluela, V. (1995). The ethics of suicide. New York: Garland.

Conwell, Y., \& Brent, D. (1995). Suicide and aging: Pattern of psychiatric diagnosis. International Psychogeriatric, 7. 149-164.

Cornelius, J. R., Salloum, I. M., Mezzich, J., Comelius, Jr., M. D., Fabrega. H., Ehler, J. G., Ulrich, R. F., Thase, M. E., \& Mann, J. J. (1995). Disproportionate suicidality in patients with comorbid major depression and alcoholism. American Journal of Psychiatry, 152, 358-364.

Creswell, J. (1998). Qualitative inquiry and research design: Choosing among the five traditions. Thousand Oaks, CA: Sage.

Dahlgren, K. G. (1977). Attempted suicide-35 years afterward. Suicide and LifeThreatening Behavior. 7. 75-79. 
Dorpat, T., \& Ripley, H. (1960). A study in the Seattle areas. Comprehensive Psychiatry, 1. 349-359.

Douglas, J. D. (1967). The social meanings of suicide. Princeton, NJ: Princeton University Press.

Douglas, J. D. (1970). Understanding everyday life. Chiacgo: Aldine.

Dubovsky, S., \& Weissberg, M. (1983). Clinical Psychiatry and Primañ Care, 25.

Durkeim, E. (1951). Suicide: A study in sociology: New York: Free Press. (Original work published 1897)

Eisner, E. (1991). The enlightened eye: Qualitative inquiry and enhancement of educational practice. New York: Macmillan Publishing.

Ellis, T. (1986). Toward a cognitive therapy for suicidal individual. Professional Psychology: Theory and Research, 17, 125-130.

Emerson, B., \& Cantor, C. (1993). Train suicides in Brisbane, Australia, 1980-1986. Crisis, 14, 90-94.

Everstine, L. (1998). The anatomy of suicide: Silence of the heart. Springfield, IL: Charles C. Thomas.

Farberow, N. L. (1969). Bibliography on suicide and suicide prevention (DHHS Public Health Service Publication No. 1979). Washington, DC: United States Government Printing Office.

Farberow, N. L. (1980). The many faces of suicide: Indirect self-destructive behavior. New York: McGraw Hill.

Felner, R. D., \& Silverman, M. M. (1995). Suicide prevention: Toward the year 2000. New York: Guilford Press.

Fremouw, W. J., Perczel, M. D., \& Ellis, T. E. (1990). Suicide risk: Assessment and response guidelines. Needham Heights, MA: Allyn and Bacon.

Freud, S. (1963). Mourning and melancholia. In J. Strachey (Ed. and Trans.), The standard edition of the complete psychological works of Sigmund Freud (Vol. 14). London: Hogarth Press. (Original work published in 1917)

Gibbs, J. T. (1997). African-American suicide: A cultural paradox. Suicide and LifeThreatening Behavior, 27, 68-79. 
Gibbs, J. P., \& Martin, W. T. (1964). Status integration and suicide. Eugene, OR: University of Oregon Press.

Guggenheim, F., \& Weisman, A. D. (1972). Suicide in the subway. Journal of Nervous and Mental Disease. 155, 404-409.

Hankoff, L. D. (1979). Judiac origins of suicide prohibition. In L. D. Hankoff \& B. Einsidler (Eds.), Suicide: Theory and clinical aspects. Littleton, MA: PSG.

Harris, E. C., \& Barraclough, B. M. (1998). Suicide as an outcome for mental disorders: A meta-analysis. British Journal of Psychiatry, 170, 205-208.

Heckler, R. (1994). Waking up alive: The descent, the suicide attempt, and the return to life. New York: Grosset/Putnam Books.

Henden, H. (1982). Suicide in America. New York: Norton.

Hennriksson, M. M., Aro, H. M., Marrunen, M. J., Heikkinen, M. E, Isometsa, E. T., Kueppasalmi, K. I., \& Lonnqvist, J. K. (1993). Mental disorders and comorbidity in suicide. American Journal of Psychiatry, 150, 935-940.

Henry, A., \& Short, J. (1954). Suicide and homicide. Glenco, IL: Free Press.

Higgerson, M. L., \& Rehwaldt, S. S. (1993). Complexities of higher education administration case. Bolton, MA: Anker Publishing Company.

Hoyert, D. L., Arias, E., Smith, B. L., Murphy, S. L., \& Kochanek, K. S. (2001). Deaths: Final data for 1999 National Vital Statistics Report. Hyattsville, MD: National Center for Health Statistics.

Humphry, D. (1996). Final exit: The practicalities of self-deliverance and assisted suicide for the dying. New York: Bantam/Doubleday Dell.

Jamison, K. R. (1999). Night falls fast: Understanding suicide. New York: Knopf.

Jensen, P. (1958). The fantasy of being rescued. Psychoanalytic Quarterly; 327, 336.

Johnson, B. D. (1965). Durkheim's one cause of suicide. American Sociological Review. 30. $875-886$.

Josephus, F. (1927). The Jewish war [Trans. H. St. J. Thackeray]. London: William Heinemann.

Kass, L. (1996). Dehumanization triumphant. In T. Roleff (Ed.), Opposing viewpoints. San Diego: Greenhaven Press. 
Kevorkian, J. (1991). Prescription medicine: The goodness of planned death. Buffalo, NY: Prometheus Books.

Kreitman, N. (1977). Parasuicide. London: Wiley.

Leenaars, A. A. (1992). Suicide notes, communications, and ideation. In R. W. Maris. A. L. Berman, J. T. Maltsberger, \& R. I. Yufit (Eds.), Assessment and prediction of suicide. New York: Guilford Press.

Leighton, A. H., \& Hughes, C.C. (1955). Notes on Eskimo patterns of suicide. Southwestern Joumal of Anthropology, 11. 327-338.

Lester, D. (1989). Suicide from a sociological perspective. Springfield, IL: Charles C. Thomas.

Lester, D. (1997). Suicide in America: A nation of immigrants. Suicide and LifeThreatening Behavior, 27, 1, 52.

Lester, D., \& Murrell, M. E. (1980). The influence of gun control laws on suicidal behavior. American Journal of Psychiatry, 137, 121-122.

Lijphart, A. (1971). Comparative politics and the comparative method. American Political Science Review, 65, 682-694.

Lincoln, Y. S., \& Guba, E. (1985). Naturalistic inquiry. Newbury Park. CA: Sage.

Lindekilde, K., \& Wang, A. G. (1985). Train suicide in the country of Fyn. Acta Psychiatrica Scandinavia. 72, 150-154.

Litman, R. E. (1967). Sigmund Freud on suicide. In E. Shneidman (Ed.), Essays in selfdestruction. New York: Science House.

Malkinson, R. (1996). Cognitive behavioral grief therapy. Journal of Rational-Emotive and Cognitive Behavior Therapy, 14, 155-171

Maltsberger, J. T. (1992). The psychodynamic formulations: An aid in assessing suicide risk. In R. W. Maris, A. L. Berman, J. T., Maltsberger, \& R.I . Yufit (Eds.), Assessment and prediction of suicide (pp. 24-49). New York: Guilford Press.

Mann, J. J. (1998). The neurobiology of suicide. Nature Medicine, 4. 25-30.

Maris, R. W. (1981). Pathwavs to suicide: A survey of self-destructive behaviors. Baltimore: Johns Hopkins University Press.

Maris, R. W. (1992). Suicide. In E. R. Borgatta (Ed.), Encyclopedia of sociology (p. 22). New York: Macmillan. 
Maris, R. W. (1993). The evolution of suicidology. In A. S. Leenaars (Ed.), Suicidology: Essays in honor of Edwin Shneidman. Northvale, NJ: Jason Aronson.

Maris, R. W., Berman. A. L., \& Silverman, M. M. (2000). A comprehensive tertbook of suicidology. New York: Guilford Press.

Markush, R. E., \& Bartolucci, A. A. (1984). Firearms and suicide in the United States. American Journal of Public Health, 74, 123-127.

Massey, A. (2001). Qualitative research. Retrieved March 10, 2001, from Alexander.massey@estud.ox.ax.uk

McCraig, L. F., \& Stussman, B. J. (1996). National hospital ambulatory care survey: 1996. Center for Disease Control Emergency Department Summay. Advance Data from Vital and Health Statistics, 293. Hyattsville, MD: National Center for Health Statistics.

McIntosh, J. L. (1996). Survivors of suicide: A comprehensive bibliography update, 1986-1995. Omega, 33, 147-175.

McIntosh, J. L. (2000). USA suicide: 2000 official final data. Retrieved October 29, 2002, from http://www.iusb.edu/ jmcintos/usa2000summary.htm

Menninger, K. (1966). Man against himself. New York: Harcourt Brace \& World.

Merriam, S. B. (1988). Case study research in education: A qualitative approach. San Francisco: Jossey-Bass.

Merriam, S. B. (1998). Qualitative research and case study applications in education. San Francisco: Jossey-Bass.

Minkoff, K., Bergman, E., Beck, A. T., \& Beck, R. (1973). Hopelessness, depression, and attempted suicide. American Journal of Psychiatry, 130. 455.

Murphy, G. E. (1985). Suicide and attempted suicide. In R. Michels (Ed.), Psychiatry (pp. 1-17). Philadelphia: JB Lippincott.

Murphy, S. L. (2000). Deaths: Final data for 1998. National Vital Statistics Report, $48(11)$, n.p.

Murray, C. J. L., \& Lopez, A. S. (1996). The global burden of disease (vol. 1). Boston: Harvard School of Public Health. 
Myers, W. C., Otto, T. A., Harris, E., Diaco, D., \& Moreno, A. (1992). Acetaminophen overdose as a suicidal gesture: A survey of adolescents; knowledge of its potential toxicity. Joumal of the American Academy of Child and Adolescent Psychiatry: $31.686-690$.

Nelson, S. H., McKinney, A., Ludwig, K., \& Davis, R. (1983). An unusual death of a patient in seclusion. Hospital and Community Psychiatry. 2, 259.

Ness, D. E., \& Pfeffer, C. R. (1990). Sequelae of bereavement resulting from suicide. American Journal of Psychiatry, 147, 279-285.

Neuringer, C. (1961). Dichotomous evaluations in suicidal individuals. Journal of Consulting Psychology, 25, 445.

Nietzsche, F. (1966). Beyond good and evil (W. Kaufmann, Trans.). New York: Vintage. (Original work published in 1886)

O'Carroll, P. W., Berman, A. S., Maris, R. W., Moscicki, E. K., Tanney, B. L., \& Silverman, M. M. (1996). Beyond the Tower of Babel: A nomenclature of suicidology. Suicide and Life-Threatening Behavior, 26, 237-252.

Patton, M. Q. (1990). Qualitative evaluative methods. Thousand Oaks, CA: Sage.

Peck, D. L. (1986). Completed suicides: Correlates of choice method. Omega, 16, 309323.

Petronis, K. R., Samuels, J. F., Moscicki, E. K., \& Anthony, J. C. (1990). An epidemiologic investigation of potential risk factor for suicide attempts. Social Psychiatry and Psychiatric Epidemiology. 25. 193-199.

Platt, S. (1992). Suicide and unemployment in Italy. Social Science and Medicine, 34. $1191-1201$.

Posner, D. M. (1987). Suicide and the Jewish tradition. In E. J. Dunne, J. L. McIntosh, \& K. Dunne-Maxim (Eds.), Suicide and its aftermath (pp. 159-162). New York: W. W. Norton.

Poussaint, A. F., \& Alexander, A. (2000). Lay my burden down: Unraveling suicide and the mental health crisis among African-Americans. Boston: Beacon Press.

Rauscher, W. V. (1981). The case against suicide. New York: St. Martin's Press.

Redlich, F. C. (1993). The death and autopsy of Adolph Hitler. In A. A. Leenaars, A. L. Berman, P. Cantor, R. E. Litman, \& R. W. Maris (Eds.), Suicidology: Essays in honor of Edwin Shneidman. Northvale, NJ: Jason Aronson. 
Rich, C. L., Young, J. G., Fowler, R. C., Wagner, J., \& Black, N. A. (1990). Guns and suicide: Possible effects of some legislation. American Joumal of Psychiatry; 147, 342-346.

Richman, J. (1991, April). Role modeling and context in the determination of method. Paper presented at the Annual Meeting of The Anıerican Association of Suicidology, Boston.

Robins, E. (1981). The final months: A study of the lives of 134 persons who committed suicide. New York: Oxford University Press.

Roleff, T. (1998). Suicide: Opposing viewpoints. San Diego, CA: Greenhaven Press.

Rosen, D. H. (1970). The serious suicide attempt: Epidemiological follow-up study of 886 patients. American Journal of Psychiatry, 127. 764-770.

Rosenthal, R., Crisafi, B. R., \& Coomaraswamy, R. P. (1980). Manual extraction of a permanent pacemaker: An attempted suicide. Pace, 3, 229-231.

Roy, A., \& Linnoila, M. (1990). Monoamines and suicidal behavior: Monoamine regulation of aggression and impulse control. New York: Brunner/Mazel.

Rubinstein, P., Mesis, B., \& Lidz, C. (1958). On attempted suicide. American Medical Association Archives Neurology and Psychiatry, 103, 111.

Rudestam, K. E. (1971). Stockholm and Los Angeles: A cross-cultural study of the communication of suicidal intent. Journal of Consulting and Clinical Psychology. $36,82-90$.

Schopenhauer, A. (1969). The world as will and representation (Vol. 1; Trans. E.F.J. Payne). New York: Dover Publications.

Schuckit, M. A., \& Schuckit, J. J. (1989). Substance use and abuse: A risk factor in youth suicide. Alcohol, drug abuse, and mental health administration (Report of the Secretary's Task Force on Youth Suicide, Vol. 2: Risk Factors for Youth Suicide). Washington, DC: U.S. Govermment Printing Office.

Shaffer, D., Gould, M., \& Hicks, R. C. (1994). Worsening suicide rate in Black teenagers. American Journal of Psychiatry, 151, 1810-1812.

Sharpe, L. (1973). Walter Charleton's early life, 1620-1659, and relationship to natural philosophy in mid-seventeenth-century England. Annals of Science, 30, $311-340$.

Shepherd, D., \& Barraclough, B. (1980). Work and suicide: An empirical investigation. British Journal of Psychiatry, 136, 469-478. 
Sherman, R. R., \& Webb, R. B. (1988). Qualitative research in education: A focus. In R. R. Sherman \& R. B. Webb (Eds.), Qualitative research in education focus and methods. Bristol, PA: Falmer Press.

Shneidman, E. S. (1976). Current overview of suicide: In E. Shneidman (Ed.), Suicidology: Contemporary developments. New York: Grune and Stratton.

Shniedman, E. S. (1985). Definition of suicide. New York: John Wiley.

Shneidman, E. S. (1993). Suicide as psychache: A clinical approach to self-destructive behavior. Northvale, NJ: Jason Aronson.

Shneidman, E. S. (1996). The suicidal mind. New York: Oxford University Press.

Shneidman, E. S., \& Farberow, N. L. (1957). Clues to suicide. New York: McGraw-Hill.

Shukla, G. D., Varma, B. L., \& Mishra, D. N. (1990). Suicide in Jhansi City. Indian Journal of Psychiatry, 32, 44-51.

Silverman, M. M., \& Maris, R. W. (1995). The prevention of suicidal behaviors: An overview. Suicidal and Life-Threatening Behavior, 25. 10-21.

Smedes, L.B. (2000). Is suicide unforgivable? Christianity Today. 44, 61.

Soubrier, J. (1993). Definitions of suicide. In A. S. Leenaars (Ed.), Suicidology: Essays in honor of Edwin S. Shneidman (pp. 35-41). Northvale. NJ: Jason Aronson.

St. Thomas Aquinas. (1990). The Catholic view. In J. Donnelly (Ed.), Stuicide: Right or wrong? (p. 34). Buffalo: Prometheus Books.

Stimming, M.T. (2000). Grace in the face of suicide. The Christian Century, 117, 272273.

Stanley, M., \& Mann, J. J. (1988). Biological factors associated with suicide. In A. J. Frances \& R. E. Hales (Eds.), Review of psychiatry (Vol. 7; pp. 334-352). Washington, DC: American Psychiatric Press.

Stengel, E. (1964). Suicide and attempted suicide. Baltimore: Penguin Books.

Styron, W. (1990). Darkness visible: A memoir of madness. New York: Random House.

Sullivan, A. (1984). Voluntary active euthanasia for the terminally ill and the constitutional right to privacy. Cornell Law Review, 363, 69.

U.S. Public Health Service. (1999). The surgeon general's call to action to prevent suicide. Washington, DC: Author. 
Unni, K. E. S., \& Mani, A. (1996). Suicidal ideators in the psychiatric facility of a general hospital: A psycho demographic profile. Indian Journal of Psychiatry, 38, 79-85.

Unni, K. E. S., Rotti, S. B., \& Chandrasekaran, R. (1995). An exploratory study of motivation in suicide attempters. Journal of Indian Medial Association, 8, 250252.

Van Hooff, A. J. L. (1998). The image of ancient suicide. Syllecta Classica. 9. 47-69.

Velirt, J. C., \& Rollins, D. E. (1988). A comparison of the frequency and severity of poisoning for ingestion of acetaminophen, aspirin, and ibuprofen. American Journal of Emergency Medicine, 6. 104-107.

Venkoba, R. A. (1977). Suicide. Journal of Indian Medical Association. 8, 250-252.

Venkoba, R. A. (1992). Parasuicide and suicide: Some psychological considerations. Indian Journal of Social Psychiatry, 8, 3-7.

Vietra, E., Nieto, E., Gasto, C., \& Cirera, E. (1992). Serious suicide attempts in affective patients. Journal of Affective Disorders, 24, 147-152.

Weir, E. (2001). Suicide: The hidden epidemic. CMAJ: Canadian Medical Association Journal. 165, 634.

Weisman, A. D., \& Kastenbaum, R. (1972). The psychological autopsy. New York: Behavioral Publications.

Weisman, A., \& Worden, J. W. (1974a). Cases for ingestion of acetaminophen, aspirin, and ibuprofen. American Journal of Emergency Medicine. 6, 104-107.

Weisman, A., \& Worden, J. W. (1974b). Risk-rescue rating in suicide assessment. In A. T. Beck, H. L. P. Resnick, \& D. J. Lettieri (Eds.), The prediction scale. Bowie, MD: Charles Press.

Weissman, M. M. (1974). The epidemiology of suicide attempters, 1960-1971. Archives of General Psychiatry, 30. 737-746.

Wiersma, W. (1991). Research methods in education: An introduction. Boston: Allyn \& Bacon.

Wilkins, J. (1967). Suicidal behavior. American Sociological Review, 32, 286-298.

Wolcott, H. F. (1992). The handbook of qualitative research in education. Orlando, FL: Academic Press. 
World Health Organization. (1968). Prevention of suicide (Public Health Paper No. 35). Geneva, Switzerland: Author.

World Health Organization. (2000). Suicide a global problem. Geneva, Switzerland: Author.

Wrobleski, A. (1995). Suicide: Why? Minneapolis: Afterwords Publishing.

Yadlowsky, J. M. (1980). Suicide by snake venom injection. Journal of Forensic Sciences, 25, 760-764.

Zeinert, K. (1990). Suicide: Tragic choice. Berkley Heights, NJ: Enslow Publishers. 
VITA

Reproduced with permission of the copyright owner. Further reproduction prohibited without permission. 
VITA

Janice Ann Johnson Browne, MS, GCM

5124 Lickton Pike

Goodlettsville, Tennessee 37072

brownej777@.aol.com

\section{Education}
Alabama A\&M University
Huntsville, AL
M.S. - Clinical Psychology
August 1973
Oakwood College
Huntsville, AL
B.S. - Psychology/Sociology
June 1973

\section{Professional Experiences}

Suicide Prevention for Tennessee

Nashville. TN

Coordinator

2000-present

Tennessee State University

Nashville, TN

Adjunct Professor of Psychology

1998-present

Tennessee Commission on Children and Youth

Nashville, TN

Ombudsman for Children and Families

1996-2000

Center for Family Development

Nashville, TN

Director of Family Services

1995-1996

Cumberland Hall Hospital

Head Clinical Therapist

Nashville, TN

1993-1995

Oakwood College

Assistant Professor of Psychology

Huntsville, AL

1988-1991

\section{Professional Memberships}

Pi Lamba Theta Honor Society

Member American Psychological Association

Association for Professional Women, Deans, and Counselors 